\title{
TONALITA DE SAN MARTÍN
}

\Cordillera Oriental Departamento de Santander

Gabriel Rodríguez, Gilberto Zapata, Ana María Correa Martínez y María Isabel Arango

Catálogo de las unidades litoestratigráficas de Colombia / Jurásico

Citación: Rodríguez, G., Zapata, G., Correa Martínez, A. M. y Arango, M. I. (2020). Tonalita de San Martín. En Catálogos de las unidades litoestratigráficas de Colombia: Macizo de Santander. Vol. 1. Servicio Geológico Colombiano. https://doi.org/10.32685/9789585279445.6 
La actividad magmática del periodo Triásico-Jurásico en el Macizo de Santander está evidenciada por el emplazamiento de plutones graníticos, así como de cuerpos hipoabisales y volcánicos riolítico-riodacíticos, con dirección preferencial N-S a NW-SE que concuerda con el rumbo de las fallas regionales, principalmente la falla de Bucaramanga, que marcan la tectónica del Macizo de Santander y delimitan las diferentes unidades.

La intrusión de la Tonalita de San Martín, clasificada como "tonalita" por Arias y Vargas (1978), es uno de esos cuerpos, producto de la actividad magmática del Triásico-Jurásico.

En el Catálogo de la Tonalita de San Martín se incluyen los análisis petrográficos, químicos y las edades radiométricas $\mathrm{U} / \mathrm{Pb}$ de este plutón. Con este trabajo se pretende hacer un aporte al desarrollo del conocimiento geológico del país.

\section{Proponente del nombre}

Cuerpo ígneo descrito por Arias y Vargas (1978) en la memoria de la plancha 86, Ábrego, quienes le dieron el nombre informal de tonalita, debido a que en su composición participa principalmente este tipo de roca. Estos autores, además, en esta denominación incluyeron dos intrusivos de tamaño stock. En este trabajo, los autores proponemos el nombre de Tonalita de San Martín.

\section{Origen del nombre y distribución geográfica}

El componente geográfico del nombre de la unidad Tonalita de San Martín proviene del municipio de San Martín, situado en el sur del departamento del Cesar. Fue descrito inicialmente por Arias y Vargas (1978) en la memoria de la plancha 86, Ábrego, con el nombre informal de tonalita.

En este catálogo se propone el nombre de Tonalita de San Martín, considerando la definición original dada por Arias y Vargas (1978) de tonalita. La composición del plutón es variable, presenta tonalitas, granodioritas y monzogranitos en proporciones similares, sin que se presente una litología predominante. El nombre de San Martín proviene del municipio donde aflora el intrusivo, y se ciñe a las recomendaciones de la International Subcommission on Stratigraphic Classification of IUGS (1987, 1994).

La unidad se encuentra cartografiada en el mapa geológico de la plancha 86, Ábrego (Vargas y Arias, 1981), donde presentan dos stocks con la denominación "tonalitas”. En el presente estudio se nombra como Tonalita de San Martín el plutón que aflora en el borde occidental de la cordillera Oriental y que tiene forma alargada de tendencia NNW-SSE, con un área aproximada de 45,5 km²;
$31 \mathrm{~km}$ de largo y $2 \mathrm{~km}$ de ancho, en promedio (figura 1), ubicado a lo largo de la región noroccidental de la plancha 86 (Ábrego), drenado por las quebradas Torcoroma, en su parte sur; La Rayita, en su parte central, y Torcoromita, en su parte norte.

\section{Descripción geológica}

\subsection{Marco geológico}

El Macizo de Santander hace parte de un bloque regional de forma triangular formado por las fallas de Santa Marta-Bucaramanga, en el lado occidental, la falla de Oca-Ancón, en el lado norte, y la falla de Boconó, en el lado oriental.

Las rocas más antiguas del Macizo de Santander comprenden unidades metamórficas como la Anfibolita de Sanín Villa, que arrojó edades U/Pb en circón del Neoproterozoico y el Neis de Bucaramanga (Ward et al., 1973), denominado también Complejo Bucaramanga (Clavijo, 1994). El Neis de Bucaramanga consiste de paraneises migmatíticos de alto grado considerados de edad proterozoica (Goldsmith et al., 1971; Restrepo et al., 1997; Cordani et al., 2005; Ordóñez et al., 2006), con un pico de metamorfismo de edad $1057 \pm 28 \mathrm{Ma} \mathrm{U} / \mathrm{Pb}-$ Shrimp en circón, relacionada con la orogenia Grenvilliana (figura 2).

Edades publicadas por Van der Lelij et al. (2016), y otras obtenidas mediante el método U/Pb-ICP-MS en circones, en el desarrollo del presente estudio en unidades cartografiadas como el Neis de Bucaramanga y Ortoneis, arrojaron edades de metamorfismo y cristalización del Ordovícico. 

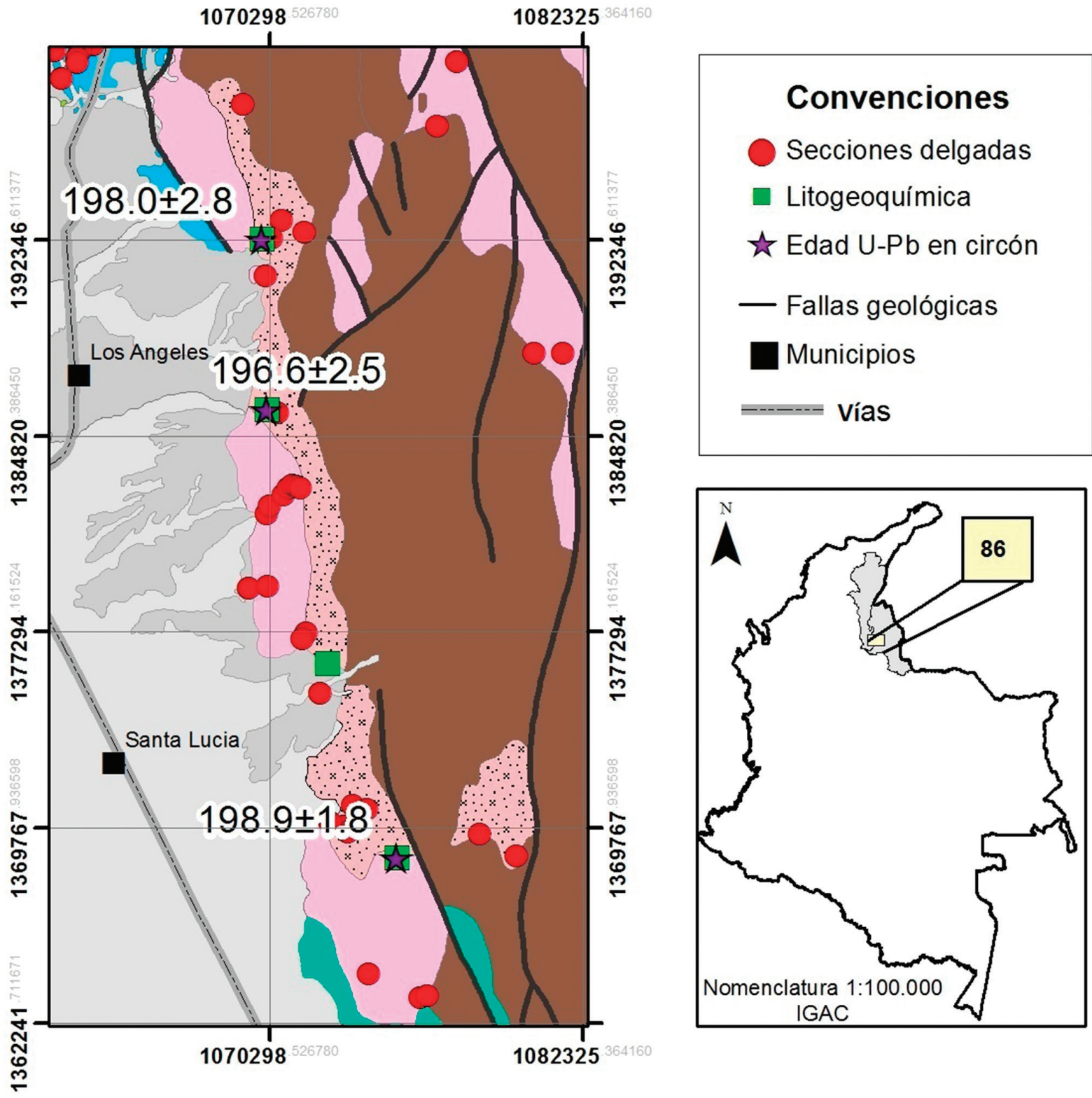

\section{Leyenda}

\begin{tabular}{l}
$\square$ Depósitos aluviales \\
$\square$ Terrazas y conos aluviales \\
\hline Formación Jordán \\
Formación Bocas
\end{tabular}

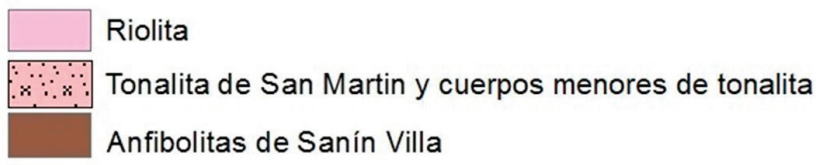

Figura 1. Localización de la Tonalita de San Martín y distribución del muestreo de secciones delgadas, litogeoquímica y dataciones U/Pb Fuente: Arias y Vargas (1978) y autores 


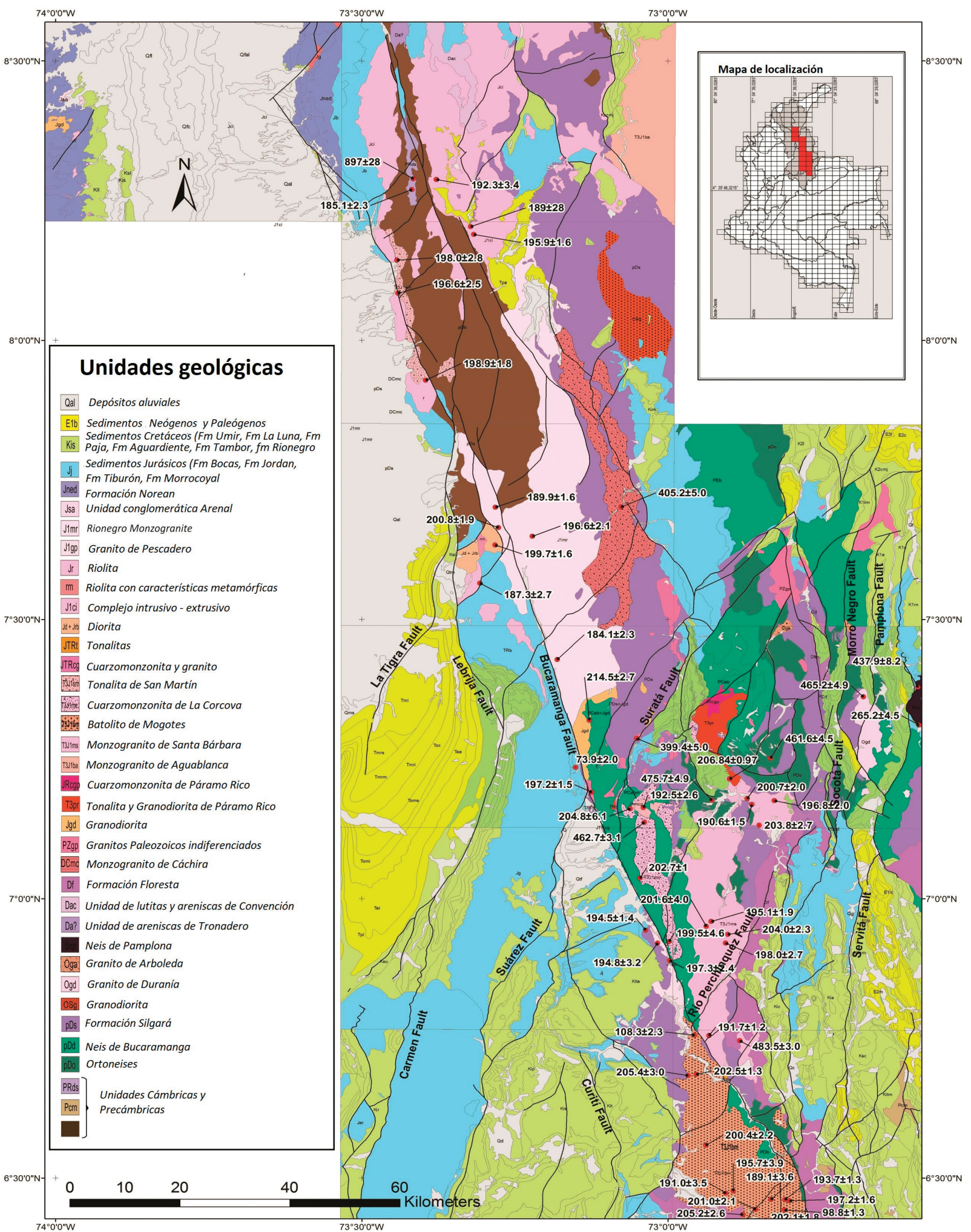

Figura 2. Localización de la Tonalita de San Martín y distribución del muestreo de secciones delgadas, litogeoquímica y dataciones U/Pb Fuente: Arias y Vargas (1978) y autores 

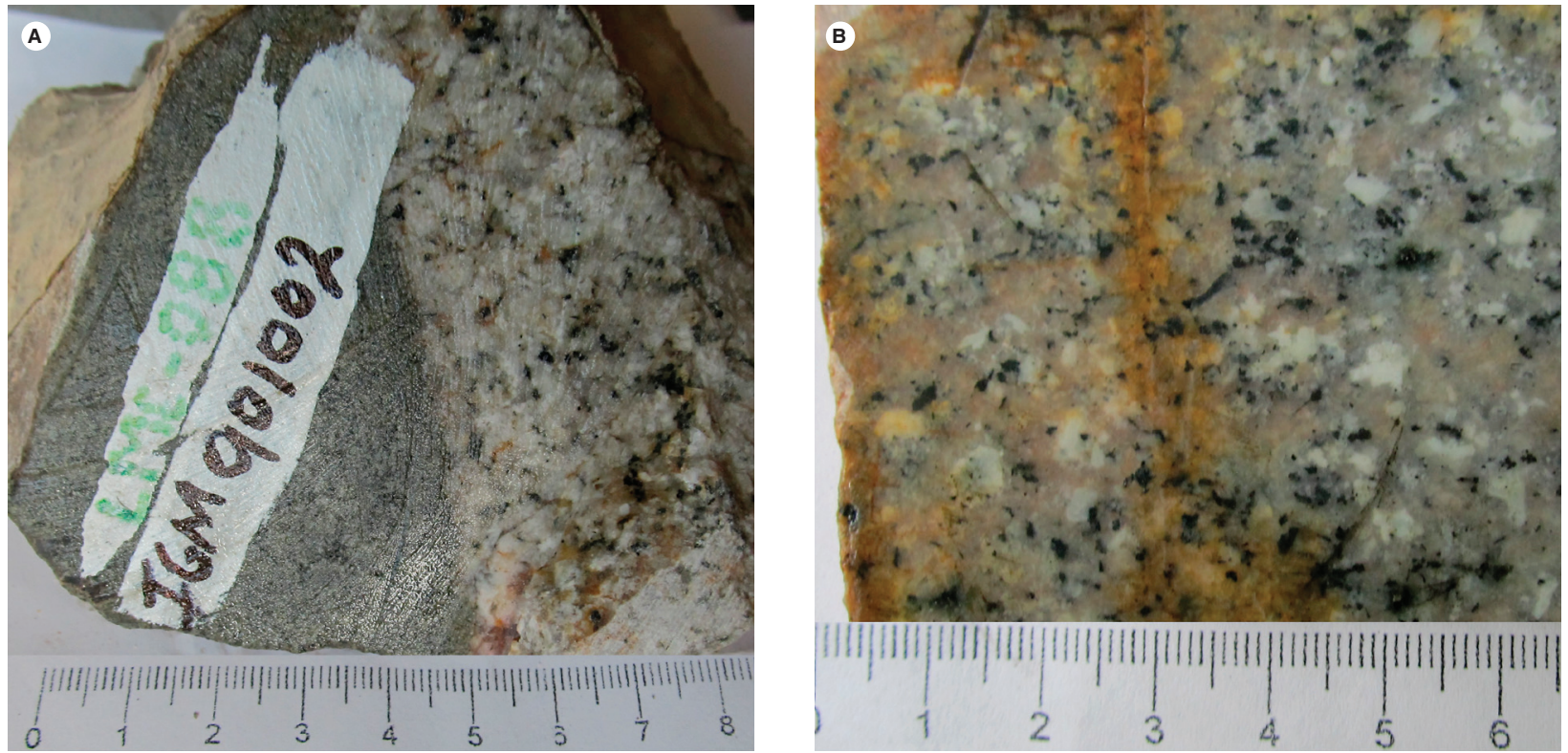

Figura 3. Aspecto macroscópico de rocas de la Tonalita de San Martín.

A) Granodiorita con xenolito de diorita, estación LMC-088. B) Cuarzomonzonita tomada en la estación TCR-399

El Neis de Bucaramanga está cubierto por la Formación Silgará, constituida por esquistos, filitas, metalodolitas, metaareniscas y escasos mármoles, rocas que hacen parte del basamento del Macizo de Santander (Ward et al., 1973; Ríos et al., 2003; Mantilla et al., 2013; Mantilla et al., 2016). La Formación Silgará presenta edades de metamorfismo del Ordovícico inferior-medio relacionadas con la orogenia Famatiniana (Ríos et al., 2003; Ordóñez Cardona et al., 2006; Clavijo et al., 2008; Mantilla et al., 2013).

Algunas edades $\mathrm{U} / \mathrm{Pb}$ en circón obtenidas en el proyecto muestran magmatismo posterior y anterior al metamorfismo, representado por metavulcanitas y plutones que intruyen el basamento metamórfico, con edades U/Pb en circón del Silúrico, Devónico inferior, Carbonífero y límite Triásico-Jurásico.

Los plutones triásico-jurásicos del Macizo de Santander se consideran emplazados en rocas metamórficas del Terreno Chibcha, en el sentido de Restrepo y Toussaint (1988) y Restrepo et al. (2011) o del Terreno Santander de Etayo et al. (1983). Estos plutones están emplazados en rocas metamórficas ordovícicas relacionadas a la orogenia Famatiniana, y probablemente algunos se emplazaron en basamento del Neoproterozoico, como la Diorita del alto de Sanín Villa y la Tonalita de San Martín, que intruyen las Anfibolitas de Sanín Villa (figura 2).

Durante el límite Triásico-Jurásico se desarrolló un importante magmatismo de arco continental, con el emplazamiento de grandes batolitos, stocks graníticos y cuerpos riolíticos subvolcánicos localizados hacia la margen occidental del Macizo de Santander, en el basamento metamórfico paleozoico (figura 2).

Unidades sedimentarias cretácicas reposan discordantes sobre el basamento metamórfico y los plutones. Después de la sedimentación cretácica hubo escaso magmatismo durante el Mioceno, que emplazó pequeños cuerpos de pórfidos con mineralización de oro (Leal, 2011; Mantilla et al., 2013).

\subsection{Características macroscópicas}

La Tonalita de San Martin es un cuerpo intrusivo de composición variable de dioritas-cuarzodioritas-cuarzomonzonitas y tonalita-granodioritas-monzogranitos, que, de acuerdo con Arias y Vargas (1978), no son separables en la cartografía a escala 1:100.000, y por esta razón fueron agrupadas en una sola unidad.

Las rocas tonalíticas son de color gris, con tonalidades verdes, textura fanerítica de grano medio, constituidas por minerales como cuarzo, plagioclasa, hornblenda y biotita (Arias y Vargas, 1978). Localmente se reconocen granitoides de color blanco a rosado, con motas negras, moderadamente meteorizados, faneríticos, de grano fino a medio, equigranulares a inequigranulares, con estructura masiva y constituidos por cuarzo, plagioclasa, feldespato potásico rosado y biotita. La Tonalita de 
San Martín tiene enclaves de microdiorita y andesita de grano fino, de formas subredondeadas y tamaños decimétricos, con contactos netos con las rocas granitoides (figura 3). El cuerpo está atravesado por diques de dacita que tienen formas tabulares y presentan contactos tajantes, cuyo espesor varía entre 10 y $70 \mathrm{~cm}$, de colores blanco a gris claro.

\subsection{Características microscópicas}

De la Tonalita de San Martín se analizaron quince secciones delgadas, que fueron clasificadas como dioritas, cuarzodioritas, cuarzomonzonitas, tonalitas, granodioritas y monzogranitos, con textura alotriomorfa granu- lar a inequigranular, ocasionalmente con texturas pertíticas, gráficas y simplectíticas locales. Está compuesta principalmente por plagioclasa ( $22 \%$ a $61 \%$ ), pueden tener feldespato alcalino ( $0 \%$ a $49 \%$ ) y, en menor proporción, cuarzo (4\% a 48\%), hornblenda, biotita y, en rocas intermedias, clinopiroxeno. Como minerales accesorios se encuentran apatito, opacos, titanita y allanita. Como minerales de alteración, clorita, sericita, epidota y agregados arcillosos. En la tabla 1 se resumen los resultados del análisis modal, y en la figura 4 se muestra el triángulo de Streckeisen (1976) con la clasificación de las rocas, donde puede observarse el predominio de rocas tonalíticas y monzograníticas en el muestreo realizado.

Tabla 1. Composición modal de las rocas de la Tonalita de San Martín

\begin{tabular}{|c|c|c|c|c|c|c|c|c|c|c|c|c|c|c|c|c|}
\hline IGM & N. ${ }^{\circ}$ de campo & $\mathbf{x}$ & $\mathbf{Y}$ & Qtz & PI & Fsp & Cpx & $\mathrm{Hbl}$ & Bt & Op & Ap & Zrn & Ttn & Matriz & Otros & Clasificación petrográfica \\
\hline 31124 & & 1070738 & 1393134 & 17 & 48 & & 4 & 23 & 3 & $\operatorname{Tr}$ & 1 & 1 & 3 & & & Tonalita \\
\hline 31125 & & 1070352 & 1392430 & 4 & 61 & & 1 & 31 & & $\operatorname{Tr}$ & $\operatorname{Tr}$ & $\operatorname{Tr}$ & 3 & & & Diorita hornbléndica \\
\hline 31134 & & 1069250 & 1397589 & 48 & 28 & 22 & & & 2 & $\operatorname{Tr}$ & & & $\operatorname{Tr}$ & & & Monzogranito \\
\hline 31197 & & 1073156 & 1369803 & 22 & 48 & 22 & & & & 1 & $\operatorname{Tr}$ & $\operatorname{Tr}$ & & & 7 & Granodiorita \\
\hline 31200 & & 1072232 & 1374914 & 37 & 31 & 28 & & 1 & 2 & 1 & $\operatorname{Tr}$ & $\operatorname{Tr}$ & & & $\operatorname{Tr}$ & Monzogranito \\
\hline 31204 & & 1073504 & 1370620 & 26 & 41 & 22 & & 3 & 6 & 2 & $\operatorname{Tr}$ & $\operatorname{Tr}$ & & & $\operatorname{Tr}$ & Granodiorita \\
\hline 31205 & & 1074019 & 1370446 & 13 & 58 & & & 16 & 10 & 3 & $\operatorname{Tr}$ & $\operatorname{Tr}$ & & & $\operatorname{Tr}$ & Cuarzodiorita \\
\hline 31206 & & 1070586 & 1385713 & 25 & 43 & 27 & & & 5 & $\operatorname{Tr}$ & $\operatorname{Tr}$ & & & & & Monzogranito \\
\hline 74856 & LJM-1238 & 1070150 & 1390970 & 33 & 51 & 4 & & 0 & 12 & $\operatorname{Tr}$ & $\operatorname{Tr}$ & $\operatorname{Tr}$ & & & & Tonalita \\
\hline 120225 & AR-77 & 1071630 & 1392660 & 42 & 22 & 35 & & & $\operatorname{Tr}$ & & & & $\operatorname{Tr}$ & & 1 & Cuarzomonzonita \\
\hline 901002 & LMC-088 & 1069983 & 1392339 & 37 & 34 & 19 & & & 10 & $\operatorname{Tr}$ & & $\operatorname{Tr}$ & & & & Granodiorita \\
\hline 901003 & LMC-090A & 1070179 & 1385799 & 7 & 57 & 20 & & & & 1 & $\operatorname{Tr}$ & $\operatorname{Tr}$ & 1 & & 14 & Cuarzomonzodiorita \\
\hline 901004 & LMC-090B & 1070179 & 1385799 & 11 & 24 & & & & 4 & 2 & $\operatorname{Tr}$ & $\operatorname{Tr}$ & & 59 & & Fenodacita (dique) \\
\hline 901032 & TCR-395A & 1075180 & 1368544 & 28 & 53 & 4 & & 4 & 6,5 & 3,5 & 0,5 & 1 & & & & Tonalita deformada \\
\hline 901033 & TCR-399 & 1072495 & 1376017 & 12 & 30 & 49 & & 1 & 8 & 0,7 & & 0,3 & & & $x$ & Cuarzomonzonita \\
\hline
\end{tabular}

Tr: trazas

1 Sienita de feldespato alcalino

2 Monzodiorita monzogabro

3 Diorita, gabro

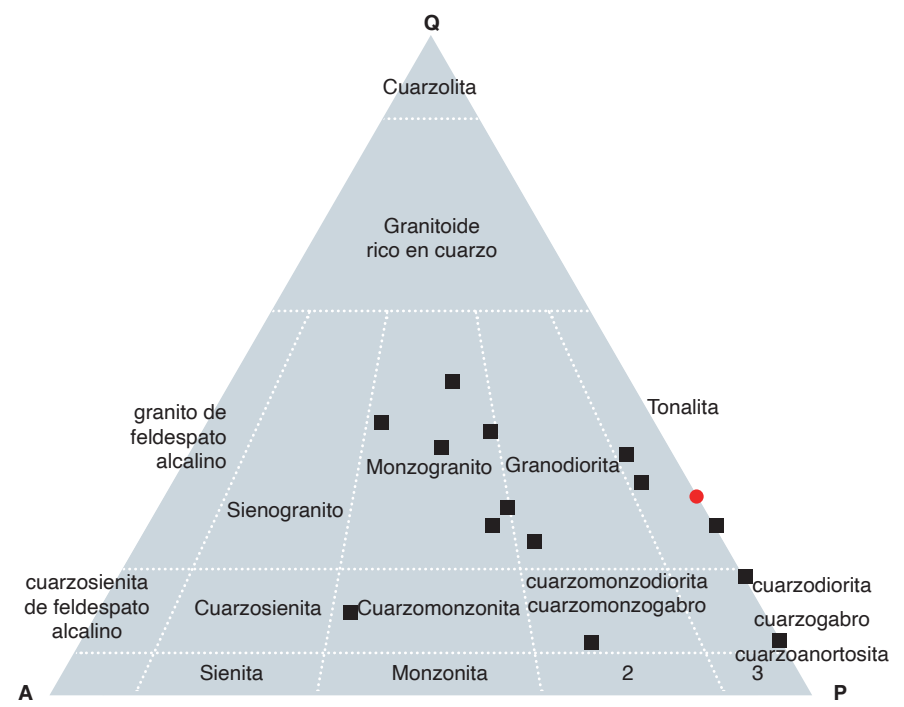

Figura 4. Clasificación modal de las rocas de la Tonalita de San Martín en cuadrados grises y círculo rojo representa el dique fenodacítico 
De los diques se analizó una fenodacita con textura porfídica y matriz desvitrificada con desarrollo de esferulitas, y en menor proporción con microcristales félsicos de cuarzo y feldespatos.

La plagioclasa varía desde oligoclasa sódica, en las rocas graníticas, hasta andesina en los dioritoides, siguiendo el método de Michel-Lévy. Se encuentra en cristales subhedrales de hábito tabular, incoloros, cuyo tamaño oscila entre 0,2 y $5 \mathrm{~mm}$, con desarrollo de macla de albita y albita-Carlsbad. Pueden alterarse a escamas de sericita y saussurita, que se presenta en agregados muy finos de tonalidades oscuras (figura 5).

El feldespato de potasio es ortosa. Se presenta en cristales anhedrales de tamaños entre 0,3 y $5 \mathrm{~mm}$, de formas irregulares, con leve moteado marrón por alteración a minerales arcillosos. Presenta textura pertítica con desmezcla de plagioclasa en forma de "flamas" y parches, y puede tener intercrecimientos micrográficos con cuarzo (figura 5A).

El cuarzo aparece en forma de cristales anhedrales incoloros, algunos con extinción ondulatoria, cuyo tamaño varía entre 0,2 y 1,5 mm, como cristales individuales. En algunas rocas, el cuarzo se presenta en intercrecimientos micrográficos, aunque también puede aparecer como inclusiones en el feldespato y tener inclusiones de plagioclasa.

La hornblenda aparece principalmente en las rocas dioritoides (figura 5C, D), en cristales de forma hexagonal, en corte basal, y en algunas rocas, longitudinal; algunos cristales, con maclas dobles. También pueden aparecer en nidos de hornblenda. Presentan color verde intenso a verde pálido, con pleocroísmo de tonos amarillos. El tamaño de los cristales fluctúa entre 0,5 y 1,5 mm, y tienen extinción de $12^{\circ}$ a $19^{\circ}$ en sección longitudinal. Algunos cristales tienen núcleo de piroxeno con inclusiones de titanita, plagioclasa y apatitos, principalmente, y leve desarrollo de textura simplectítica por presencia de pequeños cristales de cuarzo con forma de gotas en el mineral. Puede estar alterada a clorita y epidota.

La biotita es subhedral a euhedral, con pleocroísmo de color marrón oscuro a claro, con exfoliación perfecta en una dirección, de tamaños entre 0,5 y 1,5 mm, y extinción en ojo de pájaro. Algunos cristales presentan alteración a clorita, de color verde oscuro y birrefringencia anómala azul Berlín, desarrollada entre las trazas de exfoliación de los cristales.
Los circones aparecen como cristales euhedrales, en algunas rocas, algo fracturados, de forma prismática corta, incoloros, con tamaño $<0,3 \mathrm{~mm}$, birrefringencia fuerte de segundo orden color azul-fucsia. Pueden estar incluidos en biotita o junto a minerales opacos.

La titanita se encuentra en cristales euhedrales, romboédricos y anhedrales de forma irregular, oscurecida por el alto relieve, con birrefringencia fuerte de tercer orden, color rosado moteado con extinción paralela.

El apatito aparece en pequeños cristales prismáticos a redondeados y hexagonales euhedrales, de tamaño $<0,1 \mathrm{~mm}$, birrefringencia débil de primer orden gris y extinción paralela. Se presenta como inclusiones en cuarzo, principalmente.

La muestra de dique es una fenodacita (IGM901004, LMC-090C) constituida por fenocristales de cuarzo, plagioclasa y biotita envueltos por una matriz vítrea (figura 6).

Los fenocristales de cuarzo son bipiramidales, redondeados por corrosión de la matriz, y presentan bahías y "huecos" rellenos de vidrio.

La plagioclasa se presenta en fenocristales y microfenocristales de tamaños que varían entre 0,5 y $2 \mathrm{~mm}$, y microcristales subhedrales. Tiene forma tabular, con maclas de Carlsbad y albita pobremente desarrolladas y en cuñas. Los cristales tienen bordes redondeados y están alterados a saussurita en agregados y a sericita en menor proporción.

La biotita se presenta ocasionalmente en microfenocristales euhedrales de color marrón y verde producto de su alteración, con un tamaño promedio de 0,5 mm, extinción en ojo de pájaro. Se encuentra parcialmente alterada a clorita de color verde claro-oscuro pleocroico, con birrefringencia azul anómala. La mayoría de los cristales presentan inclusiones de opacos asociados.

La matriz está desvitrificada y alterada a minerales del grupo de la arcilla, con desarrollo abundante de esferulitas.

Como minerales accesorios aparecen apatito, circón y opacos de tamaños menores de $0,2 \mathrm{~mm}$.

Los opacos son cristales accesorios de forma irregular, con un tamaño menor de $0,5 \mathrm{~mm}$, y generalmente aparecen junto a biotita. 

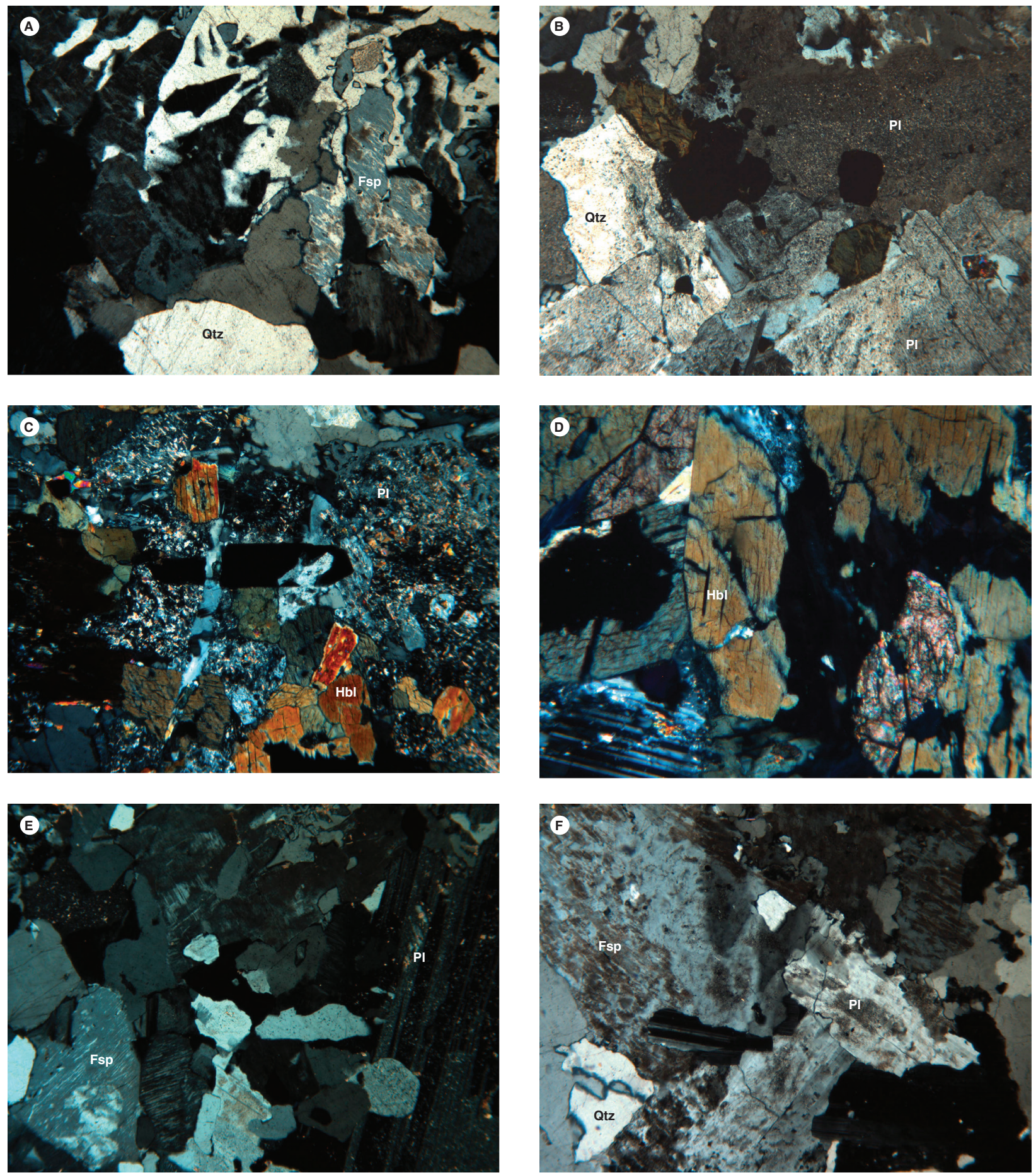

Figura 5. Aspecto microscópico de rocas de la Tonalita de San Martín. Microfotografías tomadas con nícoles cruzados

A) textura micrográfica. B) Cristales de plagioclasa (PI), cuarzo (Qtz) y biotita (Bt) en arreglo granular. C) Tonalita con hornblenda ( $\mathrm{Hbl}$ ) y plagioclasa alterada a sericita $(\mathrm{Pl})$, cuarzo intersticial $(\mathrm{Qtz})$ y venilla de cuarzo tardía. D) Cristales de hornblenda (Hbl), plagioclasa (PI) y titanita (Ttn). E y F) Textura granular con feldespato alcalino pertítico (Fsp) 

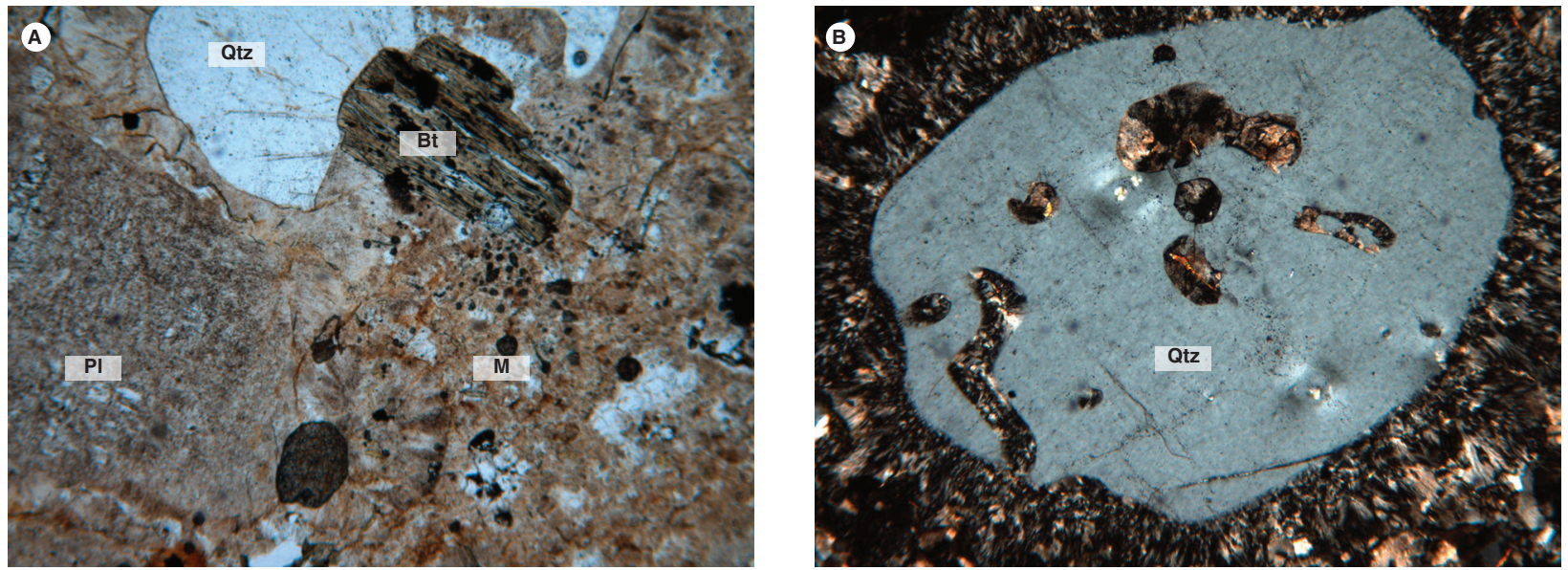

Figura 6. Aspecto microscópico de la muestra IGM-901004 LMC-090B

Fenodacita con textura porfídica y fenocristales de cuarzo (Qtz) con bahías de corrosión, biotita (Bt) alterada a clorita y plagioclasa alterada a minerales arcillosos (PI) en una matriz desvitrificada (M)

\section{Química mineral}

Los análisis de química mineral se hicieron en la Universidad Nacional de Colombia, sede Bogotá. El equipo usado es una microsonda JEOL JXA 8230, cuyas condiciones de operación fueron: 1 a $10 \mu \mathrm{m}$ de diámetro del haz, tiempo en el pico de $20 \mathrm{msec}$, intensidad $20 \mathrm{nA}$ y voltaje de aceleración de $15 \mathrm{kV}$. Los conteos del instrumento son convertidos a porcentajes de óxidos mediante comparaciones con conteos de estándares naturales y sintéticos. Los datos se han tratado mediante la corrección ZAF (Z: número atómico; A: absorción de masas; F: fluorescencia), utilizando el programa de JEOL. La adquisición de los datos consistió en obtener imágenes de electrones retrodispersados de los cristales y en realizar los análisis puntuales. Se seleccionó la muestra TCR-399, clasificada como cuarzomonzonita, teniendo en cuenta la escasa alteración de los minerales. Se escogieron para el análisis plagioclasa, feldespato, pirita y magnetita.

\subsection{Feldespato potásico}

El feldespato alcalino se analizó para la muestra TCR399 en un solo cristal, en tres puntos (figura 7), y los resultados de la química mineral se muestran en la tabla 2 y se resumen en la figura 8. En la muestra TCR-399, el feldespato potásico exhibe micropertitas en filoncillo y parches que se pueden apreciar en las imágenes petrográfica y de electrones retrodispersados (figura 7). Para el campo C3 $\left(\mathrm{Or}_{90,9}-\mathrm{Or}_{96,06,} \mathrm{Ab}_{3,77}-\mathrm{Ab}_{8,84}\right)$, los análisis grafican en el campo de la ortosa pertítica.
Tabla 2. Análisis en cristales de feldespato alcalino en la muestra TCR-399

\begin{tabular}{|c|c|c|c|}
\hline & TCR-399-C3-Kfs-1 & TCR-399-C3-Kfs-3 & TCR-399-C3-Kfs-4 \\
\hline $\mathrm{SiO}_{2}$ & 65,297 & 64,951 & 64,898 \\
\hline $\mathrm{TiO}_{2}$ & $-0,009$ & 0,001 & 0,009 \\
\hline $\mathrm{Al}_{2} \mathrm{O}_{3}$ & 18,791 & 18,715 & 18,713 \\
\hline $\mathrm{FeO}$ & 0,012 & 0,024 & 0,095 \\
\hline $\mathrm{MgO}$ & 0,027 & 0,055 & 0,036 \\
\hline $\mathrm{CaO}$ & 0,008 & 0,035 & 0,051 \\
\hline $\mathrm{Na}_{2} \mathrm{O}$ & 0,508 & 0,418 & 0,972 \\
\hline $\mathrm{K}_{2} \mathrm{O}$ & 15,921 & 16,203 & 15,182 \\
\hline $\begin{array}{c}\text { Total } \\
\text { (\% en peso) } \\
\end{array}$ & 100,501 & 100,292 & 99,884 \\
\hline $\mathrm{Si}$ & 11,979 & 11,965 & 11,963 \\
\hline $\mathrm{Al}$ & 4,063 & 4,063 & 4,065 \\
\hline $\mathrm{Ti}$ & $-0,001$ & 0,000 & 0,001 \\
\hline $\mathrm{Fe}^{2+}$ & 0,001 & 0,002 & 0,010 \\
\hline $\mathrm{Mg}$ & $-0,00738518$ & 0,0151064 & 0,00989389 \\
\hline $\mathrm{Na}$ & 0,181 & 0,149 & 0,347 \\
\hline $\mathrm{Ca}$ & 0,002 & 0,007 & 0,010 \\
\hline $\mathrm{K}$ & 3,726 & 3,808 & 3,570 \\
\hline $\begin{array}{l}\text { Total cationes } \\
\text { (a.p.f.u.) }\end{array}$ & 19,9433 & 19,980 & 19,957 \\
\hline Or & 95,34 & 96,06 & 90,90 \\
\hline$A b$ & 4,62 & 3,77 & 8,84 \\
\hline An & 0,04 & 0,17 & 0,26 \\
\hline Total & 100 & 100 & 100 \\
\hline $\begin{array}{l}\text { a.p.f. u.: átomos } \\
\text { or fórmula unitaria }\end{array}$ & & & \\
\hline
\end{tabular}



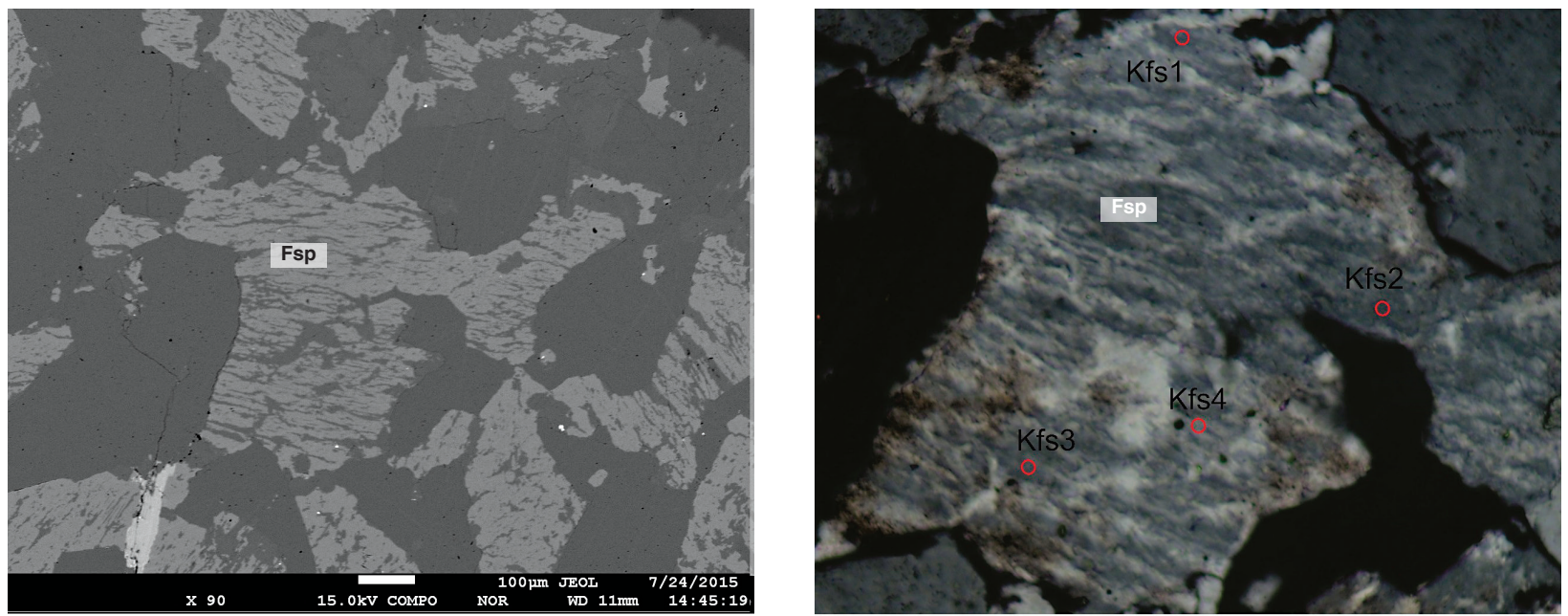

Figura 7. Imagen de electrones retrodispersados muestra TCR-399

Izquierda cristal de feldespato potásico (C3); derecha imagen petrográfica con nícoles cruzados, donde se observan las micropertitas en filoncillos y parches

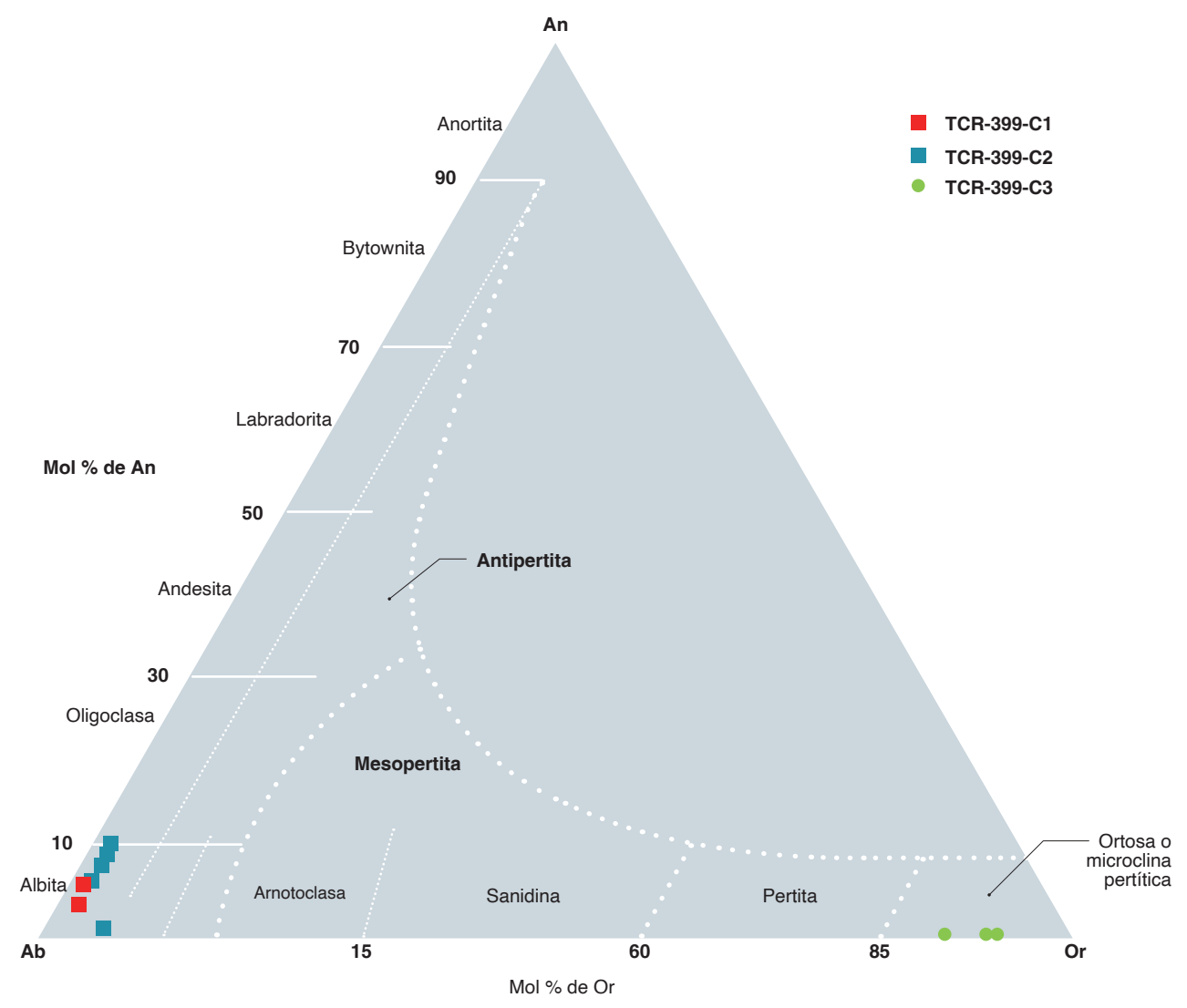

Figura 8. Composición de los feldespatos potásicos y las plagioclasas en la muestra TCR-399

Fuente: Smith-Brown (1988) y autores 


\subsection{Plagioclasa}

La plagioclasa se analizó en dos cristales (C1, C2; figura 9, tabla 3), en núcleos y bordes. El cristal C1 mostró inclusiones anhedrales de feldespato alcalino y composición homogénea albítica en la plagioclasa $\left(\mathrm{Ab}_{92,53-95,59} \mathrm{An}_{3,09-}\right.$ $\left.{ }_{6,52} \mathrm{Or}_{0,95-1,31}\right)$, con una débil zonación composicional con bordes más sódicos. Del cristal C2 se analizaron cinco puntos aleatorios distribuidos en el cristal, que tiene una leve alteración a sericita local y variación composicional que indica composición de albita $\left(\mathrm{Ab}_{88,56-97,07} \mathrm{An}_{0,76-9,82}\right.$ $\left.\mathrm{Or}_{1,23-2,1}\right)$, como se puede observar en la figura 8 .

\subsection{Magnetita y pirita}

De la muestra TCR-399 se analizaron dos cristales de magnetita (figura 10); los resultados obtenidos se pre- sentan en la tabla 4. El cálculo del $\mathrm{Fe}^{3+}$ se hizo usando la fórmula de Droop (1987).

La magnetita presenta coloración gris, con baja reflectancia, fracturamiento irregular; es homogénea y de aspecto liso, con inclusiones de pirita de color amarillo pálido, con buena reflectancia. La magnetita tiene valores altos de $\mathrm{FeO}_{\text {total }}$, entre 94,85 y 96,28 wt\% (11,86 a 11,93 a.p.f.u. de $\mathrm{Fe}^{3+}$ y aproximadamente 12 a.p.f.u. de $\mathrm{Fe}^{2+}$ ), concentraciones menores de $\mathrm{MnO}$, entre 0,08 y 0,1 4 wt\%, $\mathrm{TiO}_{2}$ bajo (alcanza 0,27 a 0,53 wt\%) y $\mathrm{Al}_{2} \mathrm{O}_{3} \mathrm{de}$ hasta $0,19 \mathrm{wt} \%$. La pirita tiene concentración en azufre (S) de 52,9 wt\% y hierro (Fe) entre 45,5 wt\% y 45,9 wt\%, valores de $\mathrm{Co}<0,11 \mathrm{wt} \%$ y valores poco representativos de Cu, As y Ni (tabla 4).

Tabla 3. Análisis en cristales de plagioclasa de la muestra TCR-399

\begin{tabular}{|c|c|c|c|c|c|c|c|c|}
\hline & TCR-399-C1-PI-1 & TCR-399-C1-PI-2 & TCR-399-C1-PI-3 & TCR-399-C2-PI-1 & TCR-399-C2-PI-2 & TCR-399-C2-PI-3 & TCR-399-C2-PI-4 & TCR-399-C2-PI-5 \\
\hline $\mathrm{SiO}_{2}$ & 67,452 & 67,413 & 68,619 & 67,286 & 67,127 & 68,038 & 68,526 & 66,227 \\
\hline $\mathrm{TiO}_{2}$ & 0,004 & 0,011 & $-0,003$ & $-0,03$ & 0,008 & $-0,02$ & $-0,017$ & 0,040 \\
\hline $\mathrm{Al}_{2} \mathrm{O}_{3}$ & 20,159 & 19,888 & 19,540 & 20,066 & 20,292 & 19,823 & 19,524 & 20,268 \\
\hline $\mathrm{FeO}$ & 0,233 & 0,087 & 0,081 & 0,048 & 0,063 & 0,032 & 0,055 & 0,036 \\
\hline $\mathrm{MgO}$ & $-0,016$ & 0,028 & 0,003 & 0,012 & 0,034 & $-0,002$ & 0,007 & $-0,008$ \\
\hline $\mathrm{CaO}$ & 1,402 & 1,324 & 0,672 & 1,921 & 1,795 & 1,444 & 0,167 & 2,095 \\
\hline $\mathrm{K}_{2} \mathrm{O}$ & 0,171 & 0,202 & 0,240 & 0,323 & 0,271 & 0,226 & 0,382 & 0,291 \\
\hline Total (\% en peso) & 100,397 & 99,877 & 100,638 & 100,149 & 100,326 & 100,594 & 100,044 & 99,389 \\
\hline $\mathrm{Si}$ & 11,796 & 11,836 & 11,943 & 11,796 & 11,754 & 11,864 & 11,978 & 11,714 \\
\hline $\mathrm{Al}$ & 4,155 & 4,116 & 4,008 & 4,146 & 4,188 & 4,074 & 4,022 & 4,225 \\
\hline $\mathrm{Ti}$ & 0,023 & 0,009 & 0,008 & 0,005 & 0,006 & 0,003 & 0,005 & 0,004 \\
\hline $\mathrm{Fe}$ & 0,001 & 0,001 & 0,000 & 0,000 & 0,001 & 0,000 & 0,000 & 0,005 \\
\hline $\mathrm{Na}$ & 3,727 & 3,719 & 3,876 & 3,577 & 3,645 & 3,737 & 3,864 & 3,580 \\
\hline $\mathrm{Ca}$ & 0,263 & 0,249 & 0,125 & 0,361 & 0,337 & 0,270 & 0,031 & 0,397 \\
\hline $\mathrm{K}$ & 0,038 & 0,045 & 0,053 & 0,072 & 0,061 & 0,050 & 0,085 & 0,066 \\
\hline Total cationes (a.p.f.u.) & 19,998 & 19,982 & 20,014 & 19,957 & 20,000 & 19,994 & 19,985 & 19,989 \\
\hline$A b$ & 92,53 & 92,67 & 95,595 & 89,200 & 90,171 & 92,111 & 97,074 & 88,56 \\
\hline An & 6,52 & 6,21 & 3,091 & 8,998 & 8,331 & 6,650 & 0,786 & 9,82 \\
\hline Or & 0,95 & 1,13 & 1,314 & 1,802 & 1,498 & 1,239 & 2,140 & 1,62 \\
\hline Total & 100,00 & 100,00 & 100,000 & 100,000 & 100,00 & 100,00 & 100 & 100,00 \\
\hline
\end{tabular}



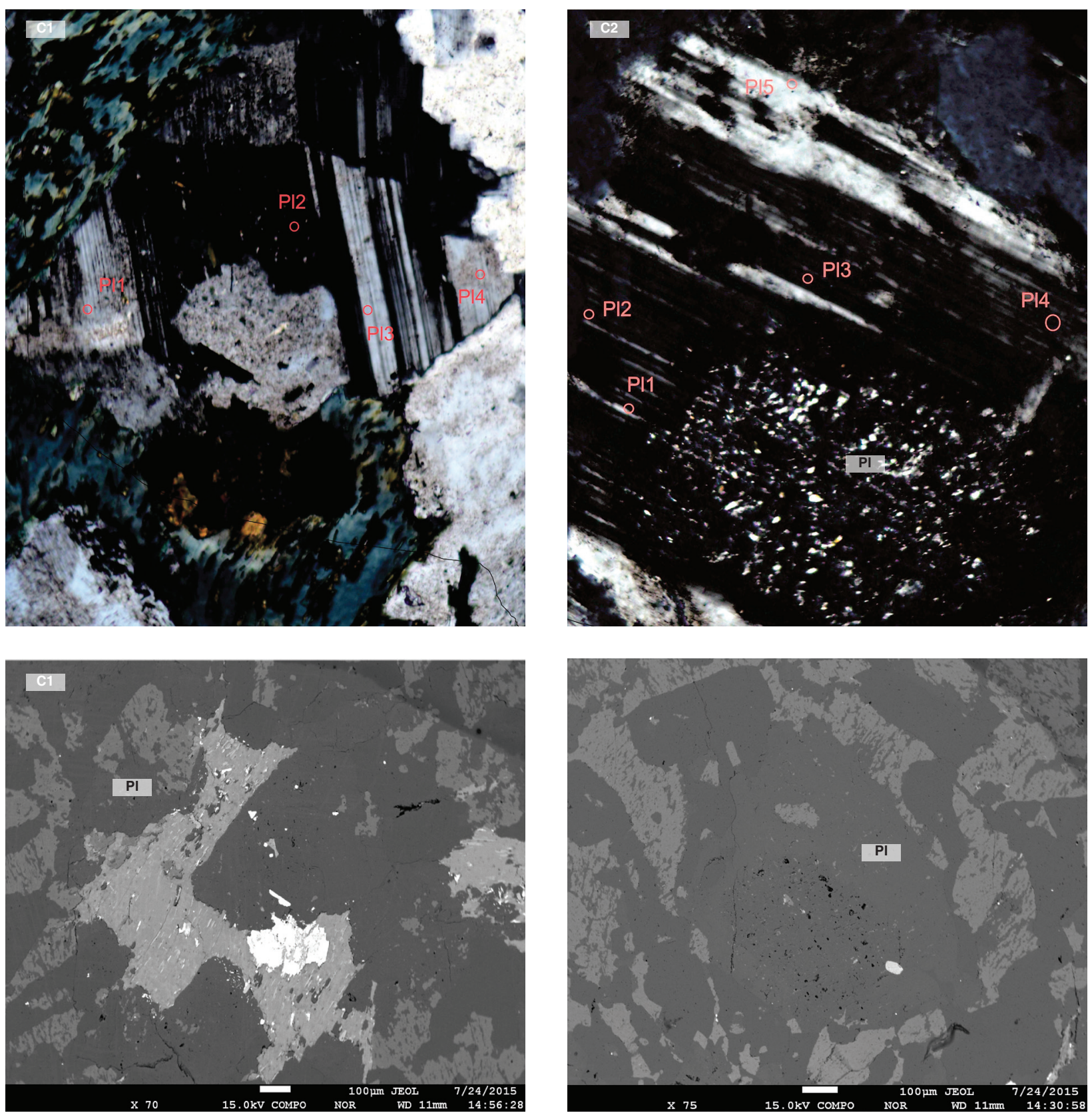

Figura 9. Cristales de plagioclasa (PI) en los campos $\mathrm{C} 1$ y $\mathrm{C} 2$ de la muestra TCR-399

Imagen de microscopía óptica con nícoles cruzados con la selección de puntos, arriba, e imagen de electrones retrodispersados, abajo 

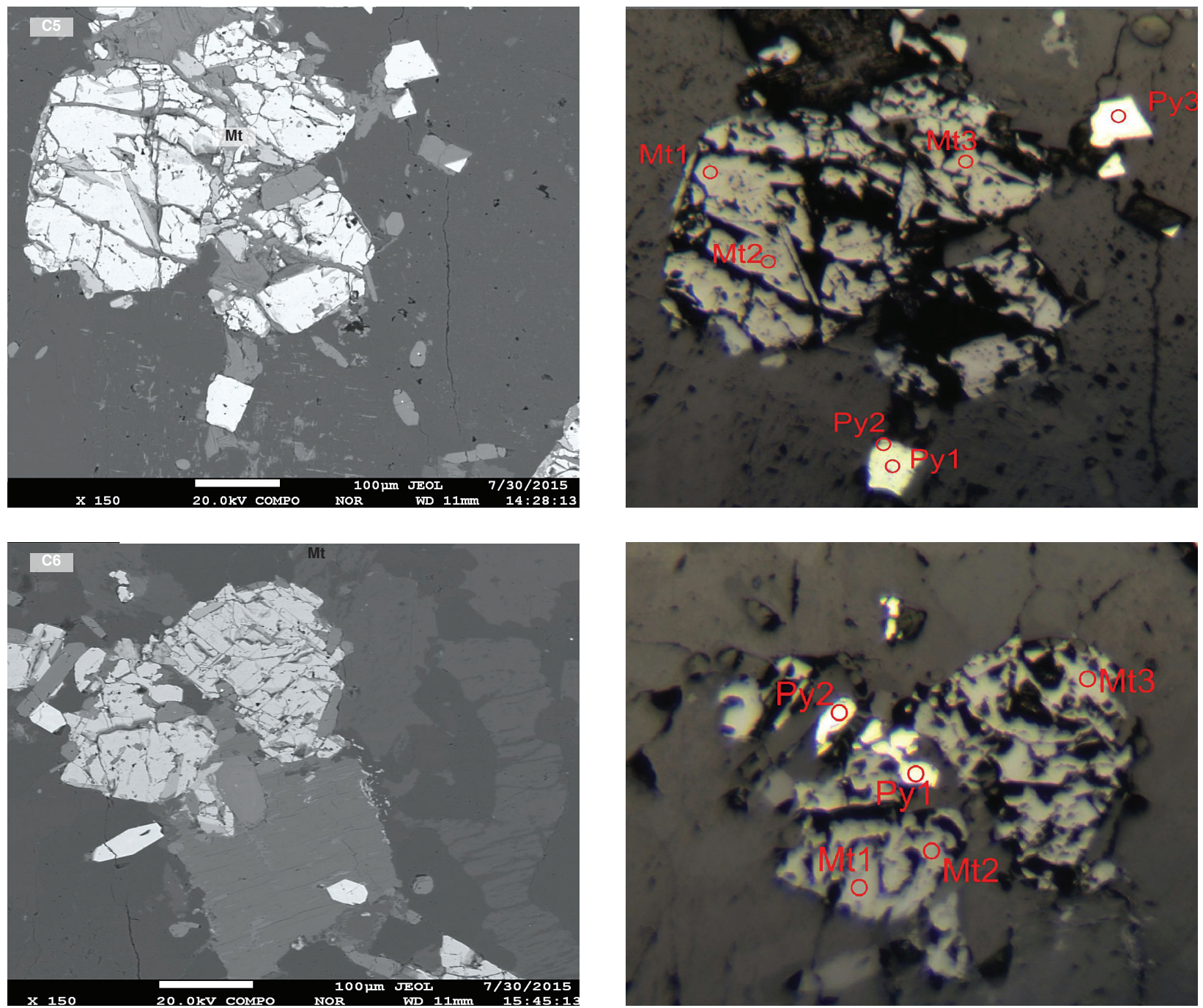

Figura 10. Imágenes de electrones retrodispersados (BSE) (izquierda) y luz reflejada (derecha), correspondientes a magnetita y pirita de la muestra TCR-399

Tabla 4. Composición química de magnetita y pirita en la muestra TCR-399

\begin{tabular}{|c|c|c|c|c|c|c|c|c|c|c|}
\hline & $\begin{array}{c}\text { TCR-399-C5- } \\
\text { Mt-1 }\end{array}$ & $\begin{array}{c}\text { TCR-399-C5- } \\
\text { Mt-2 }\end{array}$ & $\begin{array}{c}\text { TCR-399-C5- } \\
\text { Mt-3 }\end{array}$ & $\begin{array}{c}\text { TCR-399-C6- } \\
\text { Mt-1 } \\
\end{array}$ & $\begin{array}{c}\text { TCR-399-C6- } \\
\text { Mt-2 }\end{array}$ & $\begin{array}{c}\text { TCR-399-C6- } \\
\text { Mt-3 }\end{array}$ & & $\begin{array}{c}\text { TCR-399-C5- } \\
\text { Py-3 }\end{array}$ & $\begin{array}{c}\text { TCR-399-C6- } \\
\text { Py-1 }\end{array}$ & $\begin{array}{c}\text { TCR-399-C6- } \\
\text { Py-2 }\end{array}$ \\
\hline $\mathrm{SiO}_{2}$ & & & 0,001 & & 0,012 & 0,007 & $\mathrm{Zn}$ & 0,011 & N. D. & 0,038 \\
\hline $\mathrm{TiO}_{2}$ & 0,267 & 0,526 & 0,513 & 0,298 & 0,456 & 0,271 & As & N. D. & 0.125 & N. D. \\
\hline $\mathrm{Al}_{2} \mathrm{O}_{3}$ & 0,039 & 0,101 & 0,071 & 0,055 & 0,198 & 0,018 & $S$ & 52,886 & 52,939 & 52,886 \\
\hline $\mathrm{Cr}_{2} \mathrm{O}_{3}$ & 0,017 & & 0,007 & 0,016 & 0,003 & 0,038 & $\mathrm{Fe}$ & 45,647 & 45,895 & 45,523 \\
\hline $\mathrm{FeO}$ & 96,279 & 95,689 & 95,911 & 95,612 & 94,853 & 96,187 & Co & 0,112 & 0,079 & 0,066 \\
\hline $\mathrm{MnO}$ & 0,099 & 0,14 & 0,129 & 0,058 & 0,134 & 0,082 & $\mathrm{Ni}$ & N. A. & N. A. & N. A. \\
\hline $\mathrm{MgO}$ & 0,007 & & 0,015 & 0,002 & 0,023 & & $\mathrm{Sb}$ & N. A. & N. A. & N. A. \\
\hline Total & 96,708 & 96,456 & 96,647 & 96,041 & 95,679 & 96,603 & $\mathrm{Cu}$ & N. D. & 0,003 & N. D. \\
\hline \multicolumn{7}{|c|}{ Formula basada en 32 oxígenos } & Total & 98,656 & 99,041 & 98,513 \\
\hline $\mathrm{Si}$ & 0,000 & 0,000 & 0,000 & 0,000 & 0,004 & 0,002 & $\mathrm{Zn}$ & 0,007 & N. D. & 0,024 \\
\hline $\mathrm{Ti}$ & 0,060 & 0,118 & 0,115 & 0,067 & 0,103 & 0,061 & As & N. D. & 0.067 & N. D. \\
\hline Al & 0,014 & 0,035 & 0,025 & 0,019 & 0,070 & 0,006 & $\mathrm{~S}$ & 66,813 & 66,688 & 66,883 \\
\hline $\mathrm{Cr}$ & 0,004 & 0,000 & 0,002 & 0,004 & 0,001 & 0,009 & $\mathrm{Fe}$ & 33,103 & 33,189 & 33,048 \\
\hline $\mathrm{Fe}^{3+}$ & 11,931 & 11,863 & 11,871 & 11,921 & 11,857 & 11,929 & Co & 0,077 & 0,054 & 0,045 \\
\hline $\mathrm{Fe}^{2+}$ & 11,963 & 11,948 & 11,949 & 11,973 & 11,922 & 11,972 & $\mathrm{Ni}$ & N. A. & N. A. & N. A. \\
\hline $\mathrm{Mg}$ & 0,003 & 0,000 & 0,007 & 0,001 & 0,010 & 0,000 & $\mathrm{Sb}$ & N. A. & N. A. & N. A. \\
\hline
\end{tabular}




\begin{tabular}{|c|c|c|c|c|c|c|c|c|c|c|}
\hline & $\begin{array}{c}\text { TCR-399-C5- } \\
\text { Mt-1 }\end{array}$ & $\begin{array}{c}\text { TCR-399-C5- } \\
\text { Mt-2 }\end{array}$ & $\begin{array}{c}\text { TCR-399-C5- } \\
\text { Mt-3 }\end{array}$ & $\begin{array}{c}\text { TCR-399-C6- } \\
\text { Mt-1 }\end{array}$ & $\begin{array}{c}\text { TCR-399-C6- } \\
\text { Mt-2 }\end{array}$ & $\begin{array}{c}\text { TCR-399-C6- } \\
\text { Mt-3 }\end{array}$ & & $\begin{array}{c}\text { TCR-399-C5- } \\
\text { Py-3 }\end{array}$ & $\begin{array}{c}\text { TCR-399-C6- } \\
\text { Py-1 }\end{array}$ & $\begin{array}{c}\text { TCR-399-C6- } \\
\text { Py-2 }\end{array}$ \\
\hline $\mathrm{Mn}$ & 0,025 & 0,035 & 0,032 & 0,015 & 0,034 & 0,021 & $\mathrm{Cu}$ & N. D. & 0,002 & N. D. \\
\hline Total & 24,000 & 24,000 & 24 & 24,000 & 24,000 & 24,000 & Total & 99,938 & 99,983 & 99,968 \\
\hline $\mathrm{Mg} /\left(\mathrm{Mg}+\mathrm{Fe}^{2+}\right)$ & 0,000259 & 0 & 0,001 & 0,000 & 0,001 & 0 & & & & \\
\hline $\mathrm{Cr} /(\mathrm{Cr}+\mathrm{Al})$ & 0,22622 & 0 & 0,062 & 0,163 & 0,010 & 0,586 & & & & \\
\hline $\mathrm{Fe}^{2+} /\left(\mathrm{Fe}^{2+}+\mathrm{Mg}\right)$ & 0,999741 & 1 & 0,999 & 1,000 & 0,999 & 1 & & & & \\
\hline
\end{tabular}

\section{Litogeoquímica}

La caracterización litogeoquímica de la Tonalita de San Martín se realizó a partir de cuatro análisis de rocas de las facies más abundantes del plutón (LMC-088, LMC090A, TCR-395A y TCR-399). Un quinto análisis corresponde a una muestra de dique dacítico (LMC-090B). Los análisis se realizaron con un espectrómetro de fluorescencia de rayos X, FRX, Panalytical AXIOS Mineral para análisis elemental, configurado con software especializado para materiales geológicos. La cuantificación de los óxidos mayores se realizó en muestra fundida con metaborato y tetraborato de litio, y la cuantificación de elementos menores se realizó en muestra prensada $(\mathrm{V}$, Mo, Nb, Ta, W, Zr y Hf). En el análisis de elementos traza de interés geoquímico en rocas se usó un espectrómetro de masas con plasma inductivamente acoplado, ICP-MS, Perkin Elmer Nexion. Para la disolución de la muestra se realizó un ataque por pasos utilizando ácidos inorgánicos fuertes (HF, HNO3, $\mathrm{HClO} 4 \mathrm{y} \mathrm{HCl}$ ). El proceso se realiza en sistema abierto, empleando distintas rampas de temperatura y tiempos de calentamiento. Gran parte de los diagramas geoquímicos se generaron con el uso del GCDKit versión 4.0 (Janoušek et al., 2006).

\section{1. Óxidos mayores}

Para la interpretación de los óxidos mayores se hizo el recálculo, teniendo en cuenta los valores de LOI (pérdidas por ignición). Los resultados de óxidos mayores se muestran en la tabla 5 .

Los valores de $\mathrm{SiO}_{2}$ en rocas granitoides de la Tonalita de San Martín varían entre 65,2 wt\% y 74,96 wt\%, y la muestra de dique de fenodacita presenta valores de $\mathrm{SiO}_{2}$ de 75,3 wt\% (LMC-090B). Considerando las cinco muestras en conjunto, los valores $\mathrm{de}_{2} \mathrm{Al}_{2}, \mathrm{Fe}_{2} \mathrm{O}_{3}, \mathrm{MgO}$, $\mathrm{Na}_{2} \mathrm{O}$ y CaO disminuyen con el aumento de $\mathrm{SiO}_{2} ; \mathrm{el} \mathrm{K}_{2} \mathrm{O}$ varía entre 1,69 wt $\%$ y 3,26 wt \%; el CaO varía entre 0,41 y $2,05 \mathbf{w t} \%, \mathrm{MgO}<1 \mathbf{w t} \%$ y $\mathrm{TiO}_{2}<0,7 \mathbf{w t} \%$; las razones $\mathrm{K}_{2} \mathrm{O} / \mathrm{Na}_{2} \mathrm{O}>1$, y presentan contenido de álcalis $\left(\mathrm{Na}_{2} \mathrm{O}+\right.$ $\left.\mathrm{K}_{2} \mathrm{O}\right)>7 \mathrm{wt} \%$. En general, los óxidos mayores con relación al $\mathrm{SiO}_{2}$ muestran dispersión en las cinco muestras y no es claro un tren de diferenciación común; esto puede deberse al número de muestras analizadas.

En los diagramas $\mathrm{K}_{2} \mathrm{O}$ versus $\mathrm{SiO}_{2}$ (figura $11 \mathrm{~A}$ ), la muestra IGM-901003 se aparta del resto y grafica en el campo de la serie toleítica, mientras las otras muestras se distribuyen en el campo de series calcoalcalinas de contenidos medios y altos en K. No obstante, en el diagrama

Tabla 5. Composición de óxidos mayores en rocas granitoides y roca de diques de la Tonalita de San Martín

\begin{tabular}{|c|c|c|c|c|c|}
\hline IGM & 901002 & 901003 & 901032 & 901033 & 901004 \\
\hline N. ${ }^{\circ}$ campo & LMC-088 & LMC-090A & TCR-395A & TCR-399 & LMC-090B \\
\hline w & 1069983 & 1070179 & 1075180 & 1072495 & 1070179 \\
\hline $\mathbf{N}$ & 1392339 & 1385799 & 1368544 & 1376017 & 1385799 \\
\hline $\mathrm{SiO}_{2}$ & 74,48 & 69,23 & 65,24 & 74,96 & 75,33 \\
\hline $\mathrm{TiO}_{2}$ & 0,16 & 0,3 & 0,7 & 0,18 & 0,14 \\
\hline $\mathrm{Al}_{2} \mathrm{O}_{3}$ & 13,61 & 16,99 & 16,94 & 13,41 & 13,58 \\
\hline $\mathrm{Fe}_{2} \mathrm{O}_{3}$ & 2,2 & 2,25 & 4,77 & 1,74 & 1,58 \\
\hline MgO & 0,33 & 0,46 & 0,83 & 0,35 & 0,33 \\
\hline $\mathrm{CaO}$ & 1,17 & 0,41 & 2,05 & 0,67 & 0,22 \\
\hline $\mathrm{Na}_{2} \mathrm{O}$ & 4,04 & 9,1 & 6,68 & 4,25 & 4,43 \\
\hline $\mathrm{K}_{2} \mathrm{O}$ & 3,26 & 0,13 & 1,69 & 3,77 & 3,37 \\
\hline $\mathrm{P}_{2} \mathrm{O}_{5}$ & 0,057 & 0,074 & 0,118 & 0,04 & 0,047 \\
\hline MnO & 0,04 & 0,13 & 0,15 & 0,03 & 0,04 \\
\hline $\mathrm{FeO}$ & 1,13 & 1,22 & 1,82 & 0,94 & 0,19 \\
\hline LOI & 0,54 & 0,84 & 0,53 & 0,49 & 0,82 \\
\hline $\begin{array}{l}\text { Clasificación } \\
\text { petrográfica }\end{array}$ & Granodiorita & Cuarzomonzodiorita & Tonalita deformada & Cuarzomonzonita & Fenodacita \\
\hline
\end{tabular}


de Hastie, Kerr, Pearce y Mitchell (2007) (figura 11B), las rocas granitoides y la roca de dique dacítico grafican en las series calcoalcalina con contenidos medios de $\mathrm{K}$ y se separan en los campos de BA/A: andesitas basálticas y andesitas y $\mathrm{D} / \mathrm{R}^{*}$ : dacitas, riolitas, latitas y traquitas, con mejor agrupación.

(4)

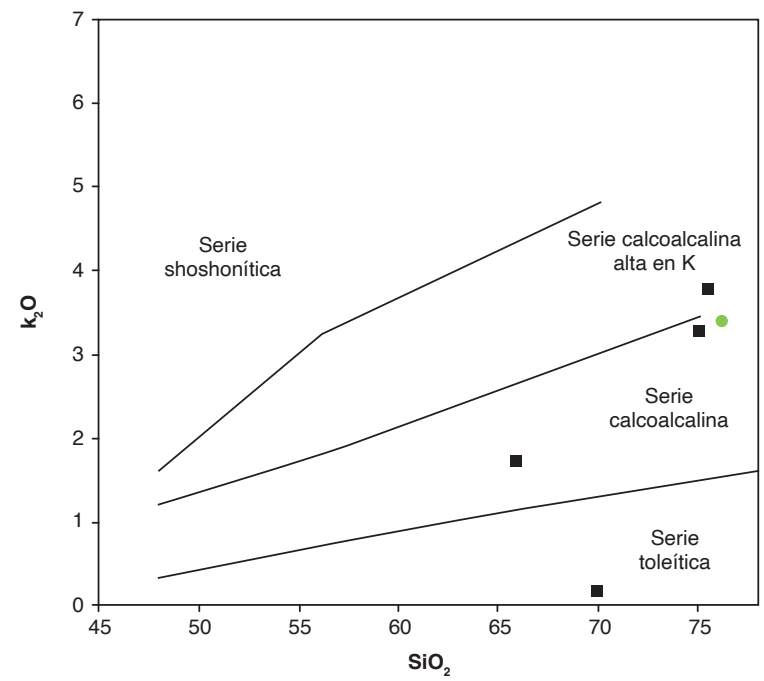

De acuerdo con el diagrama AFM (figura 12), las rocas hacen parte de la serie calcoalcalina y son altamente diferenciadas; sin embargo, la muestra IGM-901032, que corresponde a una tonalita deformada, presenta los menores valores de $\mathrm{SiO}_{2}$ y valores mayores de $\mathrm{Fe}_{2} \mathrm{O}_{3}$ (4,77 wt\%) y $\mathrm{MgO}(0,83 \mathrm{wt} \%)$.

\section{B}

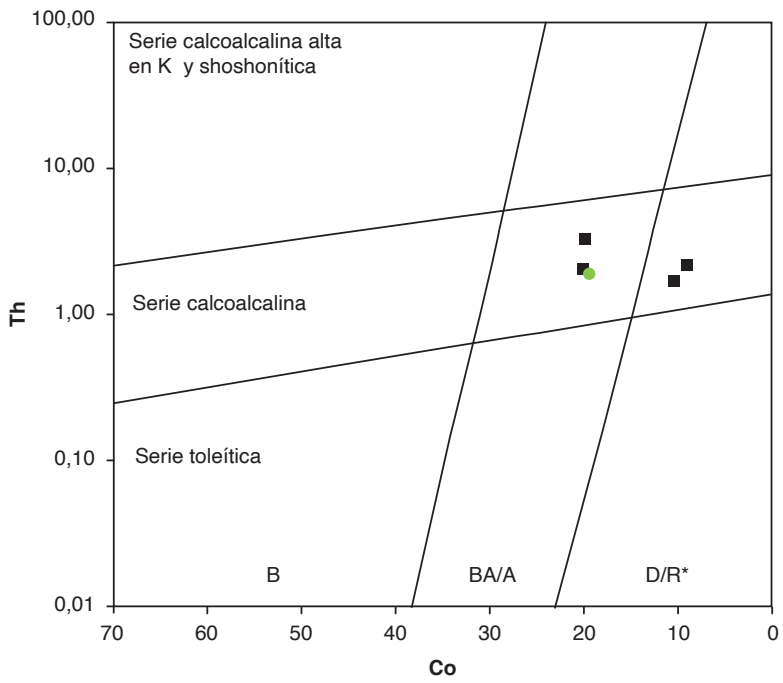

Figura 11. Diagramas de clasificación de series correspondientes a rocas de la Tonalita de San Martín A) Diagrama $\mathrm{K}_{2} \mathrm{O}$ Vs $\mathrm{SiO}_{2}$ (Peccerillo y Taylor, 1976). B) Diagrama de clasificación Th-Co (Hastie et al., 2007). B: Basalto. BA/A: andesita basáltica/ andesita. $\mathrm{D} / \mathrm{R}^{*}$ : dacita/riolita/latita traquita (en negro, facies granitoide; en verde, muestra de dique dacítico)

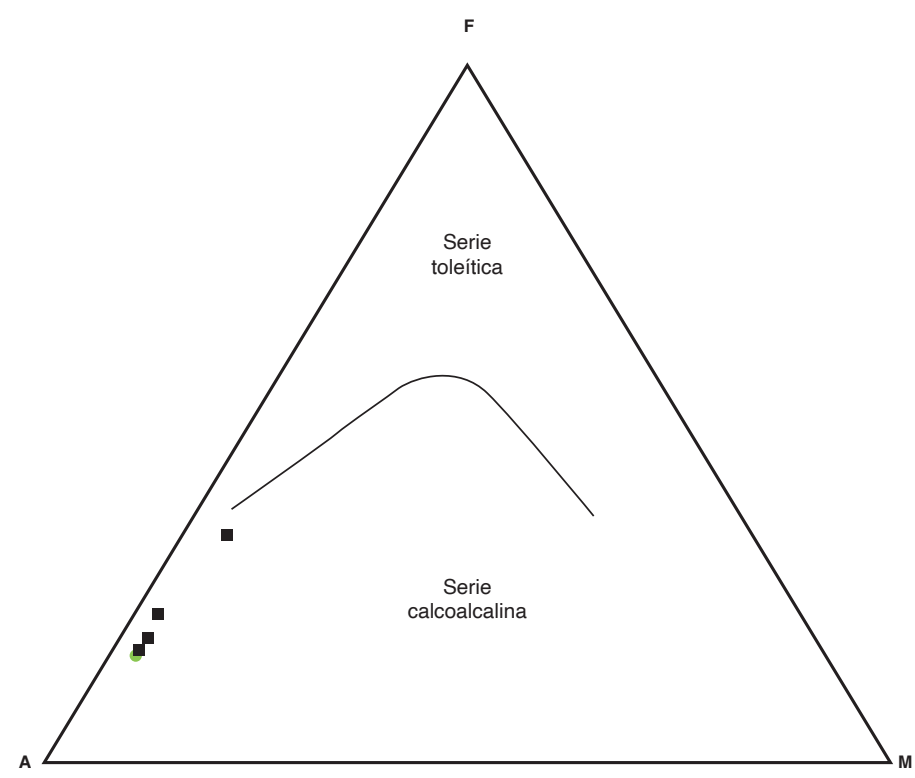

Figura 12. Diagrama AFM (Irvine y Baragar, 1971) correspondiente a las rocas de la Tonalita de San Martín 
A

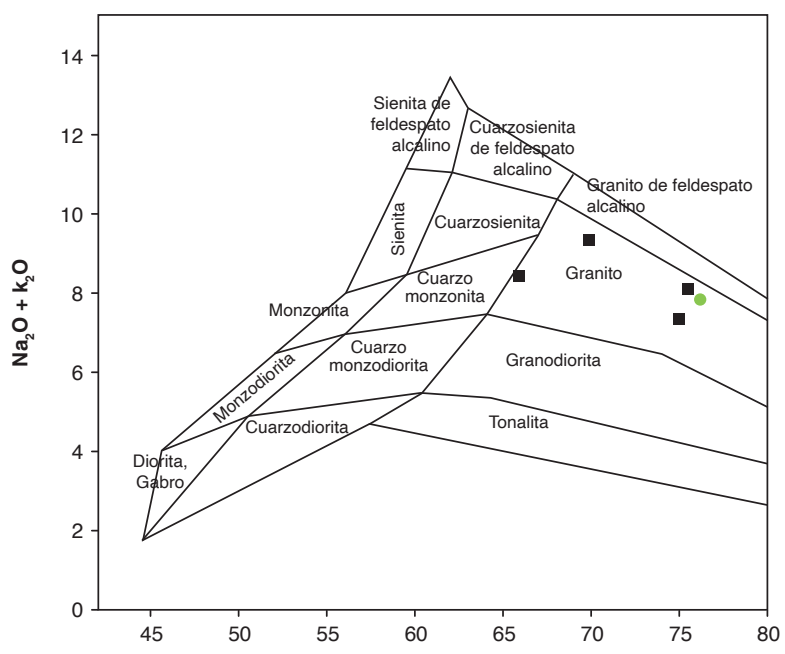

B

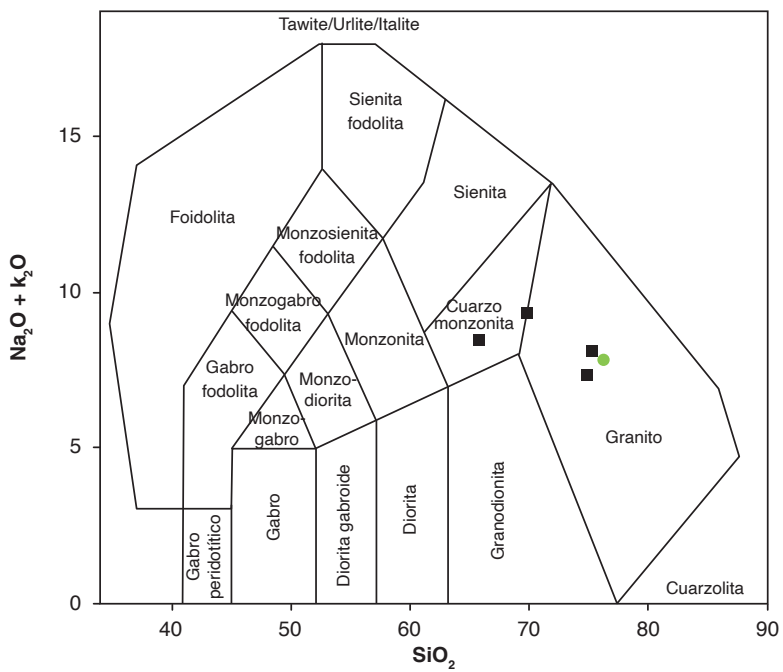

Figura 13. Clasificación con base en la composición química de rocas de la Tonalita de San Martín A) Diagrama TAS de Middlemost (1985). B) Diagrama TAS de Middlemost (1994) (el símbolo de color verde corresponde a una roca de dique)

Las rocas de la Tonalita de San Martín son subalcalinas y químicamente clasifican en los diagramas TAS de Middlemost $(1985,1994)$ (figura 13 A y B) en los granitos y cuarzomonzonitas, sin una buena concordancia con la clasificación petrográfica, debido a los valores altos de $\mathrm{SiO}_{2}$ y álcalis.

Las rocas analizadas (cuarzomonzonitas y granitos), de la Tonalita de San Martín, grafican en el campo peraluminoso del gráfico de Shand (1943), con valores de $\left(\mathrm{Na}_{2} \mathrm{O}+\mathrm{K}_{2} \mathrm{O} / \mathrm{Al}_{2} \mathrm{O}_{3}\right)_{\text {mol }}(\mathrm{A} / \mathrm{NK})>1$ y valores de $\left(\mathrm{Al}_{2} \mathrm{O}_{3} /\right.$
$\left.\mathrm{Na}_{2} \mathrm{O}+\mathrm{K}_{2} \mathrm{O}+\mathrm{CaO}\right)_{\text {mol }}(\mathrm{A} / \mathrm{CNK})>1$ (figura $14 \mathrm{~A}$ ), con valo-

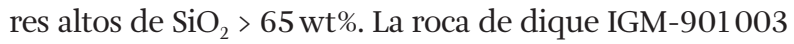
también es peraluminosa. En el diagrama de Debon y Le Fort (1983), modificado por Villaseca, Barbero y Herreros (1998) (figura 14B), las rocas se agrupan en el límite entre los campos de granitoides con baja peraluminosidad (1-p) y los granitos medianamente peraluminosos, la mayoría de ellas por debajo de la línea límite para granitoides tipos Iy $S$ y en el campo de los granitoides tipo I. La roca de dique grafica en el campo de las rocas félsicas peraluminosas.

\begin{tabular}{|c|c|c|c|c|c|}
\hline IGM & 901002 & 901004 & 901032 & 901033 & 901003 \\
\hline N. ${ }^{\circ}$ campo & LMC-088 & LMC-090B & TCR-395A & TCR-399 & LMC-090A \\
\hline $\mathrm{Li}$ & 4,89 & 7,99 & 3,49 & 1,62 & 7,86 \\
\hline $\mathrm{Be}$ & 1,58 & 1,17 & 1,30 & 1,60 & 1,70 \\
\hline Sc & 3,40 & 2,13 & 10,97 & 2,15 & 5,20 \\
\hline v & 12,27 & 12,15 & 23,18 & 9,45 & 10,20 \\
\hline $\mathrm{Cr}$ & 4,05 & 5,24 & 4,36 & 3,11 & 4,32 \\
\hline Co & 20,24 & 19,56 & 10,50 & 19,88 & 9,04 \\
\hline $\mathbf{N i}$ & 2,26 & 9,91 & 1,79 & 1,20 & 1,43 \\
\hline $\mathrm{Cu}$ & 80,24 & 4,40 & 6,90 & 5,49 & 7,04 \\
\hline $\mathrm{Zn}$ & 26,53 & 30,64 & 81,75 & 25,01 & 203,20 \\
\hline $\mathrm{Ga}$ & 15,66 & 12,59 & 20,62 & 15,73 & 18,17 \\
\hline As & 0,93 & 0,89 & 1,10 & 1,01 & 1,45 \\
\hline $\mathbf{R b}$ & 49,71 & 53,96 & 28,83 & 74,66 & 1,60 \\
\hline $\mathrm{Sr}$ & 114,41 & 116,32 & 229,94 & 88,94 & 116,75 \\
\hline $\mathbf{Y}$ & 13,72 & 9,10 & 27,57 & 13,15 & 24,56 \\
\hline $\mathrm{Cd}$ & $<0,08$ & $<0,08$ & 0,13 & $<0,08$ & 0,44 \\
\hline
\end{tabular}




\begin{tabular}{|c|c|c|c|c|c|}
\hline IGM & 901002 & 901004 & 901032 & 901033 & 901003 \\
\hline N. ${ }^{\circ}$ campo & LMC-088 & LMC-090B & TCR-395A & TCR-399 & LMC-090A \\
\hline In & 0,03 & 0,01 & 0,06 & 0,01 & 0,48 \\
\hline Cs & 0,11 & 0,13 & 0,16 & 0,12 & $<0,05$ \\
\hline $\mathrm{Ba}$ & 916,73 & 1081,52 & 1186,40 & 1130,75 & 132,92 \\
\hline La & 14,73 & 14,62 & 22,73 & 24,06 & 17,63 \\
\hline $\mathrm{Ce}$ & 27,97 & 25,83 & 51,03 & 49,69 & 39,79 \\
\hline $\mathrm{Pr}$ & 3,60 & 3,22 & 6,21 & 5,38 & 5,51 \\
\hline $\mathrm{Nd}$ & 13,24 & 11,16 & 25,10 & 18,03 & 19,41 \\
\hline Sm & 2,55 & 2,07 & 5,79 & 3,55 & 4,19 \\
\hline Eu & 0,84 & 0,78 & 3,68 & 0,81 & 0,96 \\
\hline Gd & 2,41 & 1,75 & 5,92 & 3,49 & 4,05 \\
\hline $\mathrm{Tb}$ & 0,38 & 0,26 & 0,91 & 0,46 & 0,70 \\
\hline Dy & 2,09 & 1,33 & 5,44 & 2,45 & 4,05 \\
\hline Ho & 0,42 & 0,29 & 1,11 & 0,48 & 0,84 \\
\hline Er & 1,31 & 1,00 & 3,29 & 1,41 & 2,50 \\
\hline $\mathrm{Tm}$ & 0,19 & 0,16 & 0,47 & 0,21 & 0,34 \\
\hline $\mathrm{Yb}$ & 1,32 & 1,19 & 3,10 & 1,43 & 2,20 \\
\hline Lu & 0,19 & 0,20 & 0,48 & 0,21 & 0,31 \\
\hline TI & 0,22 & 0,22 & 0,11 & 0,27 & $<0,01$ \\
\hline $\mathrm{Pb}$ & 7,91 & 3,19 & 6,10 & 8,90 & 13,13 \\
\hline Th & 2,06 & 1,93 & 1,70 & 3,27 & 2,11 \\
\hline U & 0,32 & 0,54 & 0,39 & 0,47 & 0,53 \\
\hline $\mathrm{Zr}$ & 137,70 & 109,20 & 777,00 & 152,10 & 199,40 \\
\hline $\mathrm{Nb}$ & 5,5 & 4,5 & 9,4 & 6,3 & 5,3 \\
\hline w & 81,4 & 77,6 & 37,3 & 76,4 & 23 \\
\hline $\mathrm{Hf}$ & $<8$ & $<8$ & 11,6 & $<8$ & $<8$ \\
\hline
\end{tabular}

(4)

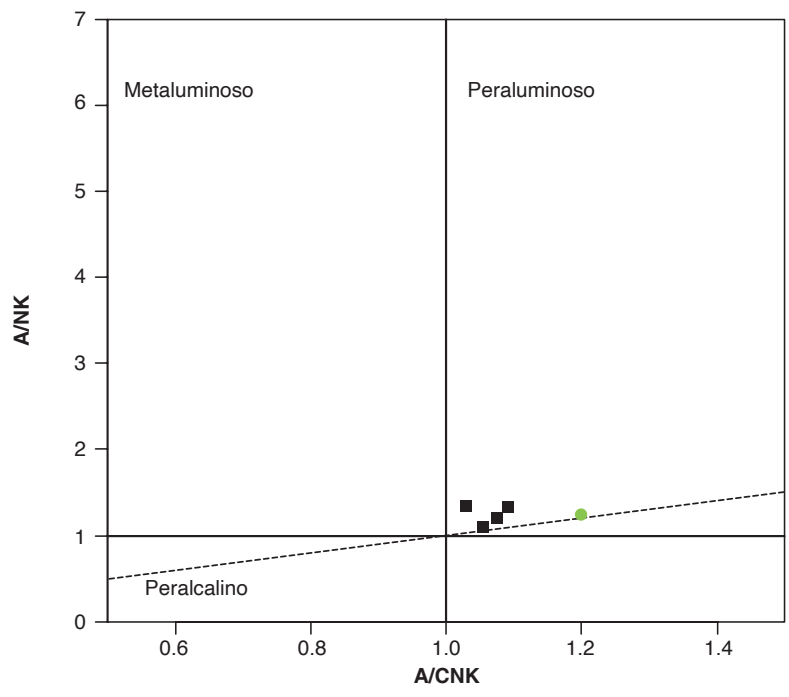

B

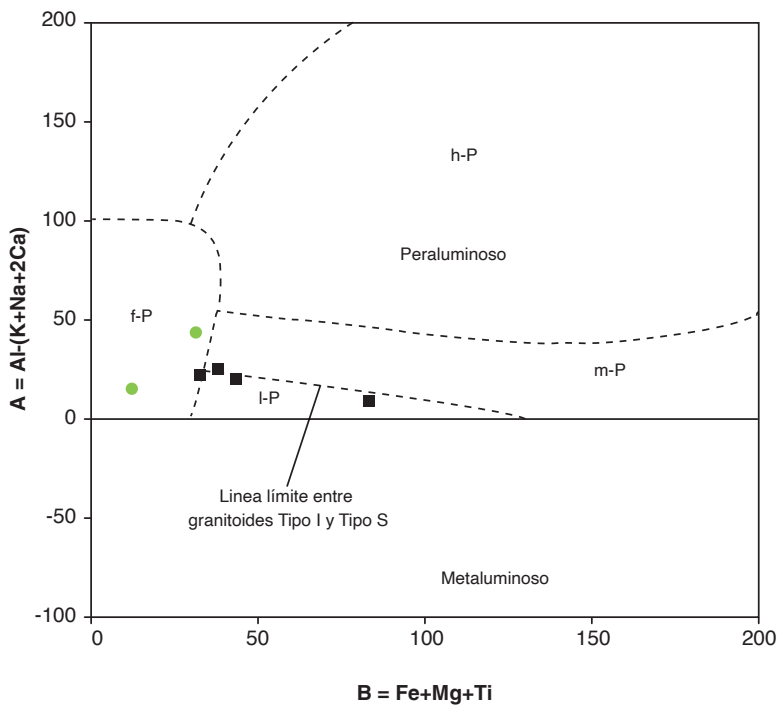

Figura 14. Diagrama de alcalinidad-aluminosidad correspondiente a rocas de la Tonalita de San Martín

A) Diagrama de Shand (1943). B) diagrama de Debon y Le Fort (1983) modificado por Villaseca et al. (1998): f-P, granitoides peraluminosos félsicos; h-P, granitoides altamente peraluminosos; m-P, granitoides medianamente peraluminosos, granitos bajo peraluminoso. (El símbolo de color verde corresponde a una roca de dique) 


\subsection{Elementos trazas}

En la tabla 6 se resumen los resultados de los análisis químicos de elementos traza y tierras raras correspondientes a las cuatro rocas de la Tonalita de San Martín y la roca de dique dacítico. Al analizar el comportamiento de los patrones de tierras raras (REE) en el diagrama multielemental de REE y contrastarlo con los valores normalizados con el condrito de Nakamura (1974) (figura 15A), se observa que las rocas tienen un patrón de REE no paralelo, con un empobrecimiento progresivo desde las tierras raras livianas (LREE) hacia las tierras raras pesadas (HREE), pendiente negativa y anomalía negativa de Eu en las muestras IGM-901 002, 9019004 y 901032 , lo que sugiere fraccionamiento de la plagioclasa en el magma. Las relaciones $\mathrm{Eu} / \mathrm{Eu}^{*}>1 \mathrm{y}(\mathrm{La} / \mathrm{Yb})_{\mathrm{N}}$ $>$ 4,5 evidencian un enriquecimiento de tierras raras ligeras con relación a las HREE en todas las muestras; además, la muestra 901033 tiene anomalía positiva de Eu. Los patrones de REE presentan diferencias en cada roca, y mayor o menor pendiente de cada uno, lo que sugiere variaciones composicionales en los magmas, diferencias que podrían explicarse por cambios en la fuente de los magmas de cada patrón, con mayor o menor aporte del manto y de corteza en cada uno de ellos. Los valores de $(\mathrm{La} / \mathrm{Yb})_{\mathrm{N}}$ que se han encontrado no son altos y sugieren mayor aporte de manto y menor aporte de corteza por contaminación cortical (Girardi, 2008). La tabla 7 presenta las relaciones normalizadas según el condrito de Nakamura (1974) de algunas REE, donde las relaciones $(\mathrm{Ce} / \mathrm{Yb})_{\mathrm{N}}$ varían entre 4,1 y 8,86 y $(\mathrm{La} / \mathrm{Sm})_{\mathrm{N}}>2$, lo que evidencia un enriquecimiento de tierras raras ligeras con relación a las HREE en todas las muestras. Las rocas tienen relación $(\mathrm{La} / \mathrm{Yb})_{\mathrm{N}}$ con valores entre 4,9 y 11 ,2, que podrían representar mayores aportes de la corteza, periodos de mayor flujo magmático o corteza más gruesa en los valores más altos de $(\mathrm{La} / \mathrm{Yb})_{\mathrm{N}}$, y los menores valores podrían indicar mayores aportes al magma de material del manto y periodos de más bajo flujo magmático; menores pendientes en los patrones de REE podrían relacionarse con profundidades menores de génesis del magma (Girardi, 2008).

Tabla 6. Resultados de elementos traza y tierras raras en rocas de la Tonalita de San Martín

\begin{tabular}{|c|c|c|c|c|c|}
\hline IGM & 901002 & 901004 & 901032 & 901033 & 901003 \\
\hline N. ${ }^{\circ}$ campo & LMC-088 & LMC-090B & TCR-395A & TCR-399 & LMC-090A \\
\hline $\mathrm{Li}$ & 4,89 & 7,99 & 3,49 & 1,62 & 7,86 \\
\hline $\mathrm{Be}$ & 1,58 & 1,17 & 1,30 & 1,60 & 1,70 \\
\hline Sc & 3,40 & 2,13 & 10,97 & 2,15 & 5,20 \\
\hline v & 12,27 & 12,15 & 23,18 & 9,45 & 10,20 \\
\hline $\mathrm{Cr}$ & 4,05 & 5,24 & 4,36 & 3,11 & 4,32 \\
\hline Co & 20,24 & 19,56 & 10,50 & 19,88 & 9,04 \\
\hline $\mathrm{Ni}$ & 2,26 & 9,91 & 1,79 & 1,20 & 1,43 \\
\hline $\mathrm{Cu}$ & 80,24 & 4,40 & 6,90 & 5,49 & 7,04 \\
\hline $\mathrm{Zn}$ & 26,53 & 30,64 & 81,75 & 25,01 & 203,20 \\
\hline Ga & 15,66 & 12,59 & 20,62 & 15,73 & 18,17 \\
\hline As & 0,93 & 0,89 & 1,10 & 1,01 & 1,45 \\
\hline $\mathbf{R b}$ & 49,71 & 53,96 & 28,83 & 74,66 & 1,60 \\
\hline $\mathrm{Sr}$ & 114,41 & 116,32 & 229,94 & 88,94 & 116,75 \\
\hline $\mathbf{Y}$ & 13,72 & 9,10 & 27,57 & 13,15 & 24,56 \\
\hline Cd & & & 0,13 & & 0,44 \\
\hline In & 0,03 & 0,01 & 0,06 & 0,01 & 0,48 \\
\hline Cs & 0,11 & 0,13 & 0,16 & 0,12 & $<0,05$ \\
\hline $\mathrm{Ba}$ & 916,73 & 1081,52 & 1186,40 & 1130,75 & 132,92 \\
\hline La & 14,73 & 14,62 & 22,73 & 24,06 & 17,63 \\
\hline $\mathrm{Ce}$ & 27,97 & 25,83 & 51,03 & 49,69 & 39,79 \\
\hline $\mathrm{Pr}$ & 3,60 & 3,22 & 6,21 & 5,38 & 5,51 \\
\hline $\mathrm{Nd}$ & 13,24 & 11,16 & 25,10 & 18,03 & 19,41 \\
\hline Sm & 2,55 & 2,07 & 5,79 & 3,55 & 4,19 \\
\hline Eu & 0,84 & 0,78 & 3,68 & 0,81 & 0,96 \\
\hline Gd & 2,41 & 1,75 & 5,92 & 3,49 & 4,05 \\
\hline Tb & 0,38 & 0,26 & 0,91 & 0,46 & 0,70 \\
\hline
\end{tabular}




\begin{tabular}{|c|c|c|c|c|c|}
\hline IGM & 901002 & 901004 & 901032 & 901033 & 901003 \\
\hline N. ${ }^{\circ}$ campo & LMC-088 & LMC-090B & TCR-395A & TCR-399 & LMC-090A \\
\hline Dy & 2,09 & 1,33 & 5,44 & 2,45 & 4,05 \\
\hline Ho & 0,42 & 0,29 & 1,11 & 0,48 & 0,84 \\
\hline Er & 1,31 & 1,00 & 3,29 & 1,41 & 2,50 \\
\hline $\mathrm{Tm}$ & 0,19 & 0,16 & 0,47 & 0,21 & 0,34 \\
\hline $\mathrm{Yb}$ & 1,32 & 1,19 & 3,10 & 1,43 & 2,20 \\
\hline Lu & 0,19 & 0,20 & 0,48 & 0,21 & 0,31 \\
\hline $\mathrm{TI}$ & 0,22 & 0,22 & 0,11 & 0,27 & $<0,01$ \\
\hline $\mathrm{Pb}$ & 7,91 & 3,19 & 6,10 & 8,90 & 13,13 \\
\hline Th & 2,06 & 1,93 & 1,70 & 3,27 & 2,11 \\
\hline U & 0,32 & 0,54 & 0,39 & 0,47 & 0,53 \\
\hline $\mathrm{Zr}$ & 137,70 & 109,20 & 777,00 & 152,10 & 199,40 \\
\hline $\mathrm{Nb}$ & 5,5 & 4,5 & 9,4 & 6,3 & 5,3 \\
\hline w & 81,4 & 77,6 & 37,3 & 76,4 & 23 \\
\hline $\mathrm{Hf}$ & & & 11,6 & & \\
\hline
\end{tabular}

El diagrama multielemental de elementos trazas normalizado con respecto al NMORB de Sun y McDonough (1989), correspondiente a rocas de la Tonalita de San Martín, muestran empobrecimiento de los elementos inmóviles Nb, Sr, Ti y P, donde el Nb se comporta geoquímicamente de modo similar al Ti (figura 15B). Los mayores valores en elementos incompatibles $\mathrm{Cs}, \mathrm{Ba}$, Th, $\mathrm{Sr}, \mathrm{K}, \mathrm{Ba}$ y Rb están relacionados con enriquecimiento del manto localizado por encima de la zona de subducción, debido a movilización de fluidos liberados durante el metamorfismo de alta presión de la placa subducida. El diagrama multielemental de elementos incompatibles (Sun y McDonough, 1989) presenta pequeñas diferencias en los trenes de los elementos traza de las rocas, lo que sugiere varios pulsos magmáticos.

Tabla 7. Valores normalizados de REE según el condrito de Nakamura (1974) en rocas de la Tonalita de San Martín

\begin{tabular}{|c|c|c|c|c|c|c|c|}
\hline & $\mathrm{Eu} / \mathrm{Eu}^{*}$ & $(\mathrm{La} / \mathrm{Yb})_{\mathrm{N}}$ & $(\mathrm{La} / \mathrm{Sm})_{\mathrm{N}}$ & $(\mathrm{Ce} / \mathrm{Yb})_{\mathrm{N}}$ & $(\mathrm{Ce} / \mathrm{Sm})_{\mathrm{N}}$ & $(\mathrm{Eu} / \mathrm{Yb})_{\mathrm{N}}$ & Sum_REE \\
\hline 901002 & 1,04 & 7,45 & 3,56 & 5,39 & 2,58 & 1,82 & 71,26 \\
\hline 901004 & 1,26 & 8,2 & 4,35 & 5,53 & 2,93 & 1,87 & 63,85 \\
\hline 901032 & 1,93 & 4,88 & 2,42 & 4,18 & 2,07 & 3,39 & 135,25 \\
\hline 901033 & 0,71 & 11,24 & 4,17 & 8,86 & 3,29 & 1,62 & 111,65 \\
\hline 901003 & 0,72 & 5,35 & 2,59 & 4,61 & 2,23 & 1,25 & 102,47 \\
\hline
\end{tabular}

A

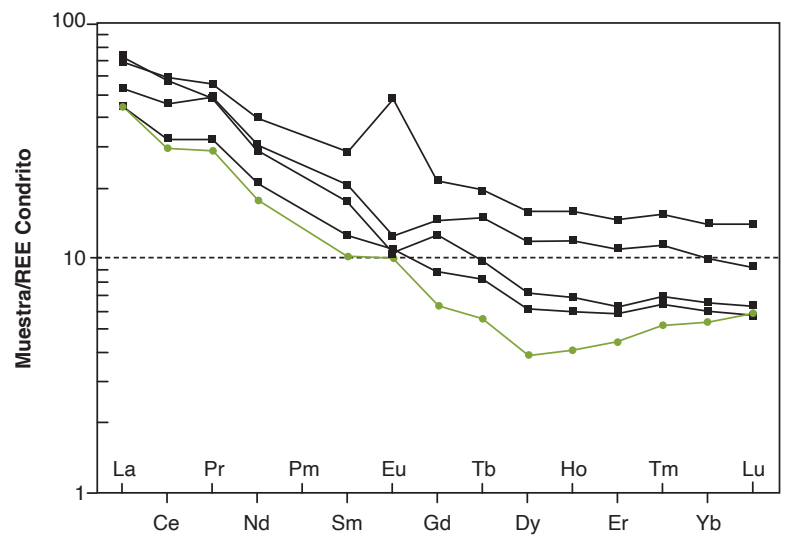

(D)

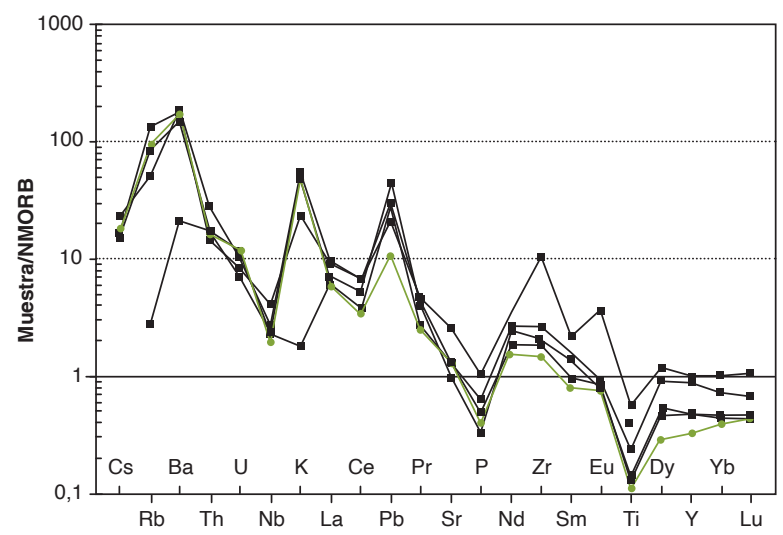

Figura 15. Diagramas multielementales de rocas de la Tonalita de San Martín. A) Diagrama de REE normalizado respecto al condrito (Nakamura, 1974); B) Diagrama multielemental normalizado al NMORB (Sun y McDonough, 1989)

En negro, rocas de la facies normal de la Tonalita de San Martín, y en verde, roca de dique 


\subsection{Discriminación del ambiente tectónico}

Las anomalías negativas de $\mathrm{Nb}$, Ti y $\mathrm{P}$ en el diagrama multielemental de elementos traza normalizados al condrito de Nakamura (1974) son características de rocas relacionadas con ambientes de subducción, que en este caso corresponde a rocas de arco magmático calcoalcalino. El empobrecimiento de las LREE hacia las HREE muestra como resultado patrones comparables al de rocas generadas en ambientes de arcos de margen continental.

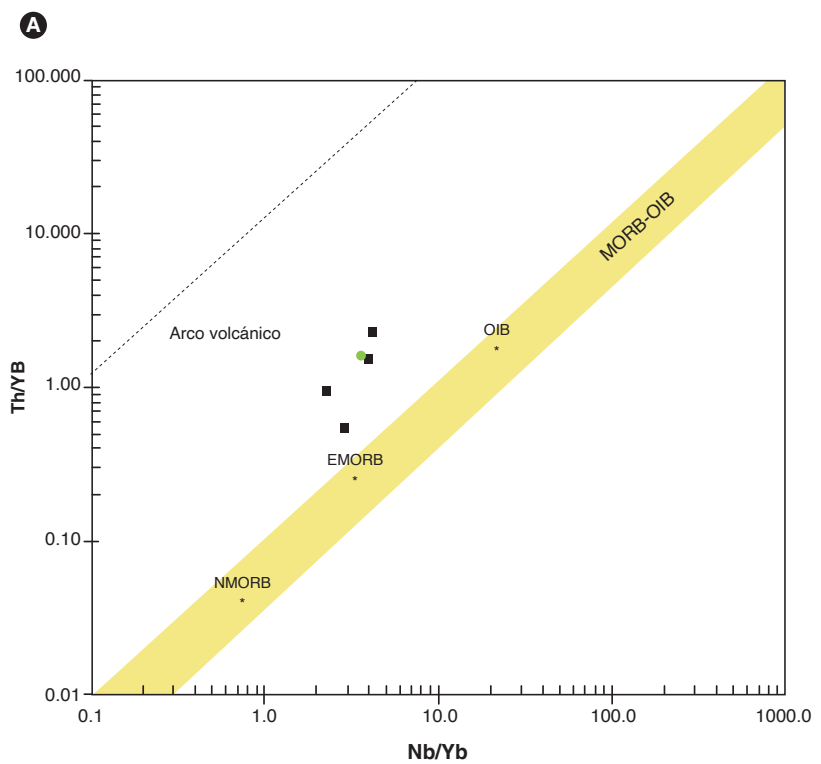

B

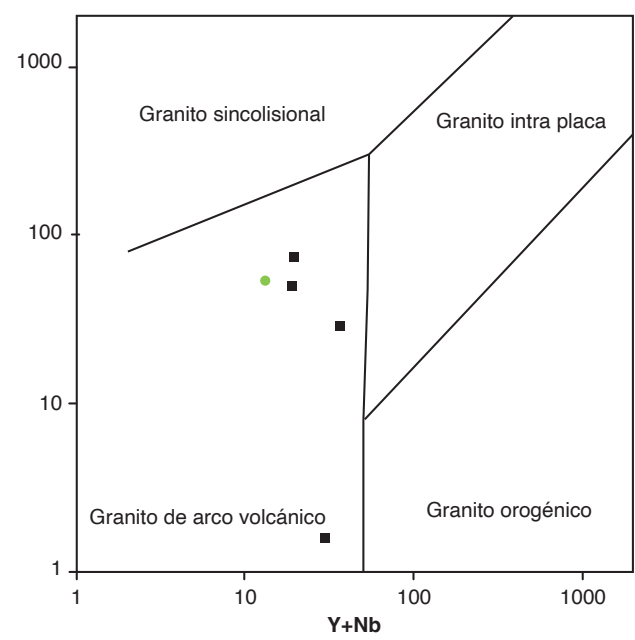

Figura 16. Diagramas de discriminación del ambiente tectónico correspondientes a rocas de la Tonalita de San Martín

El símbolo azul corresponde a una roca de dique). A) Pearce (2008). B) Pearce et al. (1984)
Según el diagrama de Pearce (2008), las muestras de la Tonalita de San Martín están por encima del campo de las rocas de corteza oceánica NMORB-OIB, lo que sugiere fusión de una fuente de manto con influencia de un componente cortical reciclado, en un ambiente de arco. En el diagrama de Pearce et al. (1984), las muestras grafican en el campo de los granitos de arco volcánico (figuras 16 A y B). La presencia de minerales como hornblenda y biotita en las facies más básicas y menos diferenciadas del plutón sugiere aporte mantélico.

En el diagrama de Frost et al. (2001), las rocas graníticas pertenecen al campo de los granitos ferrosos, junto con las rocas de dique (figura 17).

\section{Posición estratigráfica y edad}

La Tonalita de San Martín está en contacto intrusivo, al oriente, con la Anfibolita de Sanín Villa, y al occidente está intruida por riolitas subvolcánicas (Arias y Vargas, 1978), probablemente relacionadas a la Formación Noreán, y se presenta cubierta por depósitos cuaternarios.

A la fecha, la Tonalita de San Martín no ha sido datada por métodos radiométricos, y Arias y Vargas (1978) estimaron que su edad correspondía al Triásico, basados en su correlación con otras masas tonalíticas del Macizo de Santander y suponiendo que es más joven que el evento metamórfico de la Formación Silgará, del Paleozoico inferior.

En este proyecto se analizaron tres muestras distribuidas a lo largo del plutón. Los resultados finales y la localización de las muestras se presentan en la figura $1 \mathrm{y}$ en la tabla 8, mientras que el conjunto de análisis llevados a cabo en cada muestra se incluyen en el anexo 1. La separación de minerales densos se realizó en el Laboratorio Químico del Servicio Geológico Colombiano, sede

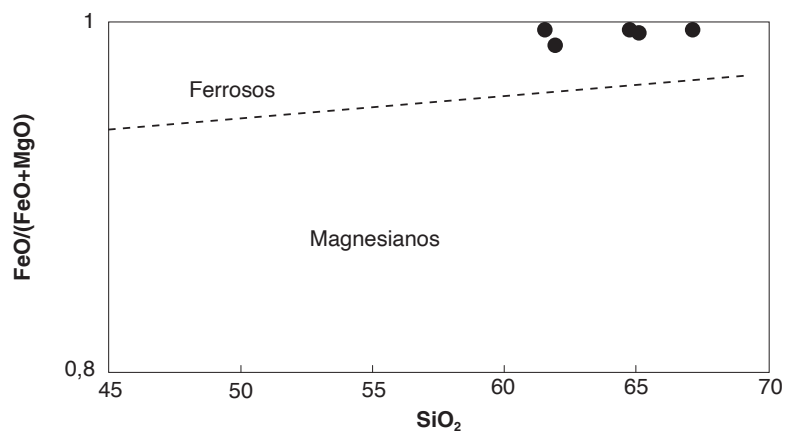

Figura 17. Diagrama de clasificación para la Tonalita de San Martín Fuente: Frost et al. (2001) y autores 
Medellín, utilizando separación hidrodinámica, magnética y, por último, el montaje de los circones.

Las muestras LMC-088 y LMC-090B se dataron por el método U/Pb LA-ICPMS en circones en el Laboratorio de Ablación Laser del Servicio Geológico Colombiano, que cuenta con un equipo de ablación laser Photon Machines, Laser Excimer de $193 \mathrm{~nm}$ y espectrómetro ICP-Masas Element 2. Se utilizaron como patrones de referencia Plesovice, 91500 y M, Dromedry. Los puntos analizados son de 20 micrones, y la reducción de datos se realizó utilizando el programa Iolite IGROpro y un espectrómetro de masas. En la línea base $0 \mathrm{~s}-38 \mathrm{~s}$ y en las muestras y patrones de referencia $32,5 \mathrm{~s}-8 \mathrm{~s}$ se utilizaron, como lapsos de integración, tiempos que concuerdan con el tiempo de corrida de los análisis. Los isótopos utilizados en la integración manual son ${ }^{238} \mathrm{U}, \mathrm{Pb}^{206} \mathrm{y}$ $\mathrm{Pb}^{204}$. Los resultados finales corresponden a la media de los datos obtenidos luego de aplicar una discriminación de datos a dos desviaciones estándares. El procesamiento se lleva a cabo con las rutinas de Isoplot V3.5, y la corrección por plomo común se realiza de acuerdo con el modelo de evolución según Stacey y Krammers (1975).
La muestra TCR-395A fue enviada al Laboratorio de Estudios Isotópicos (LEI) del Centro de Geociencias de la Universidad Nacional Autónoma de México (UNAM), campus Juriquilla, donde se aplicó la siguiente metodología: las concentraciones de $\mathrm{U}$ y Th fueron calculadas empleando un circón estándar externo, de acuerdo con Paton et al. (2010). Las incertidumbres de sigma 2 propagadas se lograron según Paton et al. (2010). Las proporciones ${ }^{207} \mathrm{~Pb} /{ }^{206} \mathrm{~Pb}$, edades y errores se calcularon según Petrus y Kamber (2012). Los puntos analizados son de 23 micrómetros, y se estudiaron utilizando un protocolo de análisis modificado de Solari et al. (2010). Los datos se midieron empleando un Thermo X series QICPMS acoplado a un Resonetics, estación de trabajo láser Excimer Resolución M050. Se realizó un análisis estadístico con el fin de mejorar el rango de confiabilidad de la edad proporcionada por el Laboratorio, teniendo en cuenta la relación $\left[\left({ }^{207} \mathrm{~Pb} /{ }^{235} \mathrm{U}\right)-\left({ }^{206} \mathrm{~Pb} /{ }^{238} \mathrm{U}\right) /{ }^{206} \mathrm{~Pb} /{ }^{238} \mathrm{U}\right)$, eliminando los datos de circones con valores discordantes que estuvieran, en general, por encima de $15 \%$ y errores de más de $5 \%$. Los gráficos de concordia e histogramas se elaboraron con el software de Isoplot/Ex vers, 4,15 (Ludwig, 2012).

Tabla 8. Resumen de los resultados de geocronología obtenidos en las muestras de la Tonalita de San Martín por el método LA-MC-ICP-MS U/Pb en circones

\begin{tabular}{cccccccc}
\hline IGM-SD & N. ${ }^{\circ}$ campo & W & N & Plancha & Clasificación & Edad & N. ${ }^{\circ} \mathbf{Z r}$ \\
\hline 901032 & TCR-395A & 1075180 & 1368544 & 86 & Tonalita & $198,9 \pm 1,8$ & 45 \\
\hline 901002 & LMC-088 & 1069983 & 1392339 & 86 & Granodiorita & $198,0 \pm 2,8$ & 55 \\
\hline 901004 & LMC-090B & 1070179 & 1385799 & 86 & Dique-fenodacita & $197,1 \pm 2,0$ & 38 \\
\hline
\end{tabular}

De las facies normales del intrusivo se dataron las muestras TCR-395A y LMC-088, localizadas en los extremos sur y norte, respectivamente. La muestra TCR395A corresponde a una tonalita deformada. Los circones tienen un tamaño que varía entre 180 y 200 mm, de forma corta, ovalada a prismática. Algunos cristales de circón presentan alargamiento marcado, con zonación concéntrica, y en ellos no se observa una relación aparente entre morfología interna y tamaño.

Los análisis efectuados revelan homogeneidad, ya que todos los zircones son concordantes y exhiben un rango limitado. Se realizó un filtro de los datos para descartar los circones con valores discordantes (discordancia $>15 \%$ ) y errores de edad corregida $>5$, con el fin de mejorar el rango de confiabilidad de la edad con un rango de edades que varía entre 1 84,8 y 205,1 Ma, lo que arroja una edad promedio ponderada de 198,9 $\pm 1,8 \mathrm{Ma}, \mathrm{n}=20$ y MSWD = 1,14, considerando esta la edad de cristalización de la roca (figura 18).

Las razones $\mathrm{Th} / \mathrm{U}$ en circones de la muestra TCR395A varían entre 0,7 y 1,2, relación que sugiere cristalización ígnea (Rubatto, 2002).

Se ha datado una segunda muestra de granodiorita (LMC-088), localizada al norte del intrusivo. Los circones son transparentes, predominan los prismáticos cortos, pero hay prismáticos largos con forma de tallos, euhedrales, de tamaños entre 50 y 100 mm. La imagen de catodoluminiscencia (CL) revela que los circones tienen estructura interna concéntrica (zonación oscilatoria) típica de cristales ígneos, algunos con núcleos 
luminiscentes, pero también hay cristales con núcleos menos luminiscentes que los bordes.

Esta edad presenta una agrupación a lo largo y en la parte baja de la discordia y algunos pocos datos tocan la curva de concordia, lo que indica que los circones fueron afectados por pérdida de plomo. El grupo más consistente lo conforman $\mathrm{n}=19$ datos, con errores de edad corregida $<5 \%$, con una edad discordante promedio ponderada de 198,0 $\pm 2,8 \mathrm{Ma}$, y MSWD = 2,2, similar a la edad concordante obtenida en la muestra TCR-395A. La edad de la muestra LMC-088 se interpreta con cautela, debido a que es discordante, como una edad de cristalización de la roca (figura 19), por estar dentro del rango de cristali- zación de la Tonalita de San Martín y de otros plutones del Macizo de Santander. La relación Th/U de los circones es cercana a 1 y varía entre 0,5 y 1,2 , valores que se asocian a circones que se formaron por cristalización ígnea (Rubatto, 2002).

La tercera muestra analizada (LMC-090B) corresponde a un dique de fenodacita que intruye las facies normales de la Tonalita de San Martín y se localiza en la parte central del cuerpo. Los circones son euhedrales prismáticos alargados con forma de tallos, translúcidos, con escasas inclusiones, algunos de tonalidad amarillenta, algo fracturados. Las imágenes de catodoluminiscencia (CL) evidencian zonación oscilatoria, con núcleo gris claro.
(4)

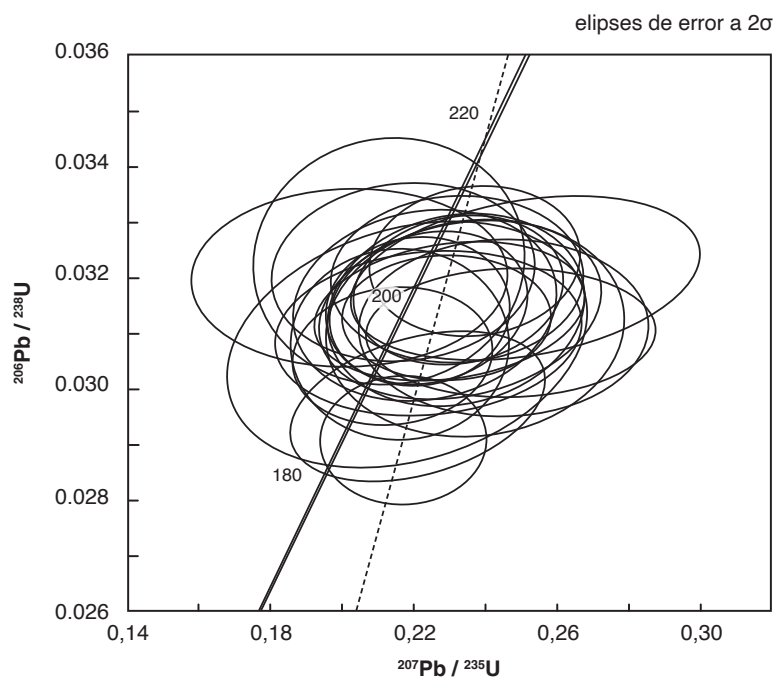

○

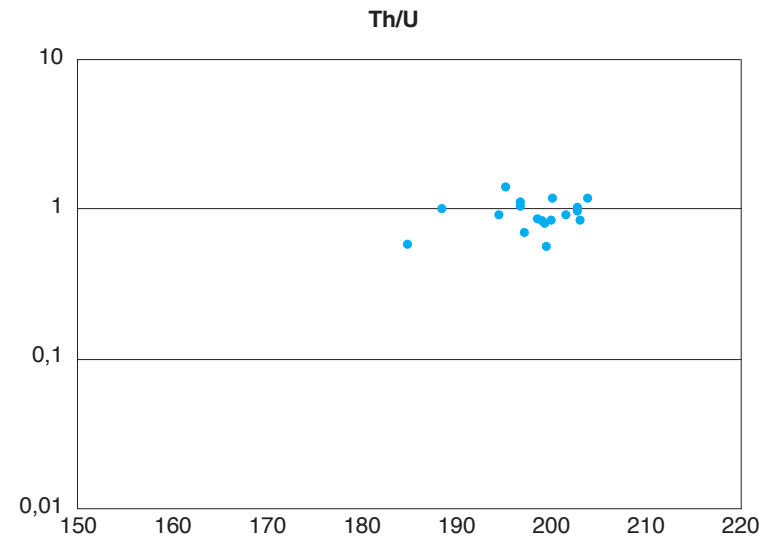

B

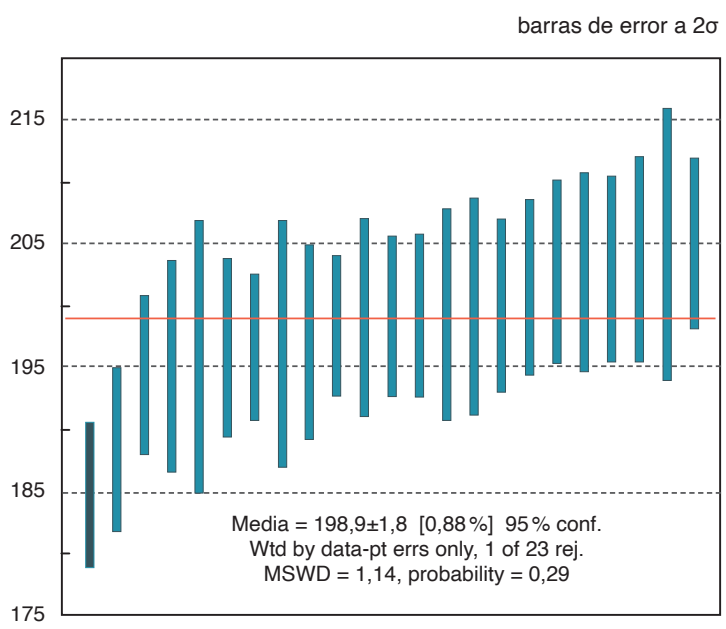

Figura 18. Calculo de la edad de la muestra TCR-395A

A) Gráfico de concordia. B) Gráfico de edad promedio ponderada C). Gráfico de relación Th/U vs. edad en circones de la muestra TCR-395A 

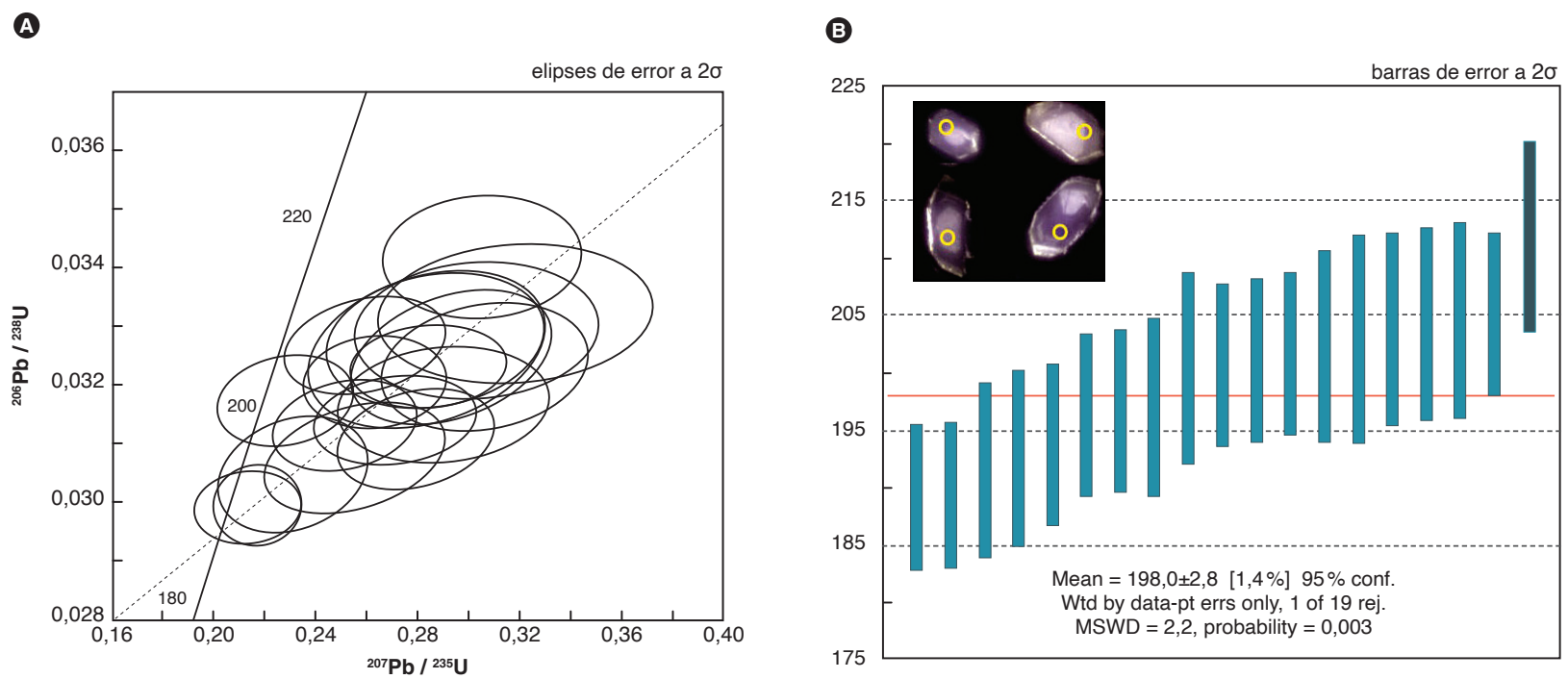

Figura 19. Calculo de la edad de la muestra LMC-088

A) Gráfico de concordia. B) Gráfico de edad promedio ponderada con imagen de catodoluminiscencia de algunos circones de la muestra

La muestra LMC-090B tiene un amplio rango de edades, que varían entre 187 y $202 \mathrm{Ma}$, tomando como grupo más coherente $\mathrm{n}=13$ circones, que arrojaron una edad promedio ponderada de 197,1 $\pm 2,0 \mathrm{Ma}$, con MSWD $=1,15$, que se interpreta como la edad de cristalización de la roca de dique (figura 20). La muestra LMC090B presenta un núcleo de circón que arrojó una edad de 999,26 $\pm 36,8 \mathrm{Ma}$ (Neoproterozoico) (figura 20), con relación $\mathrm{Th} / \mathrm{U}<0,1$, que sugiere que corresponde a un núcleo heredado de un xenocristal metamórfico. Las relaciones Th/U en el resto de circones están por encima de 0,3, lo que sugiere origen ígneo.

\subsection{Geoquímica de elementos traza en circones}

El análisis de ICP-MS permitió determinar la abundancia de los elementos traza de cada circón de la muestra TCR-395A (anexo B). Los valores de REE se normalizaron al condrito (McDonough y Sun, 1995) y se calcularon los valores teóricos de Pm* y Tm*. En el análisis de los elementos traza se tienen en cuenta las edades obtenidas en cada circón y cuáles fueron descartados por tener discordancias $>15 \%$.

En la muestra TRC-395A se observa un patrón de REE con anomalía positiva de Ce y negativa de Eu moderadamente pronunciada (figura $21 \mathrm{~A}$ ), que son caracte- rísticas de circones ígneos (Hoskin y Schaltegger, 2003), provenientes de granitoides ígneos de tipos I, A y S (Wang et al., 2012).

El patrón de REE muestra una inclinación positiva entre Lu y Gd, enriquecimiento en HREE, con anomalía negativa moderada de Eu y positiva de Ce, patrón que es más inclinado que en circones metamórficos (Rubatto, 2017 ) y similar a circones de origen ígneo. Los circones de la muestra TCR-395A presentan contenidos de Pb entre 1,02 y 3,89, Th entre 19,9 y 104 ppm, la relación Th/ $\mathrm{Pb}$ varía de 19,4 a 43,94; las concentraciones de $\mathrm{Y}$ varían de 938 a 3.208 ppm, con una anomalía negativa de Eu $\left(\mathrm{Eu} / \mathrm{Eu}^{*}=0,16\right.$ a 0,54$)$ y valores de $(\mathrm{Lu})_{\mathrm{N}}$ en el rango comprendido entre 3.528 y 7.882. Los granitos de tipo I, según Wang et al. (2012), presentan contenidos de $\mathrm{Pb}<25$ ppm, Th entre 34 y 1.746 ppm, Th/Pb de 14 a 130, (Lu) ${ }_{\mathrm{N}}$ entre 1.330 y 15.574 , anomalía negativa de $\mathrm{Eu}\left(\mathrm{Eu} / \mathrm{Eu}^{*}\right.$ $=0,14$ a 0,34) y concentraciones de Y entre 493 y 7.833 ppm (tabla 9).

Los circones de la muestra TCR-395A grafican en el diagrama de Th vs. Pb en el campo de los granitos tipo I (diagrama modificado de Wang et al., 2012) (figura 21B), con algunos pocos circones por fuera del campo. Los contenidos de $\mathrm{Pb}$ y Th en circones están en el rango propuesto por Wang et al. (2012), con valores bajos de $\mathrm{Pb}$. 
(A)

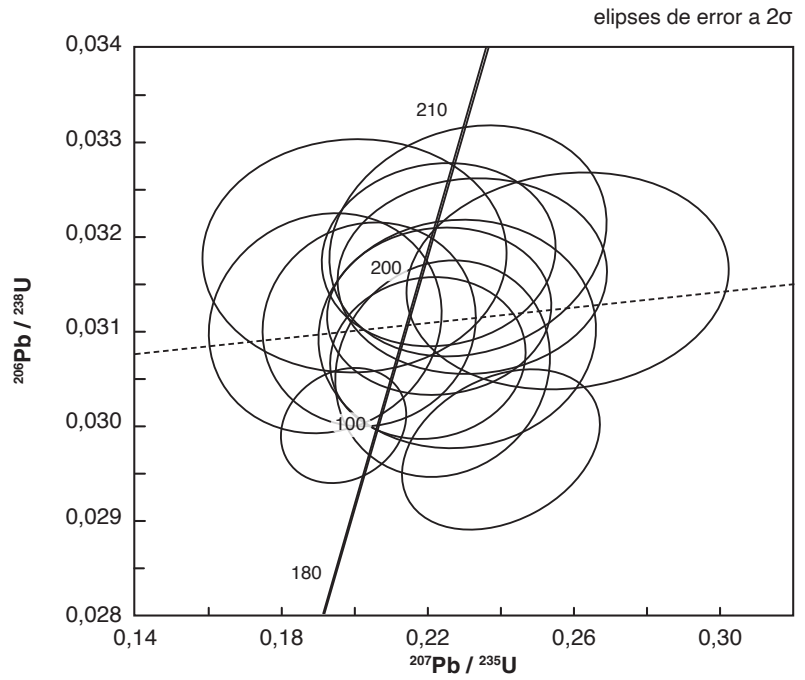

B

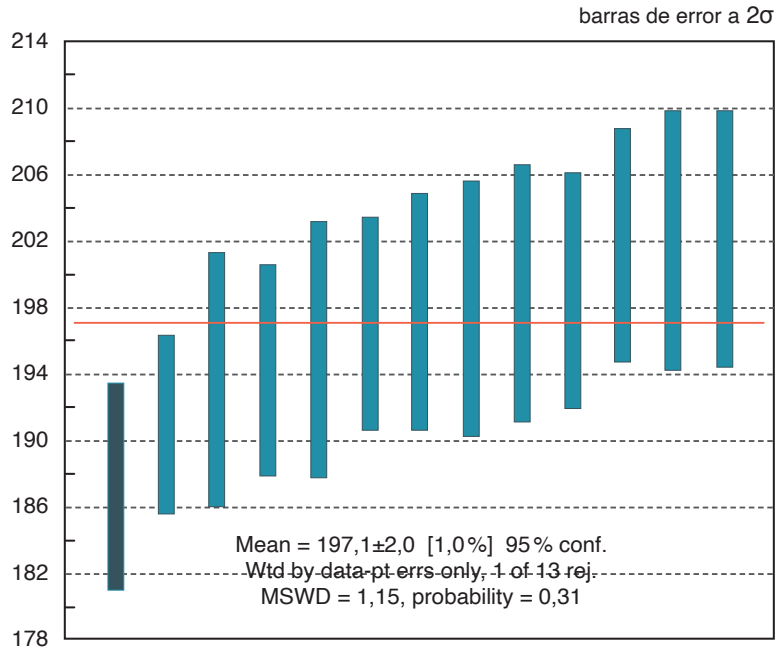

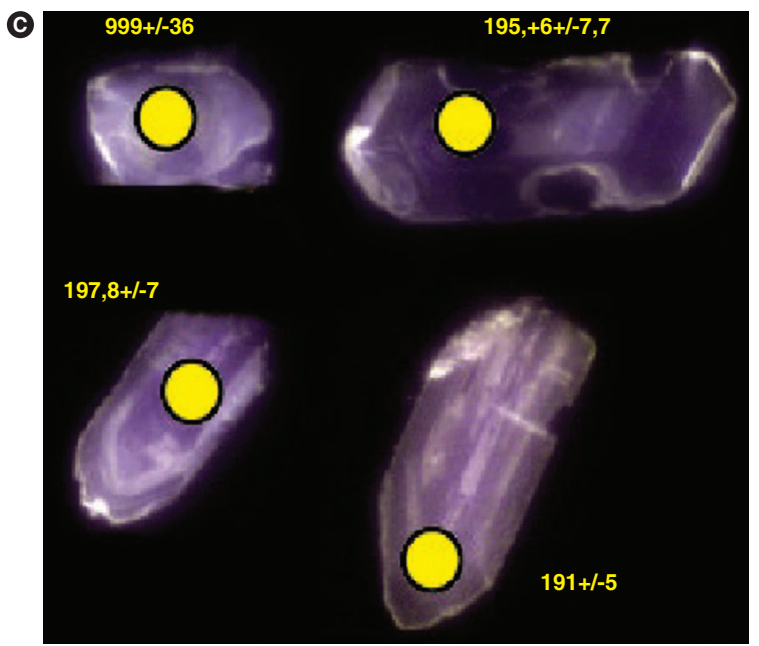

Figura 20. Calculo de la edad de la muestra LMC-090B

A) Gráfico de concordia. B) Gráfico de edad promedio ponderada. C) Imagen de catodoluminiscencia de algunos circones

A

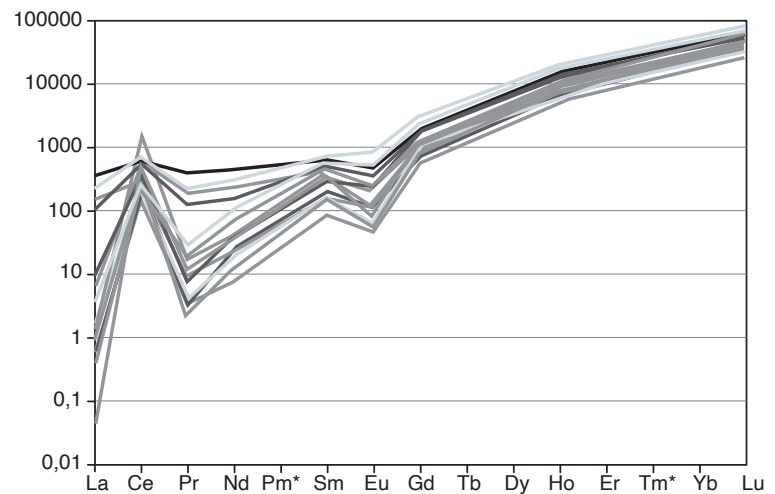

B

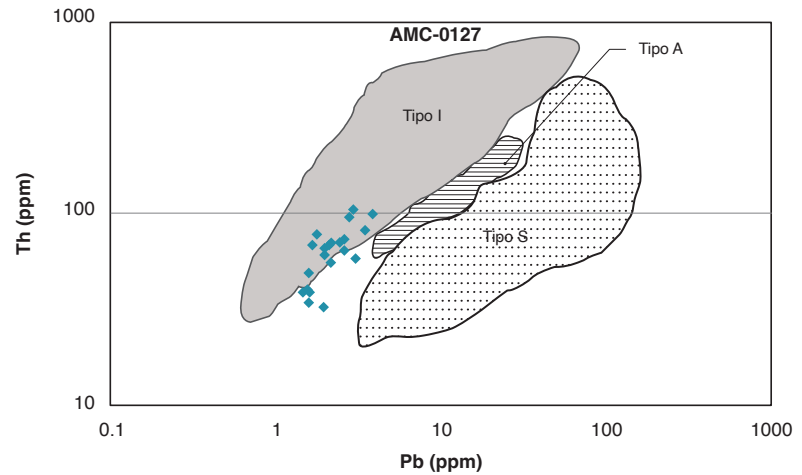

Figura 21. Diagrama REE con valores McDonough y Sun (1995) correspondiente a la muestra TCR-395A de la Tonalita de San Martín y diagrama modificado de Wang et al. (2012) 
Tabla 9. Comparación de valores de elementos traza reportados por Wang et al. (2012), con los encontrados en la Tonalita de San Martín

\begin{tabular}{|c|c|c|c|c|c|c|}
\hline & $\mathrm{Pb}$ & Th & $\mathrm{Th} / \mathrm{Pb}$ & $\mathbf{Y}$ & $\mathrm{Eu} / \mathrm{Eu}^{*}$ & $(\mathrm{Lu})_{\mathrm{N}}$ \\
\hline Tonalita de San Martín & $1,02-3,89$ & $19,9-104$ & $19,4-43,94$ & $938-3.208$ & $0,16-0,54$ & $3.528-7.882$ \\
\hline Granitos tipo I (Wang et al., 2012) & $<25$ & $34-1746$ & 14 a 130 & $493-7.833$ & $0,14-0,34$ & $1.330-15.574$ \\
\hline
\end{tabular}

\section{Correlaciones}

La posición geotectónica de la Tonalita de San Martin, asociada con los datos geocronológicos $\mathrm{U} / \mathrm{Pb}$, presentan un problema de correlación con dos eventos de magmatismo de arco: el magmatismo del Macizo de Santander característicamente peraluminoso y el magmatismo del Valle Superior del Magdalena-serranía de San Lucas-Sierra Nevada de Santa Marta, que varía de metaluminoso, en las facies iniciales, a peraluminoso en las facies finales.

La posición geotectónica no es muy clara todavía, puesto que dependerá de las edades que se obtengan del basamento metamórfico, en este caso específico, las edades en la unidad denominada Anfibolita de Sanín Villa. En caso de obtener edades proterozoicas en la Anfibolita de Sanín Villa, la Tonalita de San Martín se habría emplazado en el basamento Neo a Mesoproterozoico del Terreno Chibcha y la correlación se establecería con el magmatismo jurásico del valle superior del Magdalena-serranía de San Lucas-Sierra Nevada de Santa Marta; en caso de obtener edades del Paleozoico, la correlación se establecería con los plutones triásico-jurásicos del Macizo de Santander.

La Tonalita de San Martín se correlaciona por edad con ambos plutonismos, es decir, la edad está en los pulsos finales del magmatismo peraluminoso del Macizo de Santander y en los pulsos iniciales del magmatismo metaluminoso a peraluminoso del valle superior del Magdalena-serranía de San Lucas-Sierra Nevada de Santa Marta.

En este sentido, la correlación con los plutones del Macizo de Santander se establecería con el Monzogranito de Santa Bárbara (Rodríguez et al., 2018), el Monzogranito de La Corcova (Rodríguez et al., 2016); el Monzogranito de Rionegro (Van der Lelij, 2013; Arango et al., 2016); la Tonalita y Granodiorita de Páramo Rico (Van der Lelij, 2013; Mantilla et al., 2013; Rodríguez et al., 2017); el Batolito de Mogotes (Correa Martínez et al., 2016) y el Granito de Pescadero (Zapata et al., 2016) (tabla 10).

Tabla 10. Edades U/Pb en circones de cuerpos plutónicos del Macizo de Santander

\begin{tabular}{|c|c|c|c|c|c|}
\hline N. muestra & w & $\mathbf{N}$ & Clasificación & Unidad & Edad \\
\hline AMC-0162 & 1137867 & 1206436 & Monzogranito deformado & Batolito de Mogotes & $189,1 \pm 3,6$ \\
\hline GZ-6831 & 1140363 & 1206394 & Cuarzomonzodiorita deformada & Batolito de Mogotes & $193,7 \pm 1,3$ \\
\hline LMC-075 & 1131045 & 1208090 & Monzogranito & Batolito de Mogotes & $195,7 \pm 3,9$ \\
\hline MIA-638 & 1126040 & 1217144 & Monzogranito & Batolito de Mogotes & $200,4 \pm 2,2$ \\
\hline TCR-376 & 1124265 & 1231161 & Monzogranito & Batolito de Mogotes & $202,5 \pm 1,3$ \\
\hline MIA-636 & 1122841 & 1230947 & Monzogranito micrográfico & Batolito de Mogotes & $205,4 \pm 3,0$ \\
\hline GZ-6823 & 1117247 & 1257175 & Monzogranito & Granito de Pescadero & $194,8 \pm 3,2$ \\
\hline GZ-6824 & 1119450 & 1253741 & Monzogranito & Granito de Pescadero & $197,3 \pm 2,4$ \\
\hline AMC-0131 & 1114638 & 1284010 & Sienogranito & Monzogranito de La Corcova & $192,5 \pm 2,6$ \\
\hline JGB-456B & 1126023 & 1260523 & Cuarzodiorita & Monzogranito de La Corcova & $201,6 \pm 4,0$ \\
\hline LMC-077 & 1112260 & 1283759 & Monzogranito & Monzogranito de La Corcova & $204,8 \pm 6,1$ \\
\hline MIA-630B & 1114060 & 1270011 & Cuarzodiorita & Monzogranito de La Corcova & $202,7 \pm 1$ \\
\hline MIA-650B & 1099011 & 1313300 & Sienogranito & Monzogranito de Rionegro & $184,1 \pm 2,3$ \\
\hline LMC-082 & 1087830 & 1343414 & Diorita & Monzogranito de Rionegro & $189,9 \pm 1,6$ \\
\hline GR-6743 & 1083826 & 1397465 & Granodiorita-monzogranito & Monzogranito de Rionegro & $195,9 \pm 1,6$ \\
\hline GZ-6848A & 1094474 & 1337677 & Granodiorita & Monzogranito de Rionegro & $196,6 \pm 2,1$ \\
\hline LMC-084 & 1088404 & 1339424 & Granodiorita con hornblenda & Monzogranito de Rionegro & $200,8 \pm 1,9$ \\
\hline AMC-0137 & 1126567 & 1238901 & Monzogranito & Monzogranito de Santa Bárbara & $191,7 \pm 1,2$ \\
\hline JGB-457A & 1126936 & 1261464 & Monzogranito & Monzogranito de Santa Bárbara & $195,1 \pm 1,9$ \\
\hline GR-6719 & 1138272 & 1285445 & Monzogranito & Monzogranito de Santa Bárbara & $196,8 \pm 2,0$ \\
\hline GZ-6821 & 1129543 & 1257204 & Monzogranito & Monzogranito de Santa Bárbara & $198,0 \pm 2,7$ \\
\hline GR-6718 & 1135523 & 1280563 & Monzogranito & Monzogranito de Santa Bárbara & $203,8 \pm 2,7$ \\
\hline GR-6729 & 1135094 & 1204469 & Fenodacita & Riolita de San Joaquín & $201,0 \pm 2,1$ \\
\hline MIA-641 & 1141203 & 1206200 & Riolita porfídica & Riolitas EI Uvo & $197,2 \pm 1,6$ \\
\hline TCR-395A & 1075180 & 1368544 & Metatonalita & Tonalita de San Martín & $197,9 \pm 3,0$ \\
\hline LMC-088 & 1069983 & 1392339 & Granodiorita & Tonalita de San Martín & $198,0 \pm 2,8$ \\
\hline TCR-363 & 1130187 & 1289698 & Granodiorita & Tonalita de Páramo Rico & $206,8 \pm 1$ \\
\hline
\end{tabular}




\section{Localidad tipo}

Para la Tonalita de San Martín se propone como localidad tipo la quebrada Torcoromita, en su parte norte, en el municipio de San Martín, plancha 86, Ábrego. En este sector, la unidad muestra afloramientos continuos de fácil acceso.

\section{Génesis}

Los mayores valores de los elementos litófilos de alto radio iónico (LILE) Cs, Ba y Th indican que la génesis del plutón tiene afinidad con márgenes convergentes. Valores mayores en Sr, K, Ba y Rb y anomalías negativas de Nb, Ti y P son características de arcos continentales relacionados con ambientes de subducción; además, presentan anomalía negativa de Nb con respecto al Th y Ce, signatura geoquímica típica de magmas originados en ambientes tectónicos relacionados a arcos calcoalcalinos.

La Tonalita de San Martín se correlaciona por edad con dos eventos de plutonismo regionales diferentes; es decir, la edad está relacionada con los pulsos finales del magmatismo peraluminoso del Macizo de Santander y los pulsos iniciales del magmatismo metaluminoso a peraluminoso del valle superior del Magdalena-serranía de San Lucas-Sierra Nevada de Santa Marta. La localización geotectónica corresponde al límite de estos dos eventos. La afinidad de las muestras analizadas de la Tonalita de San Martín con magmas peraluminosos sugiere una probable correlación con el magmatismo triásico-jurásico del Macizo de Santander, correlación que se fundamenta en los datos de Rodríguez et al. (2017), donde se muestra que los pulsos iniciales del magmatismo jurásico del valle superior del Magdalena inicialmente formaron plutones metaluminosos y evolucionaron a plutones peraluminosos.

La Tonalita de San Martín presenta rocas que varían entre dioritas y granitos, lo cual sugiere diferenciación magmática y cristalización fraccionada, con presencia de minerales fraccionados como hornblenda y plagioclasa. A diferencia de otros plutones triásico-jurásicos del macizo de Santander (MS), la Tonalita de San Martín presenta escasa herencia en los circones analizados (un solo núcleo de edad neoproterozoica), mientras los demás plutones del MS presentan xenocristales con edades que van desde 1.873,1 \pm 105 (Mesoproterozoico) hasta aproximadamente 220 Ma (Triásico inferior), lo que sugiere un posible emplazamiento de este intrusivo asociado al basamento neoproterozoico del Terreno Chibcha.
La Tonalita de San Martín está constituida por rocas con ortosa pertítica, textura común en rocas plutónicas que se forman en ambientes de temperaturas intermedias.

\section{Recursos minerales}

La alteración meteórica de este cuerpo intrusivo es profunda y desarrolla perfiles de suelo y saprolito espeso, con desarrollo de saprolito de contextura arenosa, que permite localmente la extracción de material que se utiliza en la construcción como arena de mortero.

La Tonalita de San Martín presenta abundantes fracturas y un color de la roca blanco moteado de negro, que hacen de este cuerpo poco atractivo para piedra ornamental.

La Tonalita de San Martín no exhibe características petrográficas y geoquímicas que indiquen una alteración hidrotermal en los sitios visitados. Con el fin de evaluar el potencial mineral de la unidad se interpretaron algunos datos de los resultados de química de roca total a partir de las cinco muestras analizadas, utilizando diagramas que son reconocidos como indicadores de fertilidad de las rocas. En el diagrama de Rb versus Ba (figura 22), adaptado por El-Sheshtawi et al. (1999) del diagrama original de Mason (1966), se aprecia que las muestras pertenecen al campo de los granitos estériles.

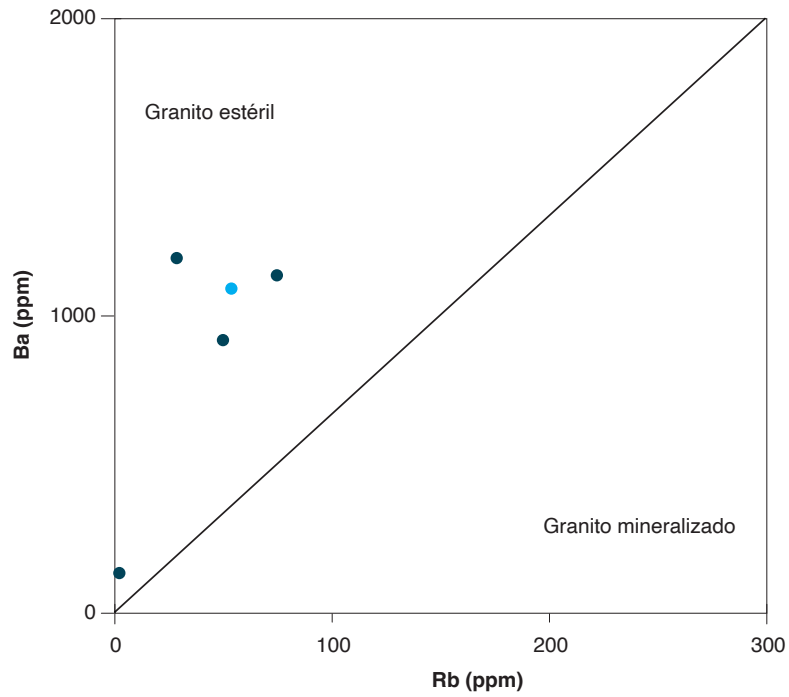

Figura 22. Diagrama de variación de Rb versus Ba en roca total (Mason, 1966 adaptado por El-Sheshtawi et al., 1999)

El símbolo azul corresponde a una roca de dique

Fuente: Mason (1966), adaptado por El-Sheshtawi et al. (1999) y autores 


\section{Conclusiones}

Este catálogo presenta nueva información de la Tonalita de San Martín y mejora el conocimiento petrográfico, litogeoquímico y geocronológico del cuerpo plutónico.

Petrográficamente, las muestras de esta unidad litológica tienen una composición variable entre dioritas-cuarzodioritas-cuarzomonzonitas y tonalitas-granodioritas-monzogranitos. Están compuestas principalmente por plagioclasa (22\% a $61 \%$ ), pueden tener feldespato alcalino (0\% a $49 \%$ ) y, en menor proporción, cuarzo ( $4 \%$ a $48 \%$ ), hornblenda, biotita y, en rocas intermedias, clinopiroxeno. Como minerales accesorios presentan apatito, opacos, titanita y allanita.

Los valores de $\mathrm{SiO}_{2}$ varían entre 65,2 wt\% y 74,96 wt\%; $\mathrm{el} \mathrm{Al}_{2} \mathrm{O}_{3}, \mathrm{Fe}_{2} \mathrm{O}_{3}, \mathrm{MgO}, \mathrm{Na}_{2} \mathrm{O}$ y CaO disminuye con el aumento de $\mathrm{SiO}_{2}$; el $\mathrm{K}_{2} \mathrm{O}$ varía entre 1,69 wt\% y 3,26 wt\%; el CaO varía entre 0,41 wt\% y 2,05 wt\%; $\mathrm{MgO}<1 \mathrm{wt} \%$ y $\mathrm{TiO}_{2}<0,7 \mathrm{wt} \%$; las razones $\mathrm{K}_{2} \mathrm{O} / \mathrm{Na}_{2} \mathrm{O}>1$; presentan contenido de álcalis $\left(\mathrm{Na}_{2} \mathrm{O}+\mathrm{K}_{2} \mathrm{O}\right)>7$, características que sugieren cristalización fraccionada de hornblenda y plagioclasa.

$\mathrm{Al}$ analizar el comportamiento de los patrones de tierras raras (REE), las rocas tienen un patrón de REE no paralelo, con un empobrecimiento progresivo de las tierras raras. Varía el patrón de una muestra a otra y solamente presentan en común la pendiente negativa, que sugiere que se generaron en un ambiente de arco continental.

La Tonalita de San Martín muestra empobrecimiento de los elementos inmóviles $\mathrm{Nb}$, Sr, Ti y P, que puede corresponder a separación de fases minerales accesorias como titanita, rutilo, circón y apatito, reflejo de la evolución magmática (Winter, 2001). Los mayores valores de los elementos litófilos Cs, Ba y Th indican una afinidad de corteza continental (márgenes convergentes), y las anomalías negativas de $\mathrm{Nb}$, Ti y P son características de arcos magmáticos relacionados con ambientes de subducción, con empobrecimiento progresivo.

Las edades de cristalización obtenidas por el método U/Pb LA-ICPMS en circones de dos rocas de la masa principal indican una edad de cristalización entre 198,9 9 1,8 Ma y 198,0 $\pm 2,8 \mathrm{Ma}$, y presencia de diques dacíticos que cristalizaron hacia 197,1 $\pm 2,0$ Ma.

\section{Referencias}

Arango, M. I., Rodríguez, G., Zapata G. y Correa, A. M. (2016). Catálogo Monzogranito de Rionegro, cordillera Oriental, departamento Santander. Medellín: Servicio Geológico Colombiano.

Arias, A. y Vargas, R. (1978). Geología de las planchas 86, Ábrego, y 97, Cáchira, departamento de Santander. Memoria explicativa, Escala 1:100.000. Bogotá: Servicio Geológico Colombiano.

Clavijo, J. (1994). Mapa geológico generalizado del departamento de Norte de Santander. Memoria explicativa. Escala 1:250.000. Informe. Ingeominas.

Clavijo, J., Mantilla, F. L. C., Pinto, J., Bernal, L. y Pérez, A. (2008). Evolución geológica de la serranía de San Lucas, norte del valle medio del Magdalena y noroeste de la cordillera Oriental. Boletín de Geología, 30 (1), 45-62.

Cordani, U. G., Cardona, A., Jiménez, D. M., Liu, D. y Nutman, A. P. (2005). Geochronology of Proterozoic basement inliers in the Colombian Andes: Tectonic history of remnants of a fragmented Grenville belt. Geological Society, London, Special Publications, 246, 329-346. https://doi.org/1 0.1144/GSL. SP.2005.246.01.13

Correa Martínez, A. M., Rodríguez, G., Arango, M. I., Zapata, G. y Bermúdez J. G. (2016). Catálogo de unidades litoestratigráficas de Colombia: Batolito de Mogotes. Medellín: Servicio Geológico Colombiano.

Droop, G. (1 987). A general equation for estimating Fe3+ concentrations in ferromagnesian silicates and oxides from microprobe analyses, using stoichiometric criteria. Mineralogical Magazine, 51 (361), 431-435. https://doi.org/10.1180/minmag.1987.051.361.10

El-Sheshtawi, Y. A., Youssef, F., Ammar, F. A., Hassaan, M. M. y Sakr, S. M. (1999). Petrography and geochemistry of some granites and their metavolcanic country rocks in the Central Eastern Desert, Egypt. The proceeding of $1{ }^{\text {st }}$ Seminar of nuclear raw material and their technology. Cairo, Egypt, 1-3.

Etayo, F., Barrero, D., Lozano, H., Espinosa, A., González, H., Orrego, A., Ballesteros, I., Forero, H. y Ramírez, C. (1983). Mapa de terrenos geológicos de Colombia. Publicaciones Geológicas Especiales del Ingeominas, n. ${ }^{\circ} 14,235$. 
Frost, R. B., Barnes, C. G., Collins, W. J., Arculus, R. J., Ellis, D. J. y Frost, C. D. (2001). A geochemical classification for granitic rocks. Journal of Petrology, 42 (11), 2033-2043. https://doi.org/1 0.1093/petrolo$\mathrm{gy} / 42.11 .2033$

Girardi, D. J. (2008). Evolution of magmas and magma sources to the Coast Mountains batholith, British Columbia, Canada, reflected by elemental and isotopic geochemistry [MSc. Thesis]. University of Arizona.

Goldsmith, R., Marvin, R. F. y Mehnert, H. H. (1971). Radiometric ages in the Santander Massif, Eastern Cordillera, Colombian Andes. U.S. Geological Survey Professional Paper, 750 (D), 44-49.

Hastie, A. R., Kerr, A. C., Pearce, J. A. y Mitchell, S. F. (2007). Classification of altered volcanic island arc rocks using immobile trace elements: Development of the Th-Co discrimination diagram. Journal of Petrology, 48 (12), 2341-2357. https://doi. org/10.1093/petrology/egm062

Hoskin, P. W. y Schaltegger, U. (2003). The composition of zircon and igneous and metamorphic petrogenesis. Reviews in Mineralogy and Geochemistry, 53 (1), 27-62. https://doi.org/10.2113/0530027

International Subcommision on Stratigraphic Classification. (1987). Stratigraphic classification and nomenclature of igneous and metamorphic rock bodies. GSA Bulletin, 99 (3), 440-442. https://doi.org/10.1130/001 6-7606(1987)99<440:SCANOI >2.0. $\mathrm{CO} ; 2$

International Subcommision on Stratigraphic Classification. (1994). International Stratigraphic Guide: A guide to stratigraphic classification, terminology and procedure. 2nd ed. Boulder: Geological Society of America. https://doi.org/10.1130/9780813774022

Irvine, T. N. y Baragar, W. R. A. (1971). A guide to the chemical classification of the common volcanic rock. Canadian Journal of Earth Sciences, 8 (5), 523548. https://doi.org/10.1139/e71-055

Janoušek, V., Farrow, C. M. y Erban, V. (2006). Interpretation of whole-rock geochemical data in igneous geochemistry: Introducing Geochemical Data Toolkit (GCDkit). Journal of Petrology, 47 (6), 1 255-1 259. https://doi.org/1 0.1093/petrology/egl013

Leal Mejía, H. (201 1). Phanerozoic gold metallogeny in the Colombian Andes: A tectono- magmatic approach $[\mathrm{Ph}$. D. thesis]. Universitat de Barcelona.
Ludwig, K. R. (2008). Isoplot version 4.15: A geochronological toolkit for Microsoft Excel. Special Publication n. ${ }^{\circ}$ 4. Berkeley Geochronology Center.

Ludwig, K. R. (2012). User's Manual for Isoplot 3.7 5-4.15. A Geochronological Toolkit Microsoft Excel. Special Publication n. ${ }^{\circ}$ 5. Berkeley Geochronology Center.

Mantilla, L. C., Bissig, T., Valencia. V. y Hart , C. (2013). The magmatic history of the Vetas-California mining district, Santander Massif Eastern Cordillera, Colombia. Journal of South American Earth Sciences, 45, 235-249. https://doi.org/10.1016/j.jsames.2013.03.006

Mantilla, L. C., García, C. A. y Valencia, V. (2016). Propuesta de escisión de la llamada "Formación Silgará" (Macizo de Santander) Colombia, a partir de edades $\mathrm{U} / \mathrm{Pb}$ en circones detríticos. Boletín de Geología, 38 (1), 33-47. https://doi.org/1 0.1 8273/revbol.v38n1 2016002

Mason, B. (1966). Principles of geochemistry. New York: John Wileys \& Sons.

McDonough, W. F. y Sun S. S. (1995). The composition of the Earth. Chemical Geology, 120 (1-3), 223-253. https://doi.org/10.1016/0009-2541(94)00140-4

Middlemost, E. (1994). Naming materials in magma-igneous rock system. Earth-Science Reviews, 37 (3-4), 215-224. https://doi.org/10.1016/00128252(94)90029-9

Middlemost, E. A. K. (1985). Magmas and Magmatic Rocks. An Introduction to Igneous Petrology. London, New York: Longman.

Nakamura, N. (1 974). Determination of REE, Ba, Fe, Mg, $\mathrm{Na}$ and $\mathrm{K}$ in carbonaceous and ordinary chondrites. Geochimica et Cosmochimica Acta, 38 (5), 757-775. https://doi.org/10.1016/001 6-7037(74)90149-5

Ordóñez Cardona, O., Restrepo Álvarez, J. J. y Pimentel, M. M. (2006). Geochronological and isotopical review of pre-Devonian crustal basement of the Colombian Andes. Journal of South American Earth Sciences, 21 (4), 372-382. https://doi.org/10.1016/j. jsames.2006.07.005

Paton, C., Woodhead, J. D., Hellstrom, J. C., Hergt, J. M., Greig, A. y Maas, R. (2010). Improved laser ablation $\mathrm{U} / \mathrm{Pb}$ zircon geochronology through robust downhole fractionation correction. Geochemistry Geophysics Geosystems, 11 (3). https://doi.org/10.1029/ 2009GC002618 
Pearce, J. A. (2008). Geochemical fingerprinting of oceanic basalts with applications to ophiolite classification and the search for Archean oceanic crust. Lithos, 100 (1-4), 14-48. https://doi.org/10.1016/j. lithos.2007.06.016

Pearce, J. A., Harris, N. W. y Tindle, A. G. (1984). Trace element discrimination diagrams for the tectonic interpretation of granitic rocks. Journal of Petrology, 25 (4), 956-983. https://doi.org/1 0.1093/petrology/25.4.956

Peccerillo, A. y Taylor, T. S. (1976). Geochemistry of Eocene calc-alkaline volcanic rocks from Kastamonu area, Northern Turkey. Contributions to $\mathrm{Mi}$ neralogy and Petrology, 58 (1), 63-81. https://doi. org/10.1007/BF00384745

Petrus, J. A. y Kamber, B. S. (2012). VizualAge: A novel approach to laser ablation ICP-MS U/Pb geochronology data reduction. Geostandards and Geoanalytical Research, 36 (3), 247-2 70. https://doi.org/10.1111/ j.1 751-908X.2012.00158.x

Restrepo Pace, P., Ruiz, J., Gehrels, G. y Cosca, M. (1997). Geochronology and Nd isotopic data of the Grenville-age rocks in the Colombian Andes: New constraints for late Proterozoic-early Paleozoic paleocontinental reconstructions of the Americas. Earth and Planetary Science Letters, 150 (3-4), 427-441. https://doi.org/1 0.1016/S001 2-821 X(97)00091-5

Restrepo, J. J. y Toussaint, J. F. (1988). Terranes and continental accretion in the Colombian Andes. Episodes, 11 (3), 189-193. https://doi.org/10.1 8814/epiiugs/1988/v1 1i3/006

Restrepo, J. J., Ordóñez Carmona, O., Armstrong, R. y Pimentel, M. M. (2011). Triassic metamorphism in the northern part of the Tahamí Terrane of the Central Cordillera of Colombia. Journal of South American Earth Sciences, 32 (4), 497-507. https://doi.org/10.1016/j.jsames.2011.04.009

Ríos, C., García, C. y Takusa, A. (2003). Tectono-metamorphic evolution of the Silgara Formation metamorphic rocks in the Southwestern Santander Massif, Colombian Andes. Journal of South American Earth Sciences, 16 (2), 133-154. https:/doi. org/10.1016/S0895-9811(03)00025-7

Rodríguez, Correa, A. M., Zapata, G. y Arango, M. I. (2018). Catálogo Monzogranito de Santa Bárbara, cordillera Oriental, departamento Santander. Medellín: Servicio Geológico Colombiano.
Rodríguez, G., Correa, A. M., Zapata, G. y Arango, M. I. (2016). Catálogo Cuarzomonzonita La Corcova, cordillera Oriental, departamento Santander. Medellín: Servicio Geológico Colombiano.

Rodríguez, G., Zapata, G., Correa Martínez, A. M. y Arango, M. (2017). Caracterización del magmatismo triásico-jurásico del Macizo de Santander. Medellín: Servicio Geológico Colombiano.

Rubatto, D. (2002). Zircon trace element geochemistry: Partitioning with garnet and the link between U/ $\mathrm{Pb}$ ages and metamorphism. Chemical Geology, 184 (1-2), 123-138. https://doi.org/10.1016/S0009$2541(01) 00355-2$

Rubatto, D. (2017). Zircon: The metamorphic mineral. Reviews in Mineralogy and Geochemistry, 83 (1), 261 295. https://doi.org/1 0.2138/rmg.201 7.83.9

Shand, S. J. (1943). Eruptive rocks: Their genesis, composition, classification, and their relation to ore-deposits with a chapter on meteorite. New York: John Wiley \& Sons.

Smith, J. V. y Brown, W. L. (1988). Feldspar minerals. I. crystal structures, physical, chemical and microtextural properties. Berlin: Springer-Verlag. https:/doi. org/1 0.1007/978-3-642-72594-4

Solari, L., Gómez Tuena, A., Bernal, J., Pérez Arvizu, O. y Tanner, M. (2010). U/Pb zircon geochronology with an integrated LA-ICP-MS microanalytical workstation: Achievements in precision and accuracy. Geostandards and Geoanalytical Research, 34 (1), 5-18. https://doi.org/10.1111/j.1 751-908X.2009.00027.x

Stacey, J. S. y Kramers, J. D. (1975). Approximation of terrestrial lead isotope evolution by a 2 -Stage model. Earth and Planetary Science Letters, 26 (2), 207-221. https://doi.org/10.1016/001 2-821X(75)90088-6

Streckeisen, A. (1976). Classification and nomenclature of plutonic rocks. Geologische Rundschau, 63 (2), 773-786. https://doi.org/10.1007/BF01 820841

Sun, S. y Mcdonough, W. (1989). Chemical and isotopic systematics of oceanic basalts: Implications for mantle composition and processes. En A. Sanders y M. Norry (eds.), Magmatism in oceanic basins, vol. 42. Londres: The Geological Society. https://doi. org/1 0.1144/GSL.SP.1 989.042.01.19

Van der Lelij, R. (2013). Reconstructing North-Western Gondwana with implications for the evolution of the lapetus and Rheic Oceans: A geochronological, thermo- 
chronological and geochemical study [Tesis de doctorado]. Université de Genéve.

Van der Lelij, R., Spikings, R., Ulianov, A., Chiaradia, M. y Mora, A. (2016). Palaeozoic to early Jurassic history of the Northwestern corner of Gondwana, and implications for the evolution of the Iapetus, Rheic and Pacific Oceans. Gondwana Research, 31, 271-294. https://doi.org/1 0.1016/j.gr.2015.01.011

Vargas, R. y Arias, A. (1981). Geología de la Plancha 86 Ábrego. Escala 1:100.000, versión digital 2009. Ingeominas.

Villaseca, C., Barbero, L. y Herreros. V. (1998). A reexamination of the typology of peraluminous granite types in intracontinental orogenic belts. Earth and Environmental Science Transactions of The Royal Society of Edinburgh, 89 (2), 113-119. https://doi. org/10.1017/S0263593300007045
Wang, Q., Zhu, D. C., Zhao, Z. D., Guan, Q., Zhang, X. Q., Sui, Q. L., Chu Hu, Z. y Mo, X. X. (2012). Magmatic zircons from I-, S- and A-type granitoids in Tibet: Trace element characteristics and their application to detrital zircon provenance study. Journal of Asian Earth Sciences, 53, 59-66. https://doi.org/10.1016/j. jseaes.2011.07.027

Ward, D., Goldsmith, R., Cruz, J. y Restrepo, A. (1973). Geología de los cuadrángulos H-1 2 Bucaramanga y H-13 Pamplona, departamento de Santander. Boletín Geológico, 21 (1-3), 1-132.

Winter, J. (2001). An introduction to igneous and metamorphic petrology. New Jersey: Prentice Hall.

Zapata, G., Correa, A. M., Rodríguez, G. y Arango, M. I. (2016). Catálogo de unidades litoestratigráficas de Colombia: Granito de Pescadero. Medellín: Servicio Geológico Colombiano. 


\section{ANEXO A}

\section{Edades U/Pb de la Tonalita de San Martín. Muestras TCR-395A (IGM 901032), LMC-088 (IGM- 901002) y LMC-090B (IGM 901004)}

\section{TCR-395A. Análisis isotópicos U/Pb en circón. Laboratorio de la UNAM}

\begin{tabular}{|c|c|c|c|c|c|c|c|c|c|c|c|c|c|c|c|c|c|c|c|c|c|c|}
\hline $\mathrm{Zr}$ & $\underset{(p p m)^{1}}{U}$ & $\begin{array}{c}\text { Th } \\
(\mathrm{ppm})^{1}\end{array}$ & Th/U & $\begin{array}{l}{ }^{207} \mathrm{~Pb} / \\
{ }^{206} \mathrm{~Pb}\end{array}$ & $\begin{array}{l} \pm 2 \mathrm{~s} \\
\text { abs }\end{array}$ & $\begin{array}{c}{ }^{207} \mathrm{~Pb} / \\
{ }^{235} \mathrm{U}\end{array}$ & $\begin{array}{l} \pm 2 s \\
\text { abs }\end{array}$ & $\begin{array}{c}{ }^{206} \mathrm{~Pb} / \\
{ }^{238} \mathrm{U}\end{array}$ & $\begin{array}{l} \pm 2 \mathrm{~s} \\
\text { abs }\end{array}$ & $\begin{array}{c}\text { Correlación } \\
\text { de errores }\end{array}$ & $\begin{array}{l}{ }^{208} \mathrm{~Pb} / \\
{ }^{232} \mathrm{Th}\end{array}$ & $\pm 2 \mathrm{~s}$ abs & Disc \% & Error & $\begin{array}{c}{ }^{206} \mathrm{~Pb} / \\
{ }^{238} \mathrm{U}\end{array}$ & $\pm 2 \mathrm{~s}$ & $\begin{array}{c}{ }^{207} \mathrm{~Pb} / \\
{ }^{235} \mathrm{U}\end{array}$ & $\pm 2 s$ & $\begin{array}{l}{ }^{207} \mathrm{~Pb} / \\
{ }^{206} \mathrm{~Pb}\end{array}$ & $\pm 2 \mathrm{~s}$ & $\begin{array}{c}\text { Best } \\
\text { age } \\
\text { (Ma) }\end{array}$ & $\pm 2 \mathrm{~s}$ \\
\hline$Z r-126$ & 30 & 25,99 & 0,87 & 0,142 & 0,032 & 0,63 & 0,16 & 0,0331 & 0,0022 & 0,18729 & 0,0164 & 0,0035 & 56,612 & $11,47 \%$ & 210 & 13 & 484 & 72 & 2180 & 250 & 2180 & 250 \\
\hline$Z r-121$ & 33,45 & 20,09 & 0,60 & 0,121 & 0,021 & 0,442 & 0,074 & 0,0293 & 0,0025 & 0,1136 & 0,017 & 0,0032 & 50,532 & $18,72 \%$ & 186 & 16 & 376 & 52 & 1870 & 350 & 1870 & 350 \\
\hline $\mathrm{Zr}-127$ & 52,7 & 50,5 & 0,96 & 0,084 & 0,011 & 0,36 & 0,044 & 0,0312 & 0,0011 & 0,07401 & 0,01138 & 0,0009 & 35,327 & $3,44 \%$ & 198 & 6,8 & 306 & 31 & 1220 & 220 & 197,9 & 6,8 \\
\hline Zr-147 & 86,4 & 49,7 & 0,58 & 0,0807 & 0,0099 & 0,37 & 0,05 & 0,0324 & 0,001 & 0,03504 & 0,0159 & 0,0014 & 35,110 & $3,11 \%$ & 206 & 6,4 & 317 & 34 & 1150 & 220 & 205,7 & 6,4 \\
\hline$Z r-134$ & 43,51 & 31,13 & 0,72 & 0,082 & 0,01 & 0,385 & 0,044 & 0,0345 & 0,0016 & 0,091984 & 0,0158 & 0,0013 & 32,708 & $4,44 \%$ & 219 & 9,7 & 325 & 32 & 1140 & 270 & 218,7 & 9,7 \\
\hline $\mathrm{Zr}-129$ & 60,1 & 36,76 & 0,61 & 0,073 & 0,023 & 0,31 & 0,15 & 0,0326 & 0,0017 & 0,39084 & 0,0133 & 0,0035 & 23,616 & $5,31 \%$ & 207 & 11 & 271 & 84 & 940 & 340 & 207 & 11 \\
\hline Zr-139 & 40,92 & 38,7 & 0,95 & 0,069 & 0,013 & 0,298 & 0,058 & 0,0316 & 0,0012 & 0,043846 & 0,01132 & 0,00097 & 20,791 & $3,59 \%$ & 200 & 7,2 & 253 & 45 & 770 & 400 & 200,4 & 7,2 \\
\hline $\mathrm{Zr}-116$ & 45 & 28,4 & 0,63 & 0,063 & 0,011 & 0,272 & 0,041 & 0,0307 & 0,0015 & 0,08091 & 0,0106 & 0,0011 & 18,708 & $4,92 \%$ & 195 & 9,6 & 240 & 32 & 650 & 330 & 195,1 & 9,6 \\
\hline Zr-125 & 29,33 & 28,4 & 0,97 & 0,066 & 0,031 & 0,29 & 0,16 & 0,0317 & 0,0023 & 0,045102 & 0,0112 & 0,0028 & 17,959 & $6,97 \%$ & 201 & 14 & 245 & 89 & 680 & 470 & 201 & 14 \\
\hline $\mathrm{Zr}-141$ & 37,71 & 23,46 & 0,62 & 0,0622 & 0,0083 & 0,253 & 0,034 & 0,0305 & 0,0016 & 0,094865 & 0,0125 & 0,0011 & 16,147 & $5,01 \%$ & 194 & 9,7 & 231 & 27 & 660 & 260 & 193,7 & 9,7 \\
\hline Zr-140 & 64,7 & 62,7 & 0,97 & 0,06 & 0,05 & 0,24 & 0,43 & 0,0314 & 0,0036 & 0,33331 & 0,0102 & 0,0093 & 9,545 & $11,06 \%$ & 199 & 22 & 220 & 160 & 460 & 520 & 199 & 22 \\
\hline$Z r-130$ & 70 & 70 & 1,00 & 0,0526 & 0,0067 & 0,221 & 0,029 & 0,0297 & 0,0011 & 0,349 & 0,00942 & 0,00073 & 5,750 & $3,50 \%$ & 189 & 6,6 & 200 & 23 & 240 & 250 & 188,5 & 6,6 \\
\hline $\mathrm{Zr}-120$ & 80,4 & 73,6 & 0,92 & 0,054 & 0,0065 & 0,214 & 0,023 & 0,0306 & 0,001 & 0,085716 & 0,01058 & 0,00079 & 0,256 & $3,29 \%$ & 195 & 6,4 & 195 & 19 & 280 & 230 & 194,5 & 6,4 \\
\hline $\mathrm{Zr}-117$ & 55,82 & 79,1 & 1,42 & 0,0518 & 0,0064 & 0,216 & 0,025 & 0,0308 & 0,0014 & 0,001299 & 0,00961 & 0,00062 & 2,400 & $4,35 \%$ & 195 & 8,5 & 200 & 21 & 250 & 260 & 195,2 & 8,5 \\
\hline Zr-148 & 31,8 & 19,9 & 0,63 & 0,049 & 0,0095 & 0,218 & 0,041 & 0,0308 & 0,0018 & 0,25211 & 0,01 & 0,0012 & 1,508 & $5,61 \%$ & 196 & 11 & 199 & 33 & 90 & 350 & 196 & 11 \\
\hline$Z r-144$ & 63,3 & 66,6 & 1,05 & 0,0534 & 0,0091 & 0,224 & 0,035 & 0,031 & 0,0012 & 0,11906 & 0,0105 & 0,0007 & 1,650 & $3,66 \%$ & 197 & 7,2 & 200 & 30 & 130 & 340 & 196,7 & 7,2 \\
\hline$Z r-149$ & 70,3 & 78,7 & 1,12 & 0,0557 & 0,0081 & 0,247 & 0,033 & 0,03101 & 0,0009 & 0,026328 & 0,01128 & 0,00074 & 10,545 & $3,00 \%$ & 197 & 5,9 & 220 & 27 & 410 & 290 & 196,8 & 5,9 \\
\hline Zr-135 & 52,4 & 69,6 & 1,33 & 0,0551 & 0,0072 & 0,237 & 0,034 & 0,0311 & 0,0016 & 0,072487 & 0,01076 & 0,00086 & 11,659 & $5,08 \%$ & 197 & 10 & 223 & 28 & 390 & 240 & 197 & 10 \\
\hline $\mathrm{Zr}-142$ & 49,7 & 34,6 & 0,70 & 0,0585 & 0,0086 & 0,245 & 0,033 & 0,0311 & 0,0013 & 0,006182 & 0,01165 & 0,00098 & 11,570 & $4,01 \%$ & 197 & 7,9 & 223 & 27 & 390 & 310 & 197,2 & 7,9 \\
\hline Zr-115 & 115,4 & 100,2 & 0,87 & 0,052 & 0,0054 & 0,229 & 0,024 & 0,03127 & 0,0009 & 0,017319 & 0,00907 & 0,00063 & 5,476 & $2,87 \%$ & 199 & 5,7 & 210 & 19 & 370 & 200 & 198,5 & 5,7 \\
\hline$Z r-123$ & 48,2 & 39,5 & 0,82 & 0,0536 & 0,0076 & 0,233 & 0,032 & 0,0314 & 0,0013 & 0,22372 & 0,01035 & 0,00088 & 4,737 & $4,02 \%$ & 199 & 8 & 209 & 26 & 290 & 290 & 199,1 & 8 \\
\hline$Z r-146$ & 70,4 & 58,1 & 0,83 & 0,0531 & 0,0073 & 0,23 & 0,031 & 0,0314 & 0,001 & 0,20615 & 0,01023 & 0,00081 & 6,038 & $3,26 \%$ & 199 & 6,5 & 212 & 26 & 320 & 280 & 199,2 & 6,5 \\
\hline Zr-136 & 79,8 & 63,5 & 0,80 & 0,0512 & 0,0055 & 0,221 & 0,021 & 0,0314 & 0,0011 & 0,044325 & 0,01063 & 0,00075 & 0,846 & $3,31 \%$ & 199 & 6,6 & 201 & 17 & 230 & 210 & 199,3 & 6,6 \\
\hline $\mathrm{Zr}-128$ & 58,4 & 33 & 0,57 & 0,0518 & 0,0067 & 0,232 & 0,029 & 0,0314 & 0,0014 & 0,15443 & 0,01037 & 0,00095 & 4,593 & $4,26 \%$ & 199 & 8,5 & 209 & 23 & 240 & 270 & 199,4 & 8,5 \\
\hline$Z r-132$ & 88 & 104 & 1,18 & 0,054 & 0,0057 & 0,226 & 0,021 & 0,0315 & 0,0011 & 0,13815 & 0,00974 & 0,00058 & 2,864 & $3,50 \%$ & 200 & 7 & 206 & 17 & 300 & 220 & 200,1 & 7 \\
\hline Zr-119 & 77 & 70,1 & 0,91 & 0,0519 & 0,0065 & 0,232 & 0,024 & 0,0318 & 0,0011 & 0,10655 & 0,00938 & 0,00069 & 4,000 & $3,52 \%$ & 202 & 7,1 & 210 & 20 & 270 & 230 & 201,6 & 7,1 \\
\hline$Z r-131$ & 50,4 & 48,7 & 0,97 & 0,057 & 0,011 & 0,251 & 0,04 & 0,032 & 0,0012 & 0,2824 & 0,0098 & 0,0013 & 12,208 & $3,65 \%$ & 203 & 7,4 & 231 & 35 & 460 & 300 & 202,8 & 7,4 \\
\hline$Z r-118$ & 59,49 & 61,3 & 1,03 & 0,0475 & 0,008 & 0,202 & 0,036 & 0,032 & 0,0013 & 0,024965 & 0,0098 & 0,00079 & $-10,217$ & $3,94 \%$ & 203 & 8 & 184 & 29 & -20 & 310 & 202,8 & 8 \\
\hline$Z r-124$ & 66,1 & 55,8 & 0,84 & 0,053 & 0,007 & 0,232 & 0,029 & 0,032 & 0,0012 & 0,043384 & 0,00956 & 0,00092 & 2,871 & $3,69 \%$ & 203 & 7,5 & 209 & 24 & 300 & 250 & 203 & 7,5 \\
\hline$Z r-145$ & 82 & 96 & 1,17 & 0,0498 & 0,0071 & 0,217 & 0,03 & 0,0321 & 0,0013 & 0,086377 & 0,00973 & 0,00081 & $-1,900$ & $4,07 \%$ & 204 & 8,3 & 200 & 25 & 180 & 280 & 203,8 & 8,3 \\
\hline$Z r-143$ & 44,32 & 40,41 & 0,91 & 0,0469 & 0,0069 & 0,213 & 0,031 & 0,0323 & 0,0018 & 0,039969 & 0,01158 & 0,00086 & $-7,330$ & $5,37 \%$ & 205 & 11 & 191 & 26 & 50 & 290 & 205 & 11 \\
\hline $\mathrm{Zr}-138$ & 100,1 & 82,7 & 0,83 & 0,0541 & 0,0057 & 0,237 & 0,024 & 0,0323 & 0,0011 & 0,10323 & 0,00967 & 0,00059 & 5,91743 & $3,36 \%$ & 205 & 6,9 & 218 & 20 & 350 & 230 & 205,1 & 6,9 \\
\hline
\end{tabular}


LMC-088. Análisis isotópicos U/Pb en circón, Laboratorio SGC

\begin{tabular}{|c|c|c|c|c|c|c|c|c|c|c|c|c|}
\hline $\begin{array}{l}\text { Identificación } \\
\text { Muestra }\end{array}$ & $\begin{array}{l}\text { Relación } \\
\text { final Pb } \\
207 / \mathrm{U}^{235}\end{array}$ & $\begin{array}{c}\text { Error interno } \\
\text { relación final } \\
\mathrm{Pb}^{207} / \mathrm{U}^{235} \\
\text { a } 2 \text { D.E. }\end{array}$ & $\begin{array}{c}\text { Relación } \\
\text { final Pb } \\
206 / \mathrm{U}^{238}\end{array}$ & $\begin{array}{c}\text { Error interno } \\
\text { relación final } \\
\mathrm{Pb}^{206} / \mathrm{U}^{235} \\
\text { a } 2 \text { D.E. }\end{array}$ & $\begin{array}{c}\text { Ajuste error } \\
\text { de correlación } \\
\text { (datos } \\
\text { negativos) }\end{array}$ & $\begin{array}{c}\text { Error de } \\
\text { correlación } \\
\mathrm{Pb}^{206} / \mathrm{U}^{238} \text { vs. } \\
\mathrm{Pb}^{207} / \mathrm{U}^{235}\end{array}$ & $\begin{array}{c}\text { Edad } \\
\text { corregida Pb } \\
206 / \mathrm{U} 238(\mathrm{Ma})\end{array}$ & $\begin{array}{c}\text { Edad Pb } \\
{ }_{207 / U^{235}(\mathrm{Ma})}\end{array}$ & $\begin{array}{c}\% \\
\text { discordia }\end{array}$ & $\begin{array}{c}\text { Edad } \\
\text { corregida } \mathrm{Pb} \\
{ }_{206 / \mathrm{U}}{ }^{238}(\mathrm{Ma})\end{array}$ & $\pm 2 \sigma$ & $\begin{array}{c}\text { Relación } \\
\text { final U/Th }\end{array}$ \\
\hline LMC_088_46 & 5,4000 & 1,0000 & 0,08190 & 0,00960 & 0,7764 & 0,77641 & 250,45 & $1.860,00$ & 642,66 & 250,45 & 56.68 & 3.14 \\
\hline LMC_088_22 & 2,9800 & 0,2400 & 0,05330 & 0,00230 & 0,6724 & 0,67236 & 191,01 & $1.361,00$ & 612,52 & 191,01 & 18.87 & 1.28 \\
\hline LMC_088_40 & 2,2900 & 0,3000 & 0,04810 & 0,00280 & 0,6446 & 0,64456 & 200,73 & $1.147,00$ & 471,43 & 200,73 & 18.64 & 1.02 \\
\hline LMC_088_48 & 2,0900 & 0,2000 & 0,04570 & 0,00190 & 0,7676 & 0,76764 & 192,47 & $1.087,00$ & 464,77 & 192,47 & 14.96 & 2.22 \\
\hline LMC_088_11 & 1,6900 & 0,1100 & 0,04370 & 0,00140 & 0,4606 & 0,46062 & 193,61 & 999,00 & 416,00 & 193,61 & 12.72 & 1.07 \\
\hline LMC_088_20 & 1,2900 & 0,1200 & 0,04140 & 0,00150 & 0,3752 & 0,37518 & 204,81 & 790,00 & 285,72 & 204,81 & 12.78 & 0.91 \\
\hline LMC_088_34 & 0,7380 & 0,0560 & 0,03176 & 0,00071 & 0,4358 & 0,43575 & 172,82 & 554,00 & 220,56 & 172,82 & 7.31 & 1.35 \\
\hline LMC_088_9 & 0,9100 & 0,1100 & 0,03780 & 0,00150 & 0,7368 & 0,73675 & 206,94 & 593,00 & 186,56 & 206,94 & 11.88 & 2.04 \\
\hline LMC_088_17 & 0,6740 & 0,0630 & 0,03300 & 0,00120 & 0,4564 & 0,45635 & 182,65 & 513,00 & 180,87 & 182,65 & 9.34 & 1.24 \\
\hline LMC_088_33 & 0,5120 & 0,0510 & 0,03350 & 0,00100 & 0,0213 & 0,02126 & 196,99 & 435,00 & 120,82 & 196,99 & 8.95 & 1.08 \\
\hline LMC_088_52 & 0,6130 & 0,0740 & 0,03470 & 0,00110 & 0,4957 & 0,49565 & 202,08 & 436,00 & 115,76 & 202,08 & 9.57 & 1.47 \\
\hline LMC_088_21 & 0,5190 & 0,0620 & 0,03310 & 0,00120 & 0,3023 & 0,30228 & 193,10 & 405,00 & 109,74 & 193,10 & 8.98 & 1.25 \\
\hline LMC_088_13 & 0,5240 & 0,0480 & 0,03420 & 0,00093 & 0,0183 & 0,01834 & 200,53 & 411,00 & 104,95 & 200,53 & 8.32 & 1.05 \\
\hline LMC_088_12 & 0,5220 & 0,0600 & 0,03324 & 0,00093 & 0,2912 & 0,29124 & 194,17 & 390,00 & 100,86 & 194,17 & 8.48 & 1.13 \\
\hline LMC_088_18 & 0,5160 & 0,0500 & 0,03560 & 0,00100 & 0,1102 & 0,11018 & 210,06 & 412,00 & 96,13 & 210,06 & 8.94 & 0.97 \\
\hline LMC_088_1 & 0,5140 & 0,0550 & 0,03450 & 0,00096 & 0,8146 & 0,81458 & 203,17 & 391,00 & 92,45 & 203,17 & 8.79 & 1.67 \\
\hline LMC_088_6 & 0,4850 & 0,0630 & 0,03350 & 0,00094 & 0,3597 & 0,35966 & 197,52 & 369,00 & 86,82 & 197,52 & 8.56 & 1.48 \\
\hline LMC_088_23 & 0,3620 & 0,0350 & 0,02923 & 0,00086 & 0,0916 & 0,09163 & 176,18 & 306,00 & 73,69 & 176,18 & 7.60 & 1.21 \\
\hline LMC_088_50 & 0,4230 & 0,0470 & 0,03345 & 0,00095 & 0,4343 & 0,43427 & 201,09 & 345,00 & 71,57 & 201,09 & 8.36 & 1.36 \\
\hline LMC_088_42 & 0,3500 & 0,0320 & 0,03079 & 0,00065 & 0,2040 & 0,20404 & 187,44 & 299,00 & 59,52 & 187,44 & 7.04 & 1.61 \\
\hline LMC_088_39 & 0,3430 & 0,0250 & 0,03110 & 0,00072 & 0,2529 & 0,25294 & 190,02 & 297,00 & 56,30 & 190,02 & 6.95 & 0.75 \\
\hline LMC_088_10 & 0,3450 & 0,0390 & 0,03194 & 0,00084 & 0,1778 & 0,17775 & 195,21 & 292,00 & 49,58 & 195,21 & 7.77 & 1.24 \\
\hline LMC_088_41 & 0,3190 & 0,0290 & 0,03044 & 0,00072 & 0,1000 & $-0,00086$ & 186,67 & 278,00 & 48,92 & 186,67 & 7.03 & 1.40 \\
\hline LMC_088_27 & 0,3470 & 0,0300 & 0,03226 & 0,00063 & 0,4715 & 0,47154 & 198,29 & 289,00 & 45,75 & 198,29 & 7.03 & 1.53 \\
\hline LMC_088_31 & 0,3430 & 0,0400 & 0,03131 & 0,00074 & 0,1839 & 0,18391 & 192,50 & 280,00 & 45,45 & 192,50 & 7.71 & 1.29 \\
\hline LMC_088_29 & 0,3164 & 0,0094 & 0,03096 & 0,00036 & 0,7488 & 0,74877 & 191,22 & 277,90 & 45,33 & 191,22 & 5.90 & 3.20 \\
\hline LMC_088_15 & 0,3650 & 0,0360 & 0,03366 & 0,00085 & 0,1804 & 0,18035 & 205,46 & 298,00 & 45,04 & 205,46 & 7.72 & 1.14 \\
\hline LMC_088_26 & 0,3610 & 0,0390 & 0,03386 & 0,00088 & 0,2376 & 0,23758 & 207,36 & 296,00 & 42,75 & 207,36 & 8.32 & 1.49 \\
\hline LMC_088_25 & 0,3700 & 0,0410 & 0,03427 & 0,00093 & 0,4102 & 0,41016 & 210,33 & 298,00 & 41,68 & 210,33 & 8.34 & 1.39 \\
\hline LMC_088_44 & 0,3670 & 0,0440 & 0,03390 & 0,00100 & 0,1963 & 0,19633 & 207,58 & 294,00 & 41,64 & 207,58 & 8.97 & 1.84 \\
\hline LMC_088_19 & 0,3140 & 0,0350 & 0,03323 & 0,00075 & 0,1000 & $-0,05541$ & 205,63 & 288,00 & 40,06 & 205,63 & 7.76 & 0.81 \\
\hline LMC_088_36 & 0,3050 & 0,0230 & 0,03060 & 0,00059 & 0,1578 & 0,15781 & 189,60 & 264,00 & 39,24 & 189,60 & 6.39 & 1.10 \\
\hline LMC_088_38 & 0,3150 & 0,0280 & 0,03151 & 0,00068 & 0,2305 & 0,23051 & 194,69 & 271,00 & 39,20 & 194,69 & 7.03 & 1.64 \\
\hline LMC_088_3 & 0,2930 & 0,0340 & 0,03043 & 0,00075 & 0,1589 & 0,15886 & 187,91 & 253,00 & 34,64 & 187,91 & 7.13 & 1.48 \\
\hline LMC_088_24 & 0,3350 & 0,0360 & 0,03259 & 0,00070 & 0,3790 & 0,37900 & 200,17 & 265,00 & 32,39 & 200,17 & 7.12 & 1.47 \\
\hline LMC_088_14 & 0,3290 & 0,0340 & 0,03280 & 0,00078 & 0,4468 & 0,44679 & 203,35 & 269,00 & 32,28 & 203,35 & 7.67 & 0.82 \\
\hline LMC_088_2 & 0,2170 & 0,0140 & 0,02995 & 0,00056 & 0,0561 & 0,05612 & 189,22 & 200,00 & 5,70 & 189,22 & 6.38 & 0.91 \\
\hline LMC_088_4 & 0,2130 & 0,0170 & 0,02992 & 0,00050 & 0,0791 & 0,07907 & 189,41 & 196,00 & 3,48 & 189,41 & 6.29 & 1.10 \\
\hline LMC_088_45 & 0,2310 & 0,0240 & 0,03047 & 0,00081 & 0,2360 & 0,23603 & 191,73 & 209,00 & 9,01 & 191,73 & 7.66 & 0.99 \\
\hline LMC_088_49 & 0,2550 & 0,0290 & 0,03076 & 0,00077 & 0,3337 & 0,33365 & 192,79 & 219,00 & 13,60 & 192,79 & 7.71 & 1.17 \\
\hline LMC_088_37 & 0,2790 & 0,0250 & 0,03108 & 0,00070 & 0,2608 & 0,26078 & 193,82 & 246,00 & 26,92 & 193,82 & 7.03 & 1.64 \\
\hline LMC_088_35 & 0,2710 & 0,0260 & 0,03139 & 0,00063 & 0,1831 & 0,18312 & 196,55 & 233,00 & 18,55 & 196,55 & 7.05 & 0.97 \\
\hline LMC_088_30 & 0,2510 & 0,0230 & 0,03131 & 0,00062 & 0,2338 & 0,23379 & 196,89 & 221,00 & 12,25 & 196,89 & 7.04 & 1.74 \\
\hline LMC_088_5 & 0,2900 & 0,0340 & 0,03166 & 0,00081 & 0,1228 & 0,12281 & 197,20 & 255,00 & 29,31 & 197,20 & 7.73 & 1.22 \\
\hline LMC_088_43 & 0,3060 & 0,0330 & 0,03230 & 0,00089 & 0,1913 & 0,19133 & 200,61 & 261,00 & 30,10 & 200,61 & 8.29 & 1.41 \\
\hline LMC_088_8 & 0,2280 & 0,0220 & 0,03173 & 0,00063 & 0,1571 & 0,15711 & 200,73 & 205,00 & 2,13 & 200,73 & 7.08 & 0.85 \\
\hline LMC_088_51 & 0,2630 & 0,0230 & 0,03204 & 0,00065 & 0,0646 & 0,06460 & 201,33 & 235,00 & 16,72 & 201,33 & 7.05 & 1.12 \\
\hline LMC_088_55 & 0,2840 & 0,0250 & 0,03231 & 0,00058 & 0,0829 & 0,08285 & 201,87 & 254,00 & 25,82 & 201,87 & 7.04 & 1.20 \\
\hline LMC_088_53 & 0,2930 & 0,0320 & 0,03247 & 0,00094 & 0,3381 & 0,33806 & 202,50 & 247,00 & 21,97 & 202,50 & 8.29 & 1.38 \\
\hline LMC_088_16 & 0,2830 & 0,0380 & 0,03260 & 0,00110 & 0,2877 & 0,28769 & 203,12 & 237,00 & 16,68 & 203,12 & 9.01 & 0.94 \\
\hline LMC_088_47 & 0,2870 & 0,0350 & 0,03275 & 0,00093 & 0,1738 & 0,17380 & 203,90 & 239,00 & 17,22 & 203,90 & 8.37 & 1.59 \\
\hline LMC_088_32 & 0,3030 & 0,0390 & 0,03292 & 0,00095 & 0,1000 & $-0,08265$ & 204,43 & 252,00 & 23,27 & 204,43 & 8.40 & 1.50 \\
\hline LMC_088_54 & 0,3180 & 0,0440 & 0,03321 & 0,00097 & 0,1000 & $-0,04091$ & 204,70 & 263,00 & 28,48 & 204,70 & 8.53 & 1.43 \\
\hline LMC_088_28 & 0,2590 & 0,0260 & 0,03266 & 0,00067 & 0,2695 & 0,26947 & 205,32 & 224,00 & 9,10 & 205,32 & 7.08 & 1.62 \\
\hline LMC_088_7 & 0,3050 & 0,0320 & 0,03418 & 0,00086 & 0,0687 & 0,06875 & 211,98 & 271,00 & 27,84 & 211,98 & 8.32 & \\
\hline
\end{tabular}


LMC-090B. Análisis isotópicos U/Pb en circón. Laboratorio SGC

\begin{tabular}{|c|c|c|c|c|c|c|c|c|c|c|c|c|}
\hline $\begin{array}{l}\text { Identificación } \\
\text { muestra }\end{array}$ & $\begin{array}{c}\text { Relación } \\
\text { final } \mathrm{Pb} \\
207 / \mathrm{U}^{235}\end{array}$ & $\begin{array}{c}\text { Error interno } \\
\text { relación final } \\
\mathrm{Pb}^{207} / \mathrm{U}^{235} \\
\text { a } 2 \text { D. E. }\end{array}$ & $\begin{array}{c}\text { Relación } \\
\text { final } \mathrm{Pb} \\
206 / \mathrm{U}^{238}\end{array}$ & $\begin{array}{c}\text { Error interno } \\
\text { relación final } \\
\mathrm{Pb}^{206} / \mathrm{U}^{235} \\
\text { a } 2 \text { D. E. }\end{array}$ & $\begin{array}{c}\text { Ajuste error } \\
\text { de correlación } \\
\text { (datos } \\
\text { negativos) } \\
\end{array}$ & $\begin{array}{c}\text { Error de } \\
\text { correlación } \\
\mathrm{Pb}^{206} / \mathrm{U}^{238} \text { vs. } \\
\mathrm{Pb}^{207} / \mathrm{U}^{235} \\
\end{array}$ & $\begin{array}{c}\text { Edad } \\
\text { corregida Pb } \\
{ }^{206} / \mathrm{U}^{238}(\mathrm{Ma})\end{array}$ & $\begin{array}{c}\text { Edad Pb } \\
{ }_{207 / \mathrm{U}^{235}}(\mathrm{Ma})\end{array}$ & $\%$ discordia & 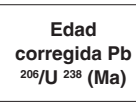 & $\pm 2 \sigma$ & $\begin{array}{l}\text { Relación } \\
\text { final U/Th }\end{array}$ \\
\hline LMC_90_B_37 & 0,91 & 0,17 & 0,0406 & 0,0024 & 0,12805 & 0,12805 & 218,971853 & 631 & 188,16489 & 218.97 & 16.58 & 3,4465195 \\
\hline LMC_90_B_21 & 0,545 & 0,062 & 0,0329 & 0,0011 & 0,3231 & 0,3231 & 190,902665 & 412 & 115,81679 & 190.90 & 8.20 & 1,8321429 \\
\hline LMC_90_B_20 & 0,494 & 0,042 & 0,03229 & 0,00084 & 0,27142 & 0,27142 & 188,50956 & 401 & 112,72131 & 188.51 & 6.77 & 1,4063444 \\
\hline LMC_90_B_34 & 0,467 & 0,083 & 0,0329 & 0,0021 & 0,2867 & 0,2867 & 194,526608 & 391 & 101,00078 & 194.53 & 13.70 & 2,2635659 \\
\hline LMC_90_B_6 & 0,408 & 0,042 & 0,032 & 0,001 & 0,18191 & 0,18191 & 192,070918 & 342 & 78,059231 & 192.07 & 7.51 & 2,2719679 \\
\hline LMC_90_B_29 & 0,427 & 0,071 & 0,0329 & 0,0016 & 0,056036 & 0,056036 & 196,336819 & 347 & 76,7371 & 196.34 & 11.51 & 2,6377953 \\
\hline LMC_90_B_24 & 0,403 & 0,036 & 0,03286 & 0,00096 & 0,088971 & 0,088971 & 197,961885 & 340 & 71,750234 & 197.96 & 7.47 & 1,6358382 \\
\hline LMC_90_B_27 & 0,382 & 0,049 & 0,031 & 0,0014 & 0,062864 & 0,062864 & 186,314451 & 311 & 66,922103 & 186.31 & 9.97 & 2,235239 \\
\hline LMC_90_B_13 & 0,369 & 0,035 & 0,03242 & 0,00079 & 0,044292 & 0,044292 & 196,966607 & 325 & 65,002588 & 196.97 & 6.95 & 2,5877378 \\
\hline LMC_90_B_14 & 0,388 & 0,061 & 0,0314 & 0,0013 & 0,029591 & 0,029591 & 189,192601 & 308 & 62,797064 & 189.19 & 9.69 & 2,2511905 \\
\hline LMC_90_B_26 & 0,34 & 0,025 & 0,03189 & 0,00081 & 0,18954 & 0,18954 & 194,804744 & 299 & 53,487022 & 194.80 & 6.83 & 2,2734761 \\
\hline LMC_90_B_16 & 0,349 & 0,039 & 0,03202 & 0,00099 & 0,20763 & 0,20763 & 195,541145 & 292 & 49,329186 & 195.54 & 7.59 & 2,2468514 \\
\hline LMC_90_B_15 & 0,312 & 0,022 & 0,03233 & 0,00069 & 0,29115 & 0,29115 & 199,679696 & 274 & 37,21976 & 199.68 & 6.25 & 2,0779944 \\
\hline LMC_90_B_22 & 0,307 & 0,027 & 0,0322 & 0,0011 & 0,071441 & 0,071441 & 198,783114 & 271 & 36,329487 & 198.78 & 8.14 & 1,7403509 \\
\hline LMC_90_B_38 & 0,31 & 0,03 & 0,0336 & 0,001 & 0,032117 & 0,032117 & 208,184105 & 275 & 32,094619 & 208.18 & 8.19 & 1,28 \\
\hline LMC_90_B_12 & 0,295 & 0,036 & 0,03161 & 0,00074 & 0,16731 & 0,16731 & 195,747295 & 257 & 31,291725 & 195.75 & 6.47 & 2,2542787 \\
\hline LMC_90_B_28 & 0,298 & 0,043 & 0,0326 & 0,0011 & 0,24494 & 0,24494 & 203,099389 & 265 & 30,47799 & 203.10 & 8.36 & 1,5017222 \\
\hline LMC_90_B_23 & 0,289 & 0,022 & 0,03322 & 0,00089 & 0,35226 & 0,35226 & 206,45334 & 259 & 25,452075 & 206.45 & 7.47 & 1,4530201 \\
\hline LMC_90_B_5 & 0,266 & 0,024 & 0,03119 & 0,00088 & 0,1762 & 0,1762 & 194,791477 & 237 & 21,668568 & 194.79 & 6.94 & 2,507837 \\
\hline LMC_90_B_7 & 0,263 & 0,018 & 0,03099 & 0,00052 & 0,14034 & 0,14034 & 193,895913 & 235 & 21,199048 & 193.90 & 5.54 & 2,3374827 \\
\hline LMC_90_B_17 & 0,24 & 0,022 & 0,02976 & 0,00069 & 0,32133 & 0,32133 & 187,350267 & 212 & 13,157031 & 187.35 & 6.17 & 1,6822323 \\
\hline LMC_90_B_8 & 0,197 & 0,014 & 0,03001 & 0,0005 & 0,17849 & 0,17849 & 191,061599 & 180 & $-5,7895458$ & 191.06 & 5.35 & 2,8662675 \\
\hline LMC_90_B_3 & 0,224 & 0,024 & 0,03061 & 0,00093 & 0,10448 & 0,10448 & 193,710807 & 199 & 2,7304582 & 193.71 & 7.64 & 2,1219512 \\
\hline LMC_90_B_35 & 0,223 & 0,025 & 0,03122 & 0,00072 & 0,068466 & 0,068466 & 197,090475 & 194 & $-1,5680489$ & 197.09 & 6.44 & 0,8566553 \\
\hline LMC_90_B_32 & 0,204 & 0,024 & 0,03108 & 0,00087 & 0,053768 & 0,053768 & 197,829959 & 181 & $-8,5072852$ & 197.83 & 7.08 & 1,3668942 \\
\hline LMC_90_B_25 & 0,258 & 0,036 & 0,03154 & 0,00093 & 0,1 & $-0,0022221$ & 198,023397 & 223 & 12,612956 & 198.02 & 7.75 & 1,9725686 \\
\hline LMC_90_B_33 & 0,192 & 0,026 & 0,03109 & 0,00095 & 0,1 & $-0,065805$ & 198,920678 & 175 & $-12,025234$ & 198.92 & 7.73 & 1,7514911 \\
\hline LMC_90_B_2 & 0,232 & 0,03 & 0,03159 & 0,00084 & 0,04663 & 0,04663 & 199,104736 & 206 & 3,4631341 & 199.10 & 7.10 & 2,3485477 \\
\hline LMC_90_B_10 & 0,179 & 0,021 & 0,03115 & 0,00076 & 0,057374 & 0,057374 & 199,447736 & 163 & $-18,274329$ & 199.45 & 6.47 & 1,2022293 \\
\hline LMC_90_B_31 & 0,272 & 0,035 & 0,03197 & 0,00097 & 0,056999 & 0,056999 & 200,24371 & 236 & 17,856386 & 200.24 & 7.69 & 1,8661616 \\
\hline LMC_90_B_30 & 0,223 & 0,026 & 0,03182 & 0,00078 & 0,067439 & 0,067439 & 201,816248 & 198 & $-1,8909518$ & 201.82 & 7.06 & 1,7964602 \\
\hline LMC_90_B_9 & 0,2 & 0,034 & 0,0318 & 0,001 & 0,029708 & 0,029708 & 202,140856 & 175 & $-13,426705$ & 202.14 & 7.82 & 2,8836545 \\
\hline LMC_90_B_18 & 0,231 & 0,031 & 0,03196 & 0,00099 & 0,1452 & 0,1452 & 202,217625 & 210 & 3,8485148 & 202.22 & 7.71 & 2,3012658 \\
\hline LMC_90_B_11 & 1,723 & 0,078 & 0,1683 & 0,0051 & 0,38363 & 0,38363 & 999,265056 & 1.025 & 2,5753872 & 999.27 & 36.82 & 21,256039 \\
\hline
\end{tabular}




\section{ANEXO B}

\section{Análisis de elementos traza en circón. Muestra TCR-395A (IGM 901032)}

\section{TCR-395A. Análisis isotópicos de elementos traza en circón (ppm)}

\begin{tabular}{|c|c|c|c|c|c|c|c|c|c|c|c|c|c|c|c|c|c|c|c|c|c|}
\hline (ppm) & $\mathbf{P}$ & $\mathrm{Ti}$ & $\mathbf{Y}$ & $\mathrm{Nb}$ & La & $\mathrm{Ce}$ & $\mathrm{Pr}$ & Nd & Sm & Eu & id & Tb & Dy & Ho & $\mathrm{Er}$ & Yb & Lu & $\mathrm{Hf}$ & $\mathrm{Pb}$ & Th & U \\
\hline Circón-115 & 1.150 & 9 & 1.810 & 5,4 & 7,1 & 48,4 & 2,4 & 14,5 & 6,6 & 0,86 & 30,1 & 11,17 & 144,1 & 60,3 & 291,2 & 622 & 131,6 & 10.310 & 3,888 & 100,2 & 115,4 \\
\hline Circón- & & 13,67 & & & & & & & & & & & & & & & & & & & 5,82 \\
\hline Circón-118 & 410 & 8,65 & 1.135 & ,91 & 0,135 & 4,29 & 122 & 1,45 & 2,95 & 0,593 & 16,26 & 6,86 & 84,1 & 36,57 & 181,9 & 403,4 & 86,8 & 9.500 & 1,975 & 61,3 & 59,49 \\
\hline Circón-119 & 674 & & 2.485 & 5,87 & 0,131 & 5,02 & 163 & 2,52 & & & & 16,36 & & & 396,8 & & 151,2 & 8.870 & 2,565 & 70,1 & 77 \\
\hline Circón-120 & 720 & 8,71 & 2.766 & 5,07 & 0,002 & 37,6 & 0,145 & 2,92 & 7,29 & 1,86 & 52,6 & 19,17 & 245,3 & 97,3 & 435 & 798 & 161,7 & 8.540 & 2,613 & 73,6 & 80,4 \\
\hline Circón-122 & 321 & 7,01 & 1.462 & 5,45 & 0,102 & 18,52 & 0,042 & 0,92 & 2,92 & 0,432 & 18,81 & 7,91 & 109,2 & 47,45 & 241,4 & 540 & 118,4 & 10.680 & 3,058 & 57,7 & 99,3 \\
\hline Circón-123 & 1.150 & 12,24 & 2.351 & 3,52 & 10,4 & 47,2 & 4,4 & 25,1 & 11,2 & 2,51 & 49,1 & 16 & 204,4 & 81,5 & 377,5 & 715 & 150,5 & 8.690 & 1,593 & 39,5 & 48,2 \\
\hline Circón-124 & 713 & 7,13 & 2.220 & 2,3 & 0,06 & 17,27 & 0,17 & 3,1 & 6,07 & 1,47 & 39,5 & 14,1 & 185 & 74,1 & 346 & 701 & 144,1 & 9.710 & 2,185 & 55,8 & 66,1 \\
\hline Circón-128 & 700 & ,62 & 1.212 & 2,34 & 4,5 & 24,4 & 1,45 & 8, & 4,04 & 0,454 & 18,2 & 6,73 & 95,5 & 40,9 & 199,9 & 442 & 97,2 & 11.120 & 1,965 & 33 & 58,4 \\
\hline Circón-130 & 1.114 & 10,71 & 2.726 & 512 & 3,21 & 42,7 & 1,51 & 9,4 & & 2,23 & 52,2 & 19,09 & 240,8 & 95,6 & 426 & 780 & 156,2 & 8.280 & 2,208 & 70 & 70 \\
\hline Circór & 600 & 150 & 1.392 & 4,17 & 0,4 & 14,63 & 0,236 & 2,11 & 2,82 & 0,44 & 22,1 & 8,44 & 108,9 & 44,8 & 215 & 452 & 95,3 & 10.580 & 1,598 & 48,7 & 50,4 \\
\hline Circón-132 & 490 & 7,32 & 1.590 & 3,99 & 0,019 & 26,9 & 0,052 & 1,59 & 3,93 & 0,67 & 25,1 & & 128 & 54,4 & 257 & 519 & 108,8 & 10.950 & 2,95 & 104 & 88 \\
\hline Circón-133 & 530 & 11,37 & 2.711 & 2,25 & 0,027 & 12,24 & 0,25 & 4,18 & 8,49 & 3,38 & 56,3 & 19,98 & 240,7 & 97 & 429,2 & 775 & 158,4 & 7.333 & 1,505 & 38,8 & 45,51 \\
\hline Circón-135 & 560 & 11,18 & 2.005 & 2,64 & 0,139 & 21,68 & 0,226 & 2,74 & 5,9 & 2,62 & 40,5 & 14,8 & 178,1 & 70,2 & 31 & 556 & 111,4 & 7.660 & 1,7 & 69,6 & 52,4 \\
\hline Circón-136 & 493 & 7,61 & 1.725 & 3,59 & 0,065 & 17,52 & 0,059 & 1,31 & 3,18 & 0, & 24,5 & 9,61 & 131,5 & 56 & 275 & 591 & 126,1 & 10.050 & 2,663 & 63,5 & 79,8 \\
\hline Circón-138 & 884 & 7,81 & 2.324 & 3,92 & 0,311 & 27,19 & 0,156 & 2,36 & 5,19 & 0,78 & 39,3 & 14,33 & 189,5 & 79,2 & 371 & 751 & 159,3 & 11.450 & 3,48 & 82,7 & 100,1 \\
\hline Circón-142 & 470 & 7,34 & 1.333 & 3,18 & 0,031 & 23,6 & 0,033 & 0,88 & 2,81 & 0,488 & 20 & & & 45,9 & 220 & 462 & 98,1 & 10.650 & 1,613 & 34,6 & 49,7 \\
\hline Circón-143 & 570 & 9,99 & 2.934 & 2,7 & 0,017 & 18,25 & 0,239 & 4,57 & 9,73 & 3,52 & 57,4 & 21,19 & 257,9 & 101,2 & 448,7 & 807 & 164,9 & 7.710 & 1,54 & 40,41 & 44,32 \\
\hline Circón-144 & 640 & 9,48 & 2.080 & 3,78 & 0,029 & 26,9 & 0,111 & 2,46 & 5,31 & 1,79 & 39,9 & 14,32 & 184,9 & 71,3 & 326,6 & 604 & 123,3 & 8.490 & 2,04 & 66,6 & 63,3 \\
\hline Circón-145 & 644 & 7,32 & 1.830 & 3,75 & 0,186 & 25,1 & 0,151 & 2,59 & 4,18 & 0,83 & 29,8 & 11,2 & 149 & 61,5 & 293 & 606 & 127 & 10.150 & 2,775 & 96 & 82 \\
\hline Circón-146 & 1.070 & 12,1 & 2.663 & 6,2 & 6,2 & 49,8 & 2,81 & 17,1 & 10 & 2,06 & 50,4 & 17,62 & 228,8 & 94,6 & 433,7 & 822 & 171,2 & 8.860 & 2,255 & 58,1 & 70,4 \\
\hline Circón-148 & 300 & 9,36 & 938 & 2,14 & 0,28 & 11,29 & 0,052 & 0,52 & 1,77 & 0,375 & 13,7 & 5,71 & 74,8 & 31 & 151,4 & 322 & 68,2 & 9.580 & 1,028 & 19,9 & 31,8 \\
\hline Circón-149 & 320 & 10,5 & 2.754 & 2,36 & 0,144 & 19,74 & 0,362 & 6,29 & 11,43 & 3,61 & 61,2 & 20,87 & 247,3 & 95 & 426,3 & 827 & 169,8 & 9.360 & 2,22 & 78,7 & 70,3 \\
\hline
\end{tabular}

